\title{
Economic analysis of technological innovations to improve sustainability of pangasius production in Vietnam
}

Pham Thi Anh Ngoc 


\section{Thesis committee}

\section{Promotor}

Prof. Dr A.G.J.M. (Alfons) Oude Lansink

Professor of Business Economics

Wageningen University

Prof. Dr J.A.J. (Johan) Verreth

Professor of Aquaculture and Fisheries

Wageningen University

\section{Co-promotor}

Dr M.P.M. (Miranda) Meuwissen

Associate professor, Business Economics Group

Wageningen University

\section{Other members}

Prof. Dr E.C. van Ierland, Wageningen University

Prof. Dr R. Leemans, Wageningen University

Dr M.J. Voors, Wageningen University

Dr R. Ihle, Wageningen University

This research was conducted under the auspices of the Wageningen School of Social Sciences (WASS). 


\title{
Economic analysis of technological innovations to improve sustainability of pangasius production in Vietnam
}

\author{
Pham Thi Anh Ngoc
}

\section{Thesis}

submitted in fulfilment of the requirements for the degree of doctor

at Wageningen University

by the authority of the Rector Magnificus

Prof. Dr A.P.J. Mol,

in the presence of the

Thesis Committee appointed by the Academic Board

to be defended in public

on Monday 19 December 2016

at 1.30 p.m. in the Aula. 
Pham Thi Anh Ngoc

Economic analysis of technological innovations to improve sustainability of pangasius production in Vietnam,

143 pages.

PhD thesis, Wageningen University, Wageningen, NL (2016)

With references, with summary in English

ISBN: 978-94-6257-988-0

DOI: http://dx.doi.org/10.18174/394048 


\section{Abstract}

In response to increasing concerns about sustainable production, a growing number of European customers expect seafood products to be certified, for example by the Aquaculture Stewardship Council (ASC) certification. Water purification technologies such as Recirculating Aquaculture Systems (RAS) could be a potential solution to reduce waste discharge and to improve water quality in fish ponds as a response to environmental regulations. In order to provide useful insights to consider investments in RAS, the overall objective of this thesis was to perform an economic analysis of technological innovations such as RAS to improve the sustainability of pangasius production in Vietnam.

This thesis first uses Data Envelopment Analysis to measure input- and output-specific technical and scale inefficiency of pangasius farmers in the traditional system and uses a bootstrap truncated regression to assess the impact of farmers' demographics and farm characteristics on these technical inefficiencies. Second, the economic feasibility of RAS in pangasius farming is analysed using a capital budgeting approach and stochastic simulation accounting for uncertainty in key parameters. Next, key determinants influencing the adoption of RAS by pangasius farmers are investigated using a choice experiment. Finally, price transmission along the international supply chain of pangasius, from the Vietnamese farm to the Polish retail stage is analysed using a vector autoregressive error correction model framework.

The results show that inadequate management skills in using capital assets and improper methods for producing fish are the main challenges for enhancing the performance of Vietnamese pangasius production. Location of the farm in a saltwater intrusion area is positively associated with inefficiency of producing fish. The results suggest further that when shifting from the traditional system to RAS, the Net Present Value (NPV) of the investment in RAS is expected to substantially increase, for both medium (1-3 ha) and large (equal or greater than $3 \mathrm{ha}$ ) farms. Lack of trust in receiving a price premium, inadequate access to finance and uncertainty about the actual performance of RAS systems are constraints for the adoption of RAS. Finally, our study provides evidence that price signals at the Polish-Vietnamese retail stage were transmitted back to wholesale, export and Vietnamese pangasius farms stages. 



\section{Contents}

$\begin{array}{lll}\text { Chapter } 1 \text { General introduction } & 7\end{array}$

Chapter 2 Technical inefficiency of Vietnamese pangasius farming: A data 15 envelopment analysis

Chapter 3 Economic Feasibility of Recirculating Aquaculture System in 33 Pangasius Farming

Chapter 4 Adoption of Recirculating Aquaculture System in Large

Pangasius Farms: A Choice Experiment

Chapter 5 Price transmission along the Vietnamese pangasius export chain $\quad 75$

Chapter 6 General discussion 99

Summary 111

$\begin{array}{ll}\text { References } & 117\end{array}$

About the author 133

$\begin{array}{ll}\text { Acknowledgements } & 137\end{array}$ 



\section{CHAPTER 1}

Introduction 


\section{Background}

Fish and fish products are highly traded in international markets; in $201038 \%$ of world fish production was exported (Msangi et al. 2013). Of all fish exports by developing countries, two thirds is directed to developed countries in terms of value (OECD 2010; Msangi et al. 2013). Vietnam is the world's largest producer of pangasius. In 2015, the total value of Vietnamese pangasius production was 1.5 billion USD (SeafoodSource 2016). In 2013, pangasius products accounted for $22.5 \%$ of all fish fillet consumption in the European Union, $20.4 \%$ in the United States, and 6.8\% in the Association of Southeast Asian Nations (ASEAN countries) (VASEP 2013). The high demand for fish products incentivised a 10fold increase of the Vietnamese production of pangasius in the last decade to 1.1 million tonnes in 2015 (Seafish 2015). Parallel to the fast growing pangasius production, world markets increasingly require seafood products to be produced in a sustainable way. The Aquaculture Stewardship Council (ASC) certification system, which addresses the environmentally sustainable and socially equitable responsibility, received a lot of attention in EU markets (Little et al. 2012; Bush et al. 2013; Beukers et al. 2015). Belton et al. (2011) indicate that water use and water quality (i.e. pond effluent management) are key issues in achieving ASC certification.

Vietnamese pangasius products have gained a large market share in international markets because of their relatively low price (Bush and Belton 2011). However, the market for cheap white fish products such as pangasius is competitive due to a large range of possible substitutes (Little et al. 2012; Troell et al. 2014; CBI 2015). If the Vietnamese pangasius sector needs to maintain and enhance its competitiveness in the export markets, efforts should be directed to eliminate the technical inefficiency in the production of pangasius farmers. Literature shows that the technical inefficiency scores in fish farming vary from 0.14 to 0.27 (see Iliyasu et al. (2014) for a review). This inefficiency might stem from many sources. For instance, weather conditions affect the use of capital for machinery, buildings, and equipment (Chiang et al. 2004; Anh et al. 2015). Poor water quality can lower fish yield due to disease outbreaks (Chiang et al. 2004; Anh et al. 2010). 
As a response to the quest for environmental sustainability, Recirculating Aquaculture System (RAS) could be an opportunity not only to reduce waste discharge and to improve water quality in the fish ponds, but also to contribute to a reduction in the occurrence of fish diseases and thus to decreased mortality and lower use of medicines (Martins et al. 2010; van Rijn 2013). The Vietnamese government wishes to stimulate ASC certification and compliance, in which RAS can play an important role. Recently, RAS has been implemented in a farm-scale pilot project for Vietnamese pangasius production (Wageningen University 2013). However, investing in such technological innovations at farm scale is costly. Also, future prices, yields, and operating expenses for RAS are uncertain. Consequently, the economic feasibility of RAS is also uncertain and this may constrain the adoption of RAS. Therefore, an investment appraisal of RAS and an analysis of the willingness to adopt RAS are essential to provide new insights for farmers to considering to invest in this new system and in the factors influencing this investment decision.

In general, the costs from labelling compliance are typically passed on to the consumers (Boyd and McNevin 2012). However, under asymmetric price transmission, price increases at the downstream stages, i.e. international wholesale and retail stages, are transmitted slowly and possibly not fully to the upstream stages, i.e. domestic export and farm stages (Meyer and von Cramon-Taubadel 2004; Vavra and Goodwin 2005). As a consequence, the allocation of capital and other resources to enable and meet the required standards may be insufficient. A better understanding of transmission of price changes from international markets back to the Vietnamsese pangasius farmers is essential for the private sectors to consider investing in more sustainable production systems.

\section{Objective}

To shed light on the above issues, the overall objective of this thesis is to perform an economic analysis of technological innovations such as RAS to improve the sustainability of pangasius production in Vietnam. As described above RAS is expected to play an 
important role in benefiting sustainability in pangasius production. The specific objectives of this thesis are:

1. To measure input- and output-specific technical and scale inefficiency of Vietnamese pangasius farmers and to assess the impact of farmers' demographics and farm characteristics on these technical and scale inefficiencies.

2. To analyse the economic feasibility of RAS in pangasius farming in Vietnam.

3. To investigate key determinants influencing the adoption of RAS by Vietnamese pangasius farmers.

4. To analyse price transmission along the international supply chain for frozen pangasius fillets.

The different stages along the chain of Vietnamese frozen pangasius fillets and specific parts of the chain covered in thesis are presented in Table 1.1.

Table 1.1 Chain of Vietnamese frozen pangasius fillets and topics covered in this thesis

\begin{tabular}{cccc}
\hline Farmers & $\begin{array}{c}\text { Processors/ } \\
\text { Exporters }\end{array}$ & $\begin{array}{c}\text { Wholesalers/ } \\
\text { Importers }\end{array}$ & Retailers \\
\hline
\end{tabular}

Chapter 2

Technical inefficiency in traditional systems

\section{Chapter 3}

Economic feasibility of RAS

\section{Chapter 4}

Farmer adoption of RAS

\section{Chapter 5}

Analyses of price transmission 


\section{Description of traditional system and RAS in Vietnamese pangasius production}

In this thesis, the analyses of inefficiency and price transmission focus on the traditional system, whereas the analyses of economic feasibility and the adoption focus on RAS. Both systems are described below.

\section{Traditional System}

Traditional pangasius farms usually operate one or several 3 to 5 meter deep fish pond(s) with one or two sluice gates, and a feed storage. In the past, the majority of the farmers applied chlorine, lime, benzalkonium chloride and salt for water purification. Stocking densities vary from 5 to $31 \mathrm{fish} / \mathrm{m}^{3}$, depending on the size, availability of fingerlings and the financial capacity of farmers to purchase feedstock (Phan et al. 2009). More recently, most pangasius farmers use extruded pellets, except for a few small farms in traditional pangasius areas, such as An Giang, where extruded pellets are used together with farmmade feed. Most farms use river water in the fish ponds and discharge waste water directly into channels leading to the Mekong River. Water exchange is done using pumping or gravity from the tides.

\section{Recirculating Aquaculture System (RAS)}

RAS can be applied in an existing pond or a completely new pond. The application of inpond RAS in pangasius farms requires additional investments in a moving bed bio-filter, filter media, septic tank, pumps and pipes for water movement and aeration. RAS treated wastewater by two processes: mechanical filtration to remove the solids such as waste and sludge discharge, and biological filtration to remove dissolved toxic wastes. More specifically, RAS separates solids from the bio-filter into septic tanks, thereby improving the water quality inside the pond and reducing effluent discharge, while supplying additional oxygen for the fish. The solids are then pumped to a separate septic tank where the solids are denitrified. Stocking densities are $76 \mathrm{fish} / \mathrm{m}^{3}$ and only extruded pellets are used with RAS. 
RAS is considered a technological innovation in aquaculture production. Martins et al. (2010) suggested that RAS offers the possibility of achieving a high production, maintaining optimal environmental conditions, securing animal welfare, while creating a minimum ecological impact. Potential advantages of RAS are reduced disease infections and use of less antibiotics and chemicals (Gutierrez-Wing and Malone 2006). However, the recirculation leads to high energy consumption either in the form of electricity or fuel for circulating in-pond water (d'Orbcastel et al. 2009). The establishment and operating mechanisms of in-pond RAS are shown in Figure 3.1.

\section{Outline of the Thesis}

The thesis consists of a general introduction (Chapter 1), four research chapters (Chapter 25) and a general discussion and conclusion (Chapter 6). Chapter 2 measures input- and output-specific technical and scale inefficiency of Vietnamese pangasius farmers in a traditional system. This is analysed by identifying the feasible reduction in the use of inputs and expansion of outputs using a nonparametric approach. The impact of farmers' demographics and farm characteristics on these technical and scale inefficiencies is assessed using an econometric model.

Chapter 3 analyses the economic feasibility of RAS in Vietnamese pangasius farming. The economic performance of two pangasius farming systems is carried out by developing investment appraisals based on the net present value (NPV) criterion. This chapter explicitly accounts for uncertainties associated with investment cost, pangasius yields, market prices and the operating expenses in a stochastic simulation model.

Chapter 4 investigates the factors that influence the willingness of Vietnamese pangasius farmers to adopt RAS. This is analysed by multiple steps to develop a short list of key attributes which are included in a choice model. Moreover, the choice model is also used to explore the impacts of key attributes and farmer demographics and farm characteristics on the likelihood of RAS adoption. 
Economic analysis of technological innovations to improve sustainability of pangasius production in Vietnam

Chapter 5 analyses the price transmission from the international retail stage to the Vietnamese farms. To do so, this chapter estimates time series models that describe the (a)symmetry in short- and long-run relationships between pair-wise prices in the frozen pangasius fillets supply chain (that is, farm, export, wholesale and retail).

Finally, Chapter 6 presents the synthesis of results in this thesis, and discusses methodological and data issues. The business and policy implications as well as the main findings in this thesis are also outlined in this chapter. 
Chapter 1 


\section{Technical inefficiency of Vietnamese pangasius farming: A data envelopment analysis}

Pham Thi Anh Ngoc ${ }^{\mathrm{a}, \mathrm{c}}$, Daniel Gaitán-Cremaschi ${ }^{\mathrm{a}}$, Miranda P. M. Meuwissen $^{\mathrm{a}}$, Tru Cong Le ${ }^{\mathrm{c}}$, Roel H. Bosma ${ }^{\mathrm{b}}$, Johan Verreth ${ }^{\mathrm{b}}$, and Alfons Oude Lansink ${ }^{\mathrm{a}}$

${ }^{a}$ Business Economics Group, Wageningen University, P.O. Box 81306700 EW Wageningen, The Netherlands

${ }^{\mathrm{b}}$ Aquaculture and Fisheries Group, Wageningen University, P.O. Box 338, 6700 AH Wageningen, The Netherlands

${ }^{c}$ Economics Faculty, Nong Lam University, Linh Trung Ward, Thu Duc district, Ho Chi Minh City, Vietnam 


\begin{abstract}
Vietnamese pangasius farming needs to produce efficiently to compete in world markets. This study investigates the input- and output-specific technical inefficiency of Vietnamese pangasius farmers. First, we used a non-radial directional input-output distance function to estimate the input- and output-specific technical inefficiency. Second, we applied a bootstrap truncated regression to analyze the factors influencing these technical inefficiencies. Results show that the main challenges for enhancing the performance of Vietnamese pangasius production are inadequate use of capital assets (inefficiency of 42\%) and improper methods to achieve higher fish yield (inefficiency of 30\%). Input-specific technical inefficiency (pond area and feed) is negatively associated with the experience and education level of pangasius farmers. Location of the farm in a salt-water intrusion area is positively associated with the inefficiency of producing fish. Outcomes of this study are useful to identify successful strategies to minimize the use of inputs while simultaneously maximizing fish production.
\end{abstract}

Key words: Aquaculture, pangasius, data envelopment analysis, truncated bootstrap regression, inefficiency. 


\section{Introduction}

Vietnam is the world's largest producer of pangasius. In 2015, the total value of Vietnamese pangasius production was 1.6 billion USD (SeafoodSource 2016). In 2013, pangasius products accounted for $22.5 \%$ of all fish fillet consumption in the European Union, $20.4 \%$ in the United States, and 6.8\% in the Association of Southeast Asian Nations (ASEAN) (VASEP 2013). However, the market for cheap white fish products, such as pangasius, is competitive because many possible substitutes are available (Little et al. 2012; Troell et al. 2014; CBI 2015). Vietnamese pangasius products have gained a large market share in international markets because of their relatively low price (Bush and Belton 2011). To maintain and enhance the competitiveness of the Vietnamese pangasius sector in the world market, efforts should be made to reduce the technical inefficiency of pangasius production.

Several studies have estimated technical inefficiency in fish farming. For instance, Alam (2011) estimated the average technical inefficiency of pangasius farmers in Bangladesh to be 0.14 , implying that farmers can reduce the use of all inputs by $14 \%$ and produce the same output level. Kareem et al. (2009) reported the technical inefficiency of fish farmers in Nigeria to be 0.21 , suggesting that farmers can improve their output level by $21 \%$ using current inputs. Technical inefficiency in fish production might stem from many sources. For example, poor quality pond water can lead to disease outbreaks and lower fish yields (Chiang et al. 2004; Anh et al. 2010), and weather conditions affect the inefficient use of capital for machinery, buildings, and equipment (Chiang et al. 2004; Anh et al. 2015). The existing studies on inefficiency in fish production have measured the maximum proportional decrease in the use of all inputs simultaneously while producing the same level of outputs. In practice, some specific inputs, or inputs and outputs, are more controllable than others. Thus, inefficient farmers have better opportunities to reduce certain inputs or increase the production of some outputs To the best of our knowledge, no study has addressed the technical inefficiency of each specific input and output in fish farming. An input- and output-specific analysis of technical inefficiency would help farmers to improve the performance of their farms by providing information to better prioritize their efforts to 
reduce the use of inputs and expand outputs. In an input- and output-specific approach, technical inefficiency is measured for each input and output separately as the maximum feasible reduction in input use and expansion of outputs.

In light of the foregoing discussion, the objective of this study was to measure the inputand output-specific technical and scale inefficiency of Vietnamese pangasius farmers and to assess the impact of farmers' demographics and farm characteristics on these technical inefficiencies. Insight into the determinants of technical inefficiencies is expected to provide useful information for policy makers, which can be used to design policies and measures to help farmers improve their farm management.

The remainder of the paper is organized as follows. Section 2 presents the methods, data collection, and the selection of variables. This is followed by the presentation of results and discussion in Section 3. Section 4 provides conclusions and policy implications.

\section{Materials and methods}

\section{Data envelopment analysis and bootstrap truncated models}

This paper used a two-stage approach to measure and explain the technical inefficiency of Vietnamese pangasius farmers. In the first stage, data envelopment analysis (DEA) was used to measure the input- and output-specific technical inefficiency, while in the second stage bootstrap truncated regression was used to estimate the impact of farmers' demographics and farm characteristics on these technical inefficiencies. DEA is a nonparametric technique that is frequently used to measure technical inefficiency in the presence of multiple inputs and outputs (Farrell 1957; Charnes et al. 1978; Dey et al. 2005; Singbo and Oude Lansink 2010; Iliyasu et al. 2014). 


\section{Non-radial directional input-output distance function}

In the first stage, the non-radial directional input-output distance function (NDDF) was used to compute the input- and output-specific technical inefficiency (see also Mahlberg and Sahoo (2011), Wang et al. (2013) and Gaitán-Cremaschi et al. (2015)). The non-radial directional distance function accounts for the inefficiency due to the slacks in inputs and outputs. Consider there are $\mathrm{k}=1, \ldots \mathrm{K}$ pangasius farms using a vector $x$ of $\mathrm{N}$ inputs and producing a vector $y$ of $\mathrm{M}$ outputs. The input- and output-specific technical inefficiency of farm $\mathrm{k}$ relative to the production frontier, assuming variable returns to scale (VRS), is computed using the following linear programming problem:

$\overrightarrow{\mathrm{D}}(x, y ; g \mid$ VRS $)=\max \left[\frac{1}{2}\left(\frac{1}{\mathrm{~N}} \sum_{\mathrm{n}=1}^{\mathrm{N}} \mu_{\mathrm{n}}+\frac{1}{\mathrm{M}} \sum_{\mathrm{m}=1}^{\mathrm{M}} \beta_{\mathrm{m}}\right)\right]$

s.t.

$$
\begin{aligned}
& \sum_{\mathrm{k}=1}^{\mathrm{K}} \alpha_{\mathrm{k}} x_{\mathrm{kn}} \leq x_{\mathrm{n}}-\mu_{\mathrm{n}} \mathrm{g}_{x \mathrm{n}}, \quad \mathrm{n}=1, \ldots, \mathrm{N}, \\
& \sum_{\mathrm{k}=1}^{\mathrm{K}} \alpha_{\mathrm{k}} y_{\mathrm{km}} \geq y_{\mathrm{m}}+\beta_{\mathrm{m}} \mathrm{g}_{y \mathrm{~m}}, \quad \mathrm{~m}=1, \ldots, \mathrm{M}, \\
& \sum_{\mathrm{k}=1}^{\mathrm{K}} \alpha_{\mathrm{k}}=1, \\
& \mu_{\mathrm{n}} \geq 0(\forall \mathrm{n}), \beta_{\mathrm{m}} \geq 0(\forall \mathrm{m}) .
\end{aligned}
$$

The objective function in Equation (2.1) represents the weighted average technical inefficiency of inputs and outputs. Each estimated $\mu_{n}$ or $\beta_{m}$ provides the $\mathrm{n}^{\text {th }}$ input-specific or $\mathrm{m}^{\text {th }}$ output-specific technical inefficiency score of a fish farm, which is weighted respectively by the total number of $\mathrm{N}$ inputs and $\mathrm{M}$ outputs. In this case, the inputs and outputs each contribute half to the weighted technical inefficiency score. An estimated technical inefficiency of zero represents a fully efficient farmer, who is located on the production frontier. An estimated technical inefficiency greater than zero indicates the presence of technical inefficiency; the farmer is located below the production frontier. The directional vectors $\left(\mathrm{g}_{x}, \mathrm{~g}_{y}\right)$ used in this study are the observed quantities of inputs and 
outputs. Hence, the technical inefficiency is interpreted as the percentage by which input use can be reduced and output can be increased (Färe and Grosskopf 2010).

The first two constraints reflect strong disposability of inputs (i) and outputs (ii), where finite inputs can only produce finite outputs (Färe et al. 2007). Constraint (iii) imposes VRS; the model in (2.1) can be transformed into a model assuming constant returns to scale (CRS) by replacing restriction $\sum_{\mathrm{k}=1}^{\mathrm{K}} \alpha_{\mathrm{k}} \geq 0$. Constraint (iv) restricts the technical inefficiency scores to non-negative values.

Scale inefficiency, which reflects the ability of a farmer to employ each input and output at an optimal scale, can be computed as the difference between the technical inefficiency under CRS and VRS. All linear programming problems consistent with Equation (2.1) were solved using General Algebraic Modelling Systems (GAMS).

\section{Bootstrap truncated regression model}

In the second stage, the bootstrap truncated regression procedure proposed by Simar and Wilson (2007) was employed to assess the impact of farmers' demographics and farm characteristics on input- and output-specific technical inefficiency. This technique has been used to study the determinants of specific technical inefficiencies in other farming systems (e.g. Singbo and Oude Lansink (2010); Singbo et al. (2014). The model in this study was specified as

$\mathrm{Y}_{\mathrm{k}}=\gamma^{\prime} \mathrm{z}_{\mathrm{k}}^{\prime}+\varepsilon_{\mathrm{k}}$

where $Y_{k}$ represents the input- or output-specific technical inefficiency of farm k, $\mathrm{z}_{\mathrm{k}}^{\prime}$ is the vector of determinants of input- and output-specific technical inefficiencies, $\gamma^{\prime}$ is the vector of estimated parameters, and $\varepsilon_{\mathrm{k}}$ is the random error term. The determinants represent farmers' demographics and farm characteristics. For the input- and outputspecific scale inefficiency, bootstrap ordinary least squares (OLS) was used because the input- and output-specific scale inefficiencies are both positive and negative. Equation (2.2) was estimated using STATA version 8. 


\section{Data collection and selection of variables}

\section{Data collection}

Data for this study were gathered in January 2013 through a questionnaire survey of 82 farmers (see also Ngoc et al. (2016b)). The farmers participating in the survey mainly represented small and medium pangasius farms (less than 3 ha). A workshop was organized in December 2013 to increase the number of observations for large farms (equal to or greater than 3 ha). During the workshop, 14 farmers with large-scale farms were invited to complete the same questionnaire as in the survey. Respondents for the survey and workshop were randomly selected from the lists of pangasius farmers maintained by the Aquaculture Department; aquaculture officers from this department assisted with the selection process.

For the survey, the selected pangasius farmers were from An Giang, Can Tho, and Soc Trang provinces. Participants in the workshop also came from the Dong Thap, Vinh Long, and Tra Vinh provinces. Respondents covered the two main production regions in Vietnam, i.e. pangasius farmers from Soc Trang and Tra Vinh mainly operate newly developed farms in the saltwater intrusion region. Pangasius farmers in the other provinces come from the traditional pangasius production areas in the freshwater region.

Of the 96 questionnaires, eight were excluded from the analysis due to incomplete information. Another eight questionnaires were excluded due to the presence of outliers. Outliers were defined as values beyond two standard deviations from the median. According to Fried et al. (2008), outliers could influence the position of the production frontier far from the inefficient farmers.

\section{Variables for the inefficiency computation}

Inputs for pangasius production consisted of three variable inputs representing the operational costs, i.e. feed, labor and others (all expenses of pond preparation, fingerling, energy, sludge discharge, and veterinary services), and two fixed inputs, i.e. pond area and 
capital. Table 2.1 presents the descriptive statistics of the input and output variables. The output is fish yield and is expressed in tons. Operational costs and capital are expressed as annual costs in USD (applied exchange rate: 1 USD equals 20,000 VND). Pond area is expressed in hectares (ha).

Feed is the main cost of pangasius farms, accounting for $84 \%$ to $86 \%$ of operational costs (Ngoc et al. 2016b). Labor consists of family labor and hired labor. Cost of hired labor was measured as the salary paid to hired labor. To quantify the cost of family labor, the monthly salary for hired labor in the aquaculture sector was used and this value was multiplied by the number of family members working fulltime on the farm. Others includes the expenses associated with pond preparation, fingerling, energy, sludge discharge, and veterinary services. Variable input costs differed among farms, with an average of 139,500 USD for capital, 779,700 USD for feed, 16,300 USD for labor, and 116,100 USD for other costs.

Pond area represents the total water surface area used for pangasius production. Pond area ranged from 0.2 ha to 8.5 ha, with an average of 1.6 ha. Capital cost includes the annual depreciation of capital invested in pond construction, sluice gates, waste water treatment (if any), storage houses, and equipment. The capital cost differed across farms, ranging between 5,700 USD and 744,100 USD, with an average of 139,500 USD. Similarly, the output variable fish yield also varied greatly, from 44 tons to 3,666 tons with an average of 879 tons.

Table 2.1 Descriptive statistics of inputs and outputs (for the most recent production cycle in 2012-2013)

\begin{tabular}{lrrrr}
\hline Item & Mean & $\begin{array}{r}\text { Standard } \\
\text { deviation }\end{array}$ & Minimum & Maximum \\
\hline Inputs (1,000 USD) & & & & \\
Pond area (ha) & 1.6 & 1.5 & 0.2 & 8.5 \\
Capital & 139.5 & 146.5 & 5.7 & 744.1 \\
Feed & 779.7 & 725.0 & 30.9 & $3,531.1$ \\
Labor & 16.3 & 14.9 & 1.6 & 72.3 \\
Others & 116.1 & 114.5 & 4.4 & 562.9 \\
Output (tons) & & & & \\
Fish yield & 879.2 & 788.8 & 44 & 3,666 \\
\hline
\end{tabular}


Economic analysis of technological innovations to improve sustainability of pangasius production in Vietnam

\section{Variables for the bootstrap truncated regression model}

The following variables were used in the bootstrap truncated regression model: age of farmers (measured in years), experience (measured as the inverse of the number of years), the level of education (number of years), gender ( 1 if female, 0 if male), and farm location (1 if saltwater intrusion region, 0 if freshwater region).

These variables were chosen based on the literature on technical inefficiency in the aquaculture sector. The literature shows negative associations between age and technical inefficiency, while experience, gender and education all have positive relationships with technical inefficiency. For instance, Iliyasu et al. (2014) concluded in an extensive review of technical inefficiency studies in aquaculture, that younger farmers may be less technically inefficient than their counterparts, presumably because of their higher willingness to adopt technological innovations. Regarding experience, more experienced farmers may make better managerial decisions and may therefore be less inefficient (Engle 2010; Iliyasu et al. 2014). Likewise, more educated farmers are generally less technically inefficient, possibly due to their open mind towards new technological information as well as better capability to access and process such information (Dey et al. 2005; Iliyasu et al. 2014). Additionally, female fish farmers were found to be more technically inefficient than their male counterparts, likely attributed to the domestic responsibility of women in most developing countries (Onumah E.E. et al. 2010). Farm characteristics such as location are also expected to have a negative effect on technical inefficiency. For instance, Anh et al. (2015) found that Vietnamese farms located in the saltwater intrusion region are less technically inefficient than those in the freshwater region.

The variable experience was measured as the inverse of the number of years of experience with fish farming (one divided by the number of years of experience). The inverse was used because a scatter diagram showed a convex nonlinear relationship between the number of years of experience in fish farming and technical inefficiency. This means that the marginal impact on technical inefficiency declines with the number of years. The inverse of the number of years can capture this relationship. The marginal effect of an additional year of experience in fish farming was computed at the sample mean of the number of years of 
experience, and is given by the partial derivative of Equation (2.2) with respect to the number of years as

$\frac{\partial \mathrm{Y}_{\mathrm{k}}}{\partial \# \text { years experience }}=\gamma *\left(-\frac{1}{\text { \#years experience }^{2}}\right) \quad$.

Table 2.2 provides the descriptive statistics of the variables used in the bootstrap truncated regression. Table 2 shows that the respondents had a relatively low average age, i.e. 43 years old, with about eight years of experience (as reflected by the average inverse ratio of 0.12 ) and up to 11 years of education. Within the sample, $92 \%$ of respondents were male (the average value of gender was 0.08 ) and $86 \%$ of respondents originated from the main pangasius freshwater production region (the average value of location was 0.14 ).

Table 2.2 Descriptive statistics of farmers' demographics and farm characteristics $(n=80)$

\begin{tabular}{lrrrr}
\hline Item & Mean & $\begin{array}{r}\text { Standard } \\
\text { deviation }\end{array}$ & Minimum & Maximum \\
\hline Farmers' demographics & & & & \\
Age (years) & 43 & 2 & 5 & 60 \\
Experience (years) & 8 & 2 & 6 & 16 \\
$\begin{array}{l}\text { Education (years) } \\
\text { Gender (1 if female, 0 if male) }\end{array}$ & 0.08 & & & \\
Farm characteristics & & & & \\
Location $^{1}$ (1 if salt water intrusion & 0.14 & & & \\
region, 0 if fresh water region) & & & & \\
\hline
\end{tabular}

${ }^{1}$ Salt water intrusion region consists of Soc Trang and Tra Vinh provinces; fresh water region consists of An Giang, Dong Thap, Can Tho, and Vinh Long provinces.

\section{Results and discussion}

\section{Technical and scale inefficiency results}

Table 2.3 shows the technical and scale inefficiency scores of Vietnamese pangasius farmers. The weighted average score of technical inefficiency relative to the frontier was 0.25 assuming VRS and 0.31 assuming CRS. The difference between the technical inefficiency under the CRS and VRS assumptions indicates the presence of scale 
inefficiency in pangasius production. The scale inefficiency was quite low, with a weighted average of 0.06 , indicating that the majority of pangasius ponds are operating close to their optimal size.

The results for the weighted average technical inefficiency scores suggest a substantial scope for improving the performance by reducing the use of inputs and increasing output. The weighted average scores, however, conceal the variation in inefficiency across inputs and output. For instance, Vietnamese pangasius farmers could reduce the use of capital by $42 \%$, labor by $23 \%$, pond area by $16 \%$, others by $10 \%$, and the use of feed by $3 \%$, while simultaneously increasing the fish yield by $30 \%$ relative to the VRS frontier. These results reveal that the technical inefficiency of pangasius farmers is mainly driven by the high inefficiency in the use of capital and the relatively low fish yield. The input- and outputspecific scale inefficiency scores ranged from -0.01 to 0.09 . It should be noted though, that no farm in the sample presented a negative weighted average scale inefficiency over both inputs and outputs. Hence, the method itself can produce negative values for input-specific and output-specific scale inefficiency. The technical inefficiency scores of capital, pond area, and labor are relatively low, which is explained by their quasi-fixed nature, i.e. their levels are not easily adjusted from one year to another. In practice, it is costly to upscale or downscale the investments in machinery, equipment, or pond area. Similarly, labor is not easily adjusted from year to year, due to the large share of family labor in total labor costs. The low feed technical inefficiency might be explained by careful fish feeding as feed costs are the main cost of pangasius production.

Results in Table 2.3 also show that farmers are more technically inefficient in producing fish yield than in utilizing inputs. Within the sample, $21 \%$ to $74 \%$ of the farms were inefficient in the use of inputs, whereas $80 \%$ of the farms were inefficient in the production of fish yield. 
Table 2.3 Input- and output-specific technical and scale inefficiencies

\begin{tabular}{|c|c|c|c|c|c|c|}
\hline \multirow[t]{2}{*}{ Item } & \multicolumn{2}{|c|}{$\begin{array}{c}\text { Technical inefficiency } \\
\text { under VRS }\end{array}$} & \multicolumn{2}{|c|}{$\begin{array}{c}\text { Technical } \\
\text { inefficiency } \\
\text { under CRS }\end{array}$} & \multicolumn{2}{|c|}{ Scale inefficiency } \\
\hline & Mean & $\begin{array}{r}\text { Frequency } \\
(\%) \\
\end{array}$ & Mean & $\begin{array}{r}\text { Frequency } \\
(\%) \\
\end{array}$ & Mean & $\begin{array}{r}\text { Frequency } \\
(\%) \\
\end{array}$ \\
\hline $\begin{array}{l}\text { Weighted } \\
\text { average } \\
\text { Input-specific }\end{array}$ & 0.25 & 84 & 0.31 & 90 & 0.06 & 88 \\
\hline Pond area & 0.16 & 60 & 0.21 & 75 & 0.05 & 79 \\
\hline Capital & 0.42 & 74 & 0.49 & 81 & 0.07 & 81 \\
\hline Feed & 0.03 & 21 & 0.02 & 15 & -0.01 & 20 \\
\hline Labor & 0.23 & 69 & 0.29 & 73 & 0.06 & 76 \\
\hline Others & 0.10 & 49 & 0.13 & 64 & 0.03 & 68 \\
\hline Output-specific & & & & & & \\
\hline Fish yield & 0.30 & 80 & 0.39 & 88 & 0.09 & 86 \\
\hline
\end{tabular}

\section{Determinants of input- and output-specific technical inefficiency}

Table 2.4 and Table 2.5 presents the estimated parameters of the bootstrap truncated regression model. The discussion in this section is mainly restricted to the variables that had a statistically significant effect on input- and output-specific technical and scale inefficiency. Most of the signs of the estimated parameters for the determinants of technical and scale inefficiency were in line with a priori expectations.

Regarding the technical inefficiency relative to the VRS frontier, the variable experience (years) had a significantly negative effect on pond area and feed technical inefficiency, indicating that an additional year of experience is associated with a better management of the pond by $1.6 \%$ and the use of feed by $4 \%$. Experienced fish farmers may make better managerial decisions on farms and be more efficient in utilizing the pond and feed to their full potential. This is in line with Kaliba and Engle (2006), who found that experienced farmers may take better decisions regarding the feed brand, feed ingredients, and feed practices. In contrast, experience was found to have a positive and significant relation with the technical inefficiency of fish yield. This might be because experienced farmers are more 
conservative and find it difficult to adjust and adopt new technologies, as suggested by Onumah et al. (2010).

We also found that education has a negative effect on the technical inefficiency of pond area, feed, others, and fish yield, implying that, ceteris paribus, an additional year of education decreases inefficiency in the use of these inputs and producing fish yield by $3 \%$ to $4 \%$. This result is consistent with our prior expectation that more educated farmers are generally more likely to adopt technological innovations due to their open mind towards new technologies and because they have a better capability to access and process information (Dey et al. 2005; Ngoc et al. 2016a). Therefore, more educated farmers are better in managing the pond, feeding fish, and using other variable inputs to increase fish yield.

The location of farms in the saltwater intrusion region was negatively associated with the technical inefficiency of capital and fish yield. The negative relationship between location and capital technical inefficiency suggests that farmers farming in the saltwater intrusion region are, ceteris paribus, $33 \%$ better in managing their capital assets than those in the freshwater region. Farmers with farms located in the saltwater intrusion region might be more careful in investing in and operating their capital assets because they have to cope with salinity intrusion, as suggested by Anh et al. (2015). However, these farmers also adapt to the salinity intrusion by limiting their stocking frequency, i.e. only once a year, and thus appear more inefficient (29\%) in producing fish yield than farmers in the freshwater region, in line with our prior expectation.

The results of the regression of technical inefficiency relative to the CRS frontier were not always consistent with the results of the regression relative to the VRS frontier, given the scale component in the former. For instance, age of farmers was negatively and significantly associated with the technical inefficiency of fish yield, implying that each additional year decreases, ceteris paribus, the technical inefficiency of fish feeding by $1 \%$. This result contradicts our prior expectation and suggests that farmers gain experience in using resources effectively over time, as suggested by Amos (2007). 
Furthermore, there was a negative and significant relationship between location of farms and the technical inefficiency of other inputs, suggesting that farmers with farms located in the saltwater intrusion region are, ceteris paribus, $9 \%$ less technically inefficient in the use of other variable inputs than those in the freshwater region. In the long-run, the unpredictable level of salinity intrusion can be controlled by investing in technological innovations and learning from others. This might give farmers farming in the saltwater intrusion region better opportunities to also monitor the use of other variable inputs.

Regarding scale inefficiency, none of the variables were found to have a significant relation with input-specific scale inefficiency, whereas experience and location were found to influence the scale inefficiency of fish yield. The negative coefficient of experience indicates that experienced farmers are better in adjusting the scale of their operation as measured by the size of output, resulting in an improvement of fish yields by $2 \%$. Better scale adjustment was also found for farmers farming in the freshwater region, with a $13 \%$ improvement in fish yield compared to farmers in the saltwater intrusion region. This confirms the findings of Anh et al. (2015) that farmers limit the stocking frequency and thus reduce the annual yield of the farm in order to cope with salinity problems.

The non-significant effect of gender on both technical and scale inefficiency implies that the technical and scale inefficiency of farms operated by men are, ceteris paribus, the same as the technical and scale inefficiency of farms operated by women. This result contrasts with the findings of Onumah (2010) for Ghana and Ekunwe and Emokaro (2009) for Nigeria; both these studies found that male fish farmers operate less inefficiently than their female counterparts. 


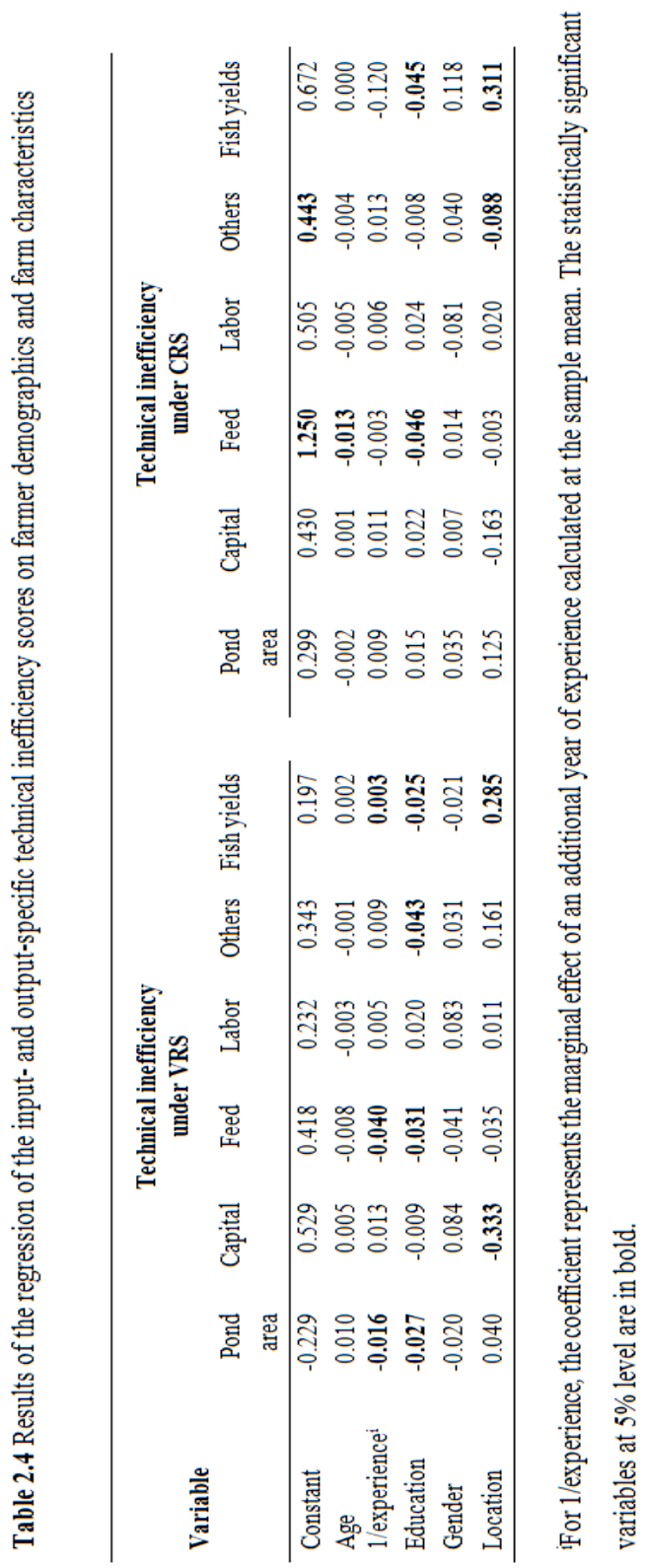




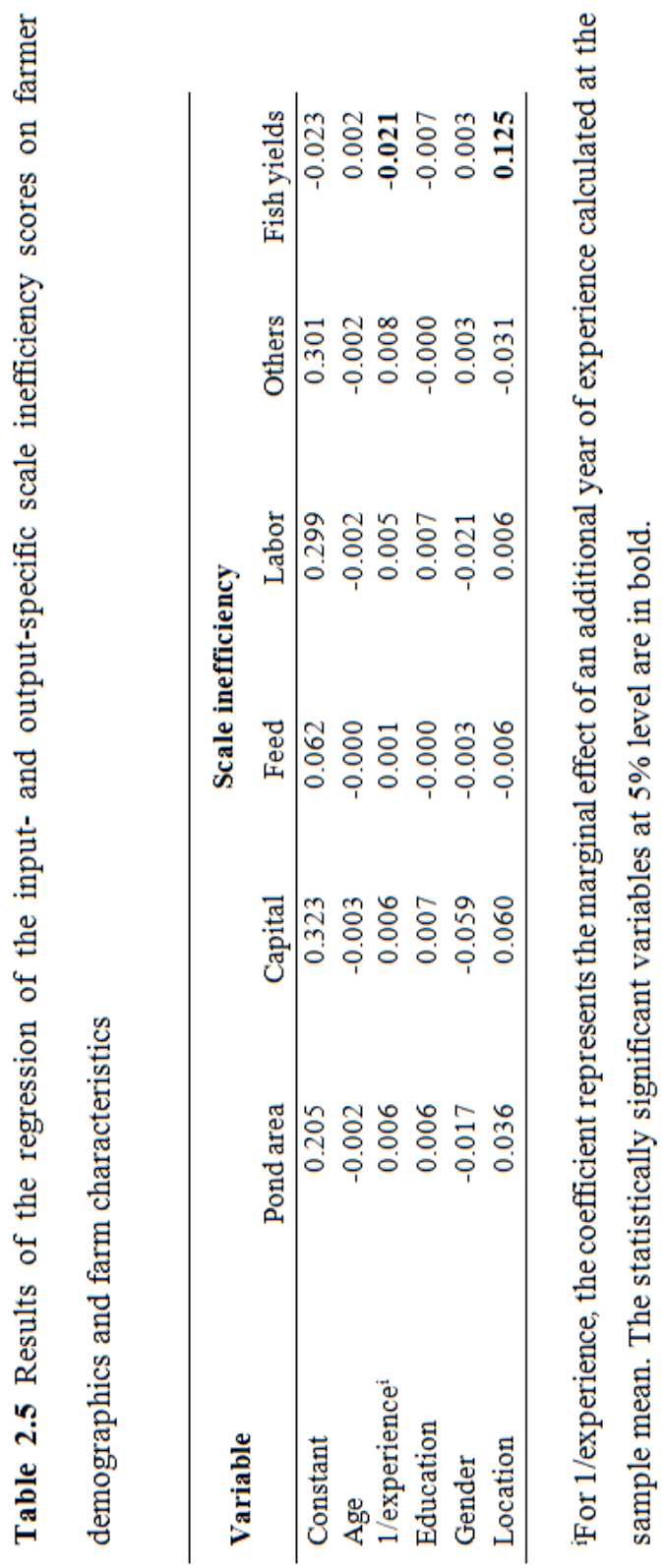




\section{Conclusions and policy implications}

The main objective of this paper was to measure the input- and output-specific technical and scale inefficiency of Vietnamese pangasius production to identify potential areas for improvement and to assess the effect of farmers' demographics and farm characteristics on these technical and scale inefficiencies. The results provide information that is useful in designing measures to help farmers improve their farm management.

We found that the main challenges for enhancing the performance of Vietnamese pangasius production are inadequate management skills in using capital assets, as indicated by a capital technical inefficiency of $42 \%$, and improper methods for producing fish, as indicated by fish yield technical inefficiency of 30\%. Furthermore, farmers with a higher education level and more years of experience are generally better in managing the pond area, using fish feed, and producing fish yield. Farming in areas with salt water intrusion is associated with a lower technical inefficiency in the use of capital assets and other variable inputs, but also with a higher technical inefficiency in the production of fish yield.

Results provide useful information for farmers and policy makers who aim to improve the performance of Vietnamese pangasius farms. The recommendations for pangasius farmers are targeted towards those inputs and output with relatively high inefficiency. For instance, pangasius farmers can improve their capital management skills by better estimating the amount of required capital and the timing of capital asset replacement, and by monitoring the use of capital assets. Furthermore, the introduction of technological innovations that enable higher stocking densities and improve the quality of pond water, such as recirculating aquaculture systems (RAS) (see also the discussion in Ngoc et al. (2016a, b)), could potentially increase the pangasius yields. Policy makers can assist farmers to improve their farm management by targeting farmers with lower education levels, fewer years of experience and farms located in salt water intrusion areas. 
Chapter 2 


\section{CHAPTER 3}

\section{Economic Feasibility of Recirculating Aquaculture System in Pangasius Farming}

Pham Thi Anh $\operatorname{Ngoc}^{\mathrm{a}, \mathrm{c}}$, Miranda P. M. Meuwissen ${ }^{\mathrm{a}}$, Tru Cong Le $^{\mathrm{c}}$, Roel H. Bosma ${ }^{\mathrm{b}}$, Johan Verreth ${ }^{\mathrm{b}}$, and Alfons Oude Lansink ${ }^{\mathrm{a}}$

${ }^{a}$ Business Economics Group, Wageningen University, P.O. Box 81306700 EW Wageningen, The Netherlands

${ }^{\mathrm{b}}$ Aquaculture and Fisheries Group, Wageningen University, P.O. Box 338, 6700 AH Wageningen, The Netherlands

${ }^{c}$ Economics Faculty, Nong Lam University, Linh Trung Ward, Thu Duc district, Ho Chi Minh City, Vietnam

Published in Aquaculture Economics \& Management DOI: $10.1080 / 13657305.2016 .1156190$ 


\begin{abstract}
This study aims to analyse the economic feasibility of recirculating aquaculture system (RAS) in pangasius farming in Vietnam. The study uses a capital budgeting approach and accounts for uncertainty in key parameters. Stochastic simulation is used to simulate the economic performance of medium and large farms operating with a traditional system or RAS. Data are obtained through structured surveys and a workshop in the Mekong River Delta. Results show that for large farms, net present value increases from an average of $589,000 \mathrm{USD} / \mathrm{ha}$ to $916,000 \mathrm{USD} / \mathrm{ha}$ after implementing RAS. Overall, the probability of RAS being a profitable investment is $99 \%$ for both farm sizes. With RAS, the crucial parameters determining profitability are price, yield, costs of fingerling, feed, and initial investment. Findings on the robustness of the economic performance of RAS are useful to support public and private decision making towards increasing the sustainability of pangasius production.
\end{abstract}

Keywords: Pangasius production, recirculating aquaculture system (RAS), economic feasibility, Monte Carlo simulation. 


\section{Introduction}

Vietnam is the world's largest producer of pangasius. The European Union (EU) is the main market, accounting for $22.5 \%$ of filet consumption, followed by the United States (20.4\%), and ASEAN (Association of Southeast Asian Nations) countries (6.8\%) (VASEP 2013). Total production has increased in recent years, from 37,500 tons in 2001 to 1.3 million tons in 2012 (Directorate of Fisheries 2012). World markets increasingly require seafood products to be produced in a sustainable way. Certification systems aim to guarantee consumers that the product is produced sustainably (Sahota et al. 2009; Bush et al. 2013). To maintain the industry's export markets, pangasius producers need to ensure that their fish meet sustainability standards, such as those of the Aquaculture Stewardship Council (ASC) or Global G.A.P. (Belton et al. 2011). Belton et al. (2011) indicate that water use and water quality (i.e. pond effluent management) are key issues in achieving ASC certification.

One of the main sustainability concerns in pangasius production is the impact on the environment, in particular the discharge of organic matter and nutrients, such as nitrogen and phosphorus, to the environment causing eutrophication (Bosma et al. 2009). One way to mitigate these concerns and fulfil the criteria of the ASC standard is to apply water purification at the farm (Anh et al. 2010). Water purification not only has the potential to decrease environmental pollution but can also contribute to a reduction in the occurrence of fish diseases and thus to decreased mortality and lower use of medicines. Recirculating aquaculture system (RAS) have been introduced to reduce waste discharge and to improve water quality in fish ponds as a response to environmental regulations (Martins et al. 2010; van Rijn 2013). In order to improve sustainability and enhance ASC certification of Vietnamese pangasius production, RAS has recently been established at a pilot facility at Cai Be station in the Tien Giang province (Wageningen University 2013). With ASC certified products, Vietnamese pangasius exporters expect to become more competitive in export markets (Beukers et al. 2013). 
Literature on RAS is limited and generally focuses on technical issues, such as the impact on the environment (Martins et al. 2010; Zhang et al. 2011) and growth of the fish (Webb Jr et al. 2007; Martins et al. 2009). Economic feasibility analyses have been carried out for some fish species, such as Murray cod in Australia (De Ionno et al. 2006), asp (Aspius Aspius) and ide (Leuciscus idus) in Poland (Kupren et al. 2008), and tilapia (Oreochromis niloticus) in Egypt (Ali 2012) and Norway (Appiah-Kubi 2012). Some studies conclude that RAS is an economically viable option (Kupren et al. 2008; Ali 2012), but others argue that RAS is only feasible for large-scale production facilities (Appiah-Kubi 2012). Past economic studies on RAS have not addressed pangasius, nor assessed the risks of RAS arising from uncertainties about different factors, such as future prices, yields, and operating expenses. This lack of information may hamper future adoption of RAS by Vietnamese pangasius farmers.

The objective of this paper was to analyse the economic feasibility of RAS in pangasius farming in Vietnam. Uncertainty about future prices, yields, operating expenses, and initial investment costs is captured using a Monte Carlo simulation. The investment appraisal is expected to provide useful insights to private (e.g. farmers) and public sectors considering investment in RAS.

This paper proceeds with a brief description of the two pangasius farming systems (i.e. traditional system and RAS), the data collection procedure, and the methodology. This is followed by the presentation of results, discussion and conclusions.

\section{Materials and methods}

\section{Description of the two systems}

Traditional pangasius farms usually operate one or several 3 to 5 meter deep fish pond(s) with one or two sluice gates, and a feed storage. Stocking densities vary from 5 to 31 fish $/ \mathrm{m} \neg 3$, depending on the size and availability of fingerlings and the financial capacity of 
farmers to purchase feedstock (Phan et al. 2009). More recently, most pangasius farmers use extruded pellets, except for a few small farms in traditional pangasius areas, such as An Giang, where extruded pellets are used together with farm-made feed. Most farms use river water in the fish ponds and discharge waste water directly into channels leading to the Mekong River. Water exchange is done using pumping or gravity from the tides.

The application of RAS in pangasius farms requires additional investment in a moving bed bio-filter, filter media, septic tank, pumps and pipes for water movement and aeration (Figure 3.1). Only extruded pellets are applicable with RAS.

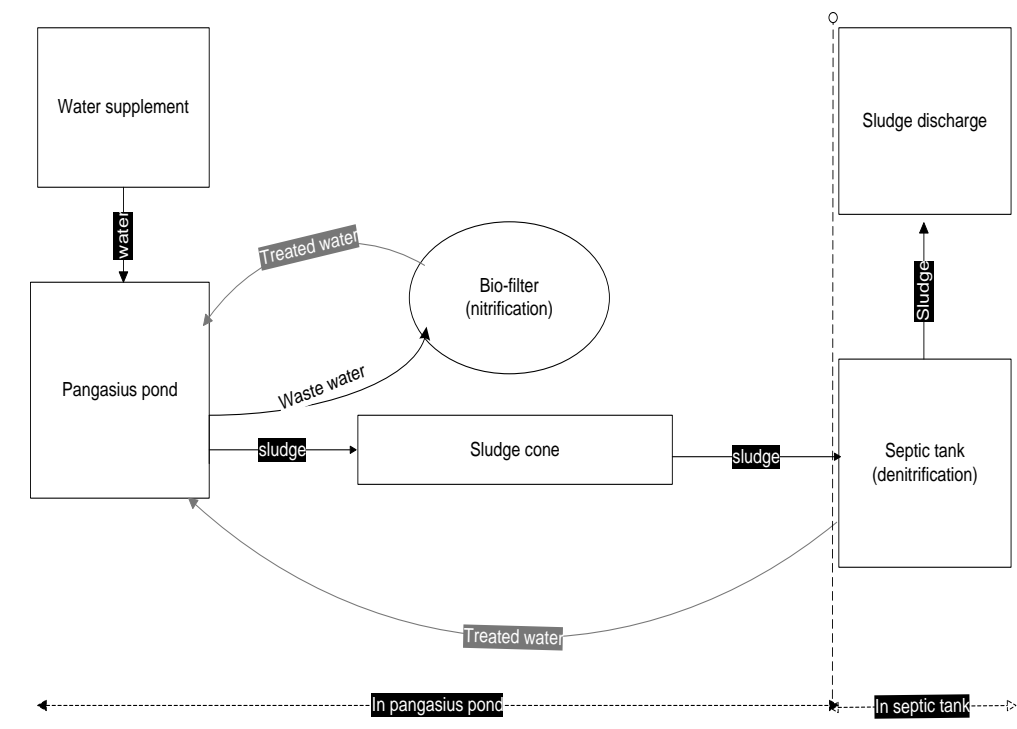

Figure 3.1 Schematic design of pond with RAS facility, based on Nguyen (2013)

\section{Data collection}

Economic and technical data were gathered in 2013. A survey was conducted to collect data on the traditional system and a workshop was conducted to obtain data on the expected performance of RAS. The workshop was also used (1) to increase the number of observations on the traditional system for large farms, and (2) to elicit future projections of 
pangasius prices and yields for both traditional and RAS systems. Surveyed farmers originated from An Giang, Can Tho, and Soc Trang provinces, while participants in the workshop also came from the Dong Thap, Vinh Long and Tra Vinh provinces (Figure 3.2). Soc Trang and Tra Vinh are new areas (salt water intrusion), while the other provinces are from the main pangasius areas (fresh water).

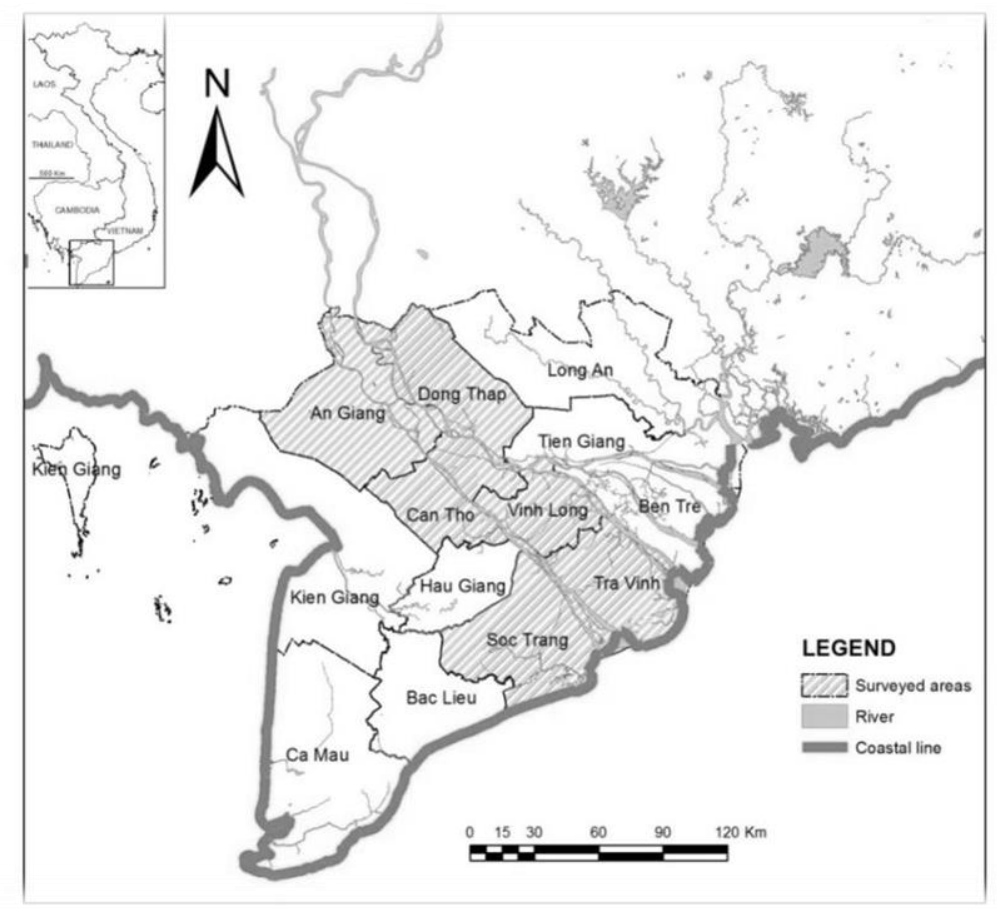

Figure 3.2 The sampling location of pangasius farms in the Mekong River Delta

\section{Survey}

The survey on the traditional system used a structured questionnaire and was carried out by personal visits in January 2013. Eighty-two farms located in An Giang, Can Tho, and Soc Trang provinces were selected for the survey. These three provinces were selected because 
pangasius culture in these provinces takes place on relatively small farms. Respondents were selected with the help of local aquaculture officers. Questionnaires were pre-tested a week before the main survey to improve clarity. The questionnaire consisted of three parts addressing 1) initial investment costs; 2) variable costs, fixed costs, and revenues for the most recent production cycle from 2012 until January 2013; and 3) farmers' socioeconomic characteristics.

Initial investment costs included pond construction, sluice gates, waste water treatment (if any), storage houses, and equipment. In case investments were made more than a year ago, replacement costs were assessed. Variable costs covered expenses for pond preparation before stocking (such as costs of lime, salt, and fungicide), fingerling, feed, energy, repair and maintenance, sludge discharge, veterinary services, and labor. Fixed costs consisted of land use, depreciation, and interest paid. If a respondent had multiple ponds, then the respondent chose one of their ponds as a basis for providing information. Production costs and revenues are expressed in USD (applied exchange rate: 1 USD equals 20,000 VND).

Incomplete questionnaires were excluded from the analysis. The survey resulted in 75 complete questionnaires and an additional 14 respondents (large farms) completed the questionnaire during the workshop. A total of 89 questionnaires were available for the data analysis. The average age of the respondents is relatively young, 49 years old, but with considerable experience (about 10 years), and up to 9 years of education (Table 3.1). 
Table 3.1 Number of respondents (farmers and experts) for the traditional system and RAS, and the mean and standard deviation of socio-economic characteristics of the respondents

\begin{tabular}{|c|c|c|c|c|c|c|c|}
\hline \multirow[b]{2}{*}{$\begin{array}{l}\text { Traditional system } \\
\underline{\text { Farmers }}\end{array}$} & \multirow[t]{2}{*}{$\begin{array}{l}\text { Small } \\
(<1 \text { ha) })\end{array}$} & \multirow[t]{2}{*}{$\begin{array}{l}\text { Medium } \\
(1-3 h a) \\
\end{array}$} & \multirow[t]{2}{*}{$\begin{array}{l}\text { Large } \\
(>3 h a)^{1}\end{array}$} & \multirow[t]{2}{*}{ Total $^{1}$} & \multicolumn{3}{|c|}{$\begin{array}{l}\text { Socio-economic } \\
\text { characteristics }\end{array}$} \\
\hline & & & & & $\begin{array}{c}\text { Age } \\
\text { (years) }\end{array}$ & $\begin{array}{l}\text { Education } \\
\text { (years) }\end{array}$ & $\begin{array}{c}\text { Experience } \\
\text { (years) }\end{array}$ \\
\hline $\begin{array}{l}\text { Main area (fresh } \\
\text { water) }\end{array}$ & 25 & 27 & $2(+9)$ & $54(+9)$ & $49(5)$ & $9(2)$ & $12(2)$ \\
\hline $\begin{array}{l}\text { New area (salt } \\
\text { water intrusion) }\end{array}$ & 9 & 10 & $2(+5)$ & $17(+5)$ & $43(0)$ & $9(1)$ & $7(1)$ \\
\hline Total & 34 & 37 & $4(+14)$ & $\begin{array}{l}75 \\
(+14)\end{array}$ & $46(4)$ & $9(2)$ & $10(2)$ \\
\hline \multicolumn{7}{|l|}{ RAS } & \\
\hline $\begin{array}{l}\text { Main area (fresh } \\
\text { water) }\end{array}$ & 1 & 9 & 9 & 19 & $47(5)$ & $10(3)$ & $13(1)$ \\
\hline $\begin{array}{l}\text { New area (salt } \\
\text { water intrusion) }\end{array}$ & 3 & 2 & 5 & 10 & $45(6)$ & $10(2)$ & $8(2)$ \\
\hline$\underline{\text { Experts }}$ & & & & 6 & $40(5)$ & $16(1)$ & $12(4)$ \\
\hline Total & 4 & 11 & 14 & 35 & $45(7)$ & $12(2)$ & $11(5)$ \\
\hline
\end{tabular}

${ }^{1}$ Number of respondents from the survey and workshop (in brackets), the classification of farm size is based on the study of Belton and Little $(2011) ;{ }^{2}$ Area consists of An Giang, Dong Thap, Can Tho, and Vinh Long provinces; ${ }^{3}$ Area consists of Soc Trang and Tra Vinh provinces; ${ }^{4}$ Mean values with standard deviations in brackets.

\section{Workshop}

The workshop was organized near the RAS pilot facility in Cai Be in December 2013. Participants were 29 farmers and 6 experts (Table 3.1). Small and medium farms were selected from the list of the previous survey, whereas the representatives of large farms were newly invited through companies and cooperatives. Experts were local aquaculture specialists and aquaculture researchers. At the start of the workshop, participants visited the pilot site where RAS experts explained the design and operation of the system. Afterwards, the large farms (14) were given the opportunity to complete the questionnaire on the traditional system first. Next, all participants assessed the perceived costs and revenues of RAS using a questionnaire similar to the one used in the survey about the traditional system. 
Economic analysis of technological innovations to improve sustainability of pangasius production in Vietnam

Previously filled information on the traditional system was provided as anchor information. Respondents could choose either to implement RAS in a completely new pond or in an existing pond. All farmers chose the latter. The data obtained from the survey and workshop on the traditional system and RAS are summarized in Table 3.2 and 3.3.

Outliers, defined as values beyond two standard deviations from the median, were excluded from the analysis (1.5\% of the total number of observations). In addition, zero values attributed to sludge discharge costs in RAS were excluded. Some respondents did not perceive these costs as being part of the system. 


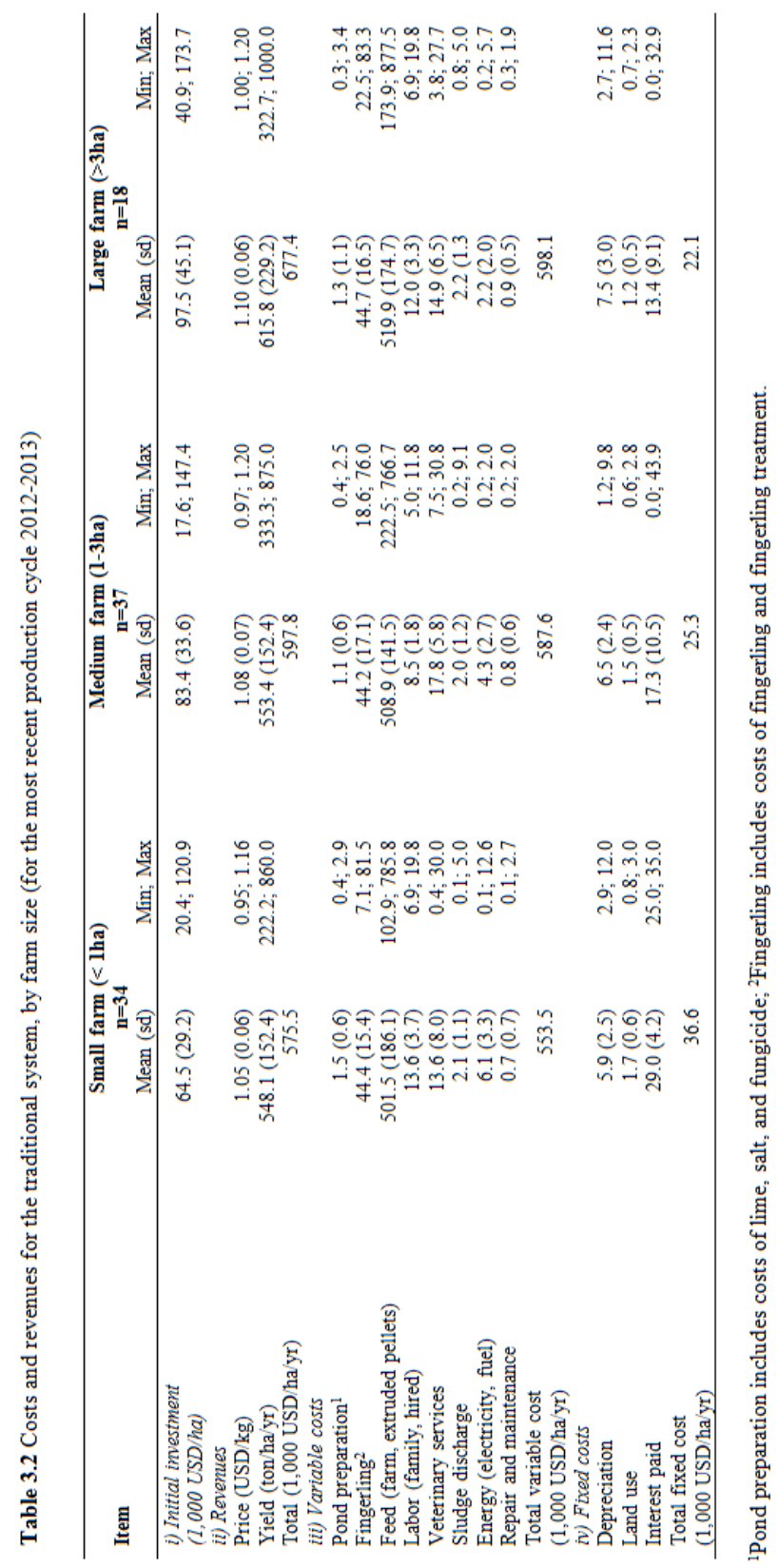




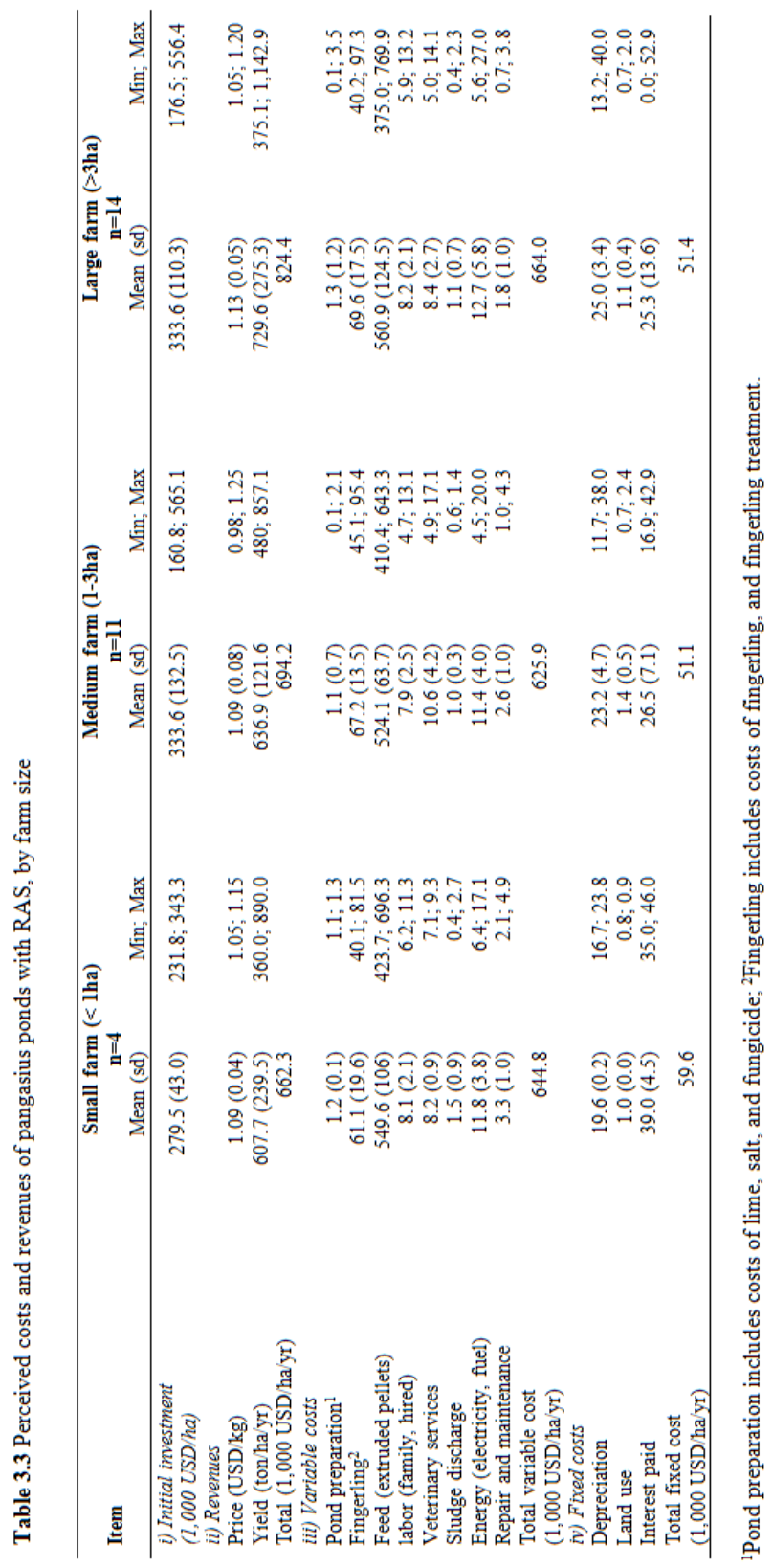


Initial investment costs per hectare for the traditional system vary widely amongst the categories of farm size, from an average of 64,500 USD for small farms to 83,400 USD for medium farms and 97,500 USD for large farms. Likewise, total variable costs per hectare differ amongst farm sizes, from an average of 553,500 USD for small farms to 587,600 USD for medium farms and 598,100 USD for large farms. This variation is due to different fish stocking densities and varying prices of feed and veterinary services. The main cost items are feed cost (ranging between $84-86 \%$ of total variable costs across farm sizes), fingerling cost (7-8\%), and veterinary services (2-3\%).

Initial investment cost per hectare for ponds with RAS are perceived to be less variable across farm sizes, average costs per hectare are perceived to be 279,500 USD, 333,600 USD, and 334,000 USD for small, medium, and large farms respectively. Differences likely relate to different quantities of granules filter media, which account for about $80 \%$ of total initial investment cost. Total variable costs per hectare are perceived to be higher than for the traditional system, with an average of 644,800 USD, 625,900 USD, and 664,000 USD for small, medium, and large farms respectively. The main cost items are attributed to extruded pellets (ranging between $84-85 \%$ across farm sizes), fingerling (9-10\%), and veterinary services $(1-2 \%)$.

The perceived revenues and costs for ponds with RAS are largely consistent with our expectations. In comparison with traditional system, ponds with RAS allow for higher stocking density (an increase in fingerling costs of 30-34\%), less disease outbreaks (reduced veterinary service costs of 39-44\%), and lower sludge discharge costs (a decrease of 28-50\%). Additionally, the continuous need for electricity or back-up power for circulation increases energy costs (an increase of 48-80\%). Values for interest paid are lower than we expected, probably because farmers believe that they will be eligible for lowinterest loan programs offered by the government for investments in aquaculture innovations. In the next phase of the workshop, participants projected pangasius prices and yields for a period of 15 years (2013-2028), for both the traditional system and RAS. The 
15-year period was chosen to capture the assumed lifetime of ponds. Each farmer and expert projected prices and yields by filling in figures in the questionnaire (similar to Figure 3.3). A final estimate of prices and yields per year was obtained in two steps. First, we calculated the mean values of all respondents' projections for four years $(2013,2018,2023$, and 2028) and drew a trend line through these four values. Second, a discussion was initiated among the respondents until $95 \%$ reached a consensus about the trend of the presented line. The agreement level is in line with the recommendation of Kaner (2014), i.e. at least $80 \%$ agreement is acceptable to reflect consensus. Respondents, who did not totally agree with the price trend for RAS, stated that "there has been no explicit price premium offered by processing companies for Global G.A.P certified pangasius products”. Hence, they believe that the price premium for ASC certified pangasius products is also not guaranteed.

The projected consensus values for yields and prices for RAS and traditional systems are shown in Figure 3.3. Values for RAS are higher than those of the traditional system. Respondents expect a price premium of 0.03 USD per kilogram fish per year with RAS compared to the traditional system and the annual yields with RAS are expected to be 1.3 times higher. 


\section{Price projection from 2013 to 2028}

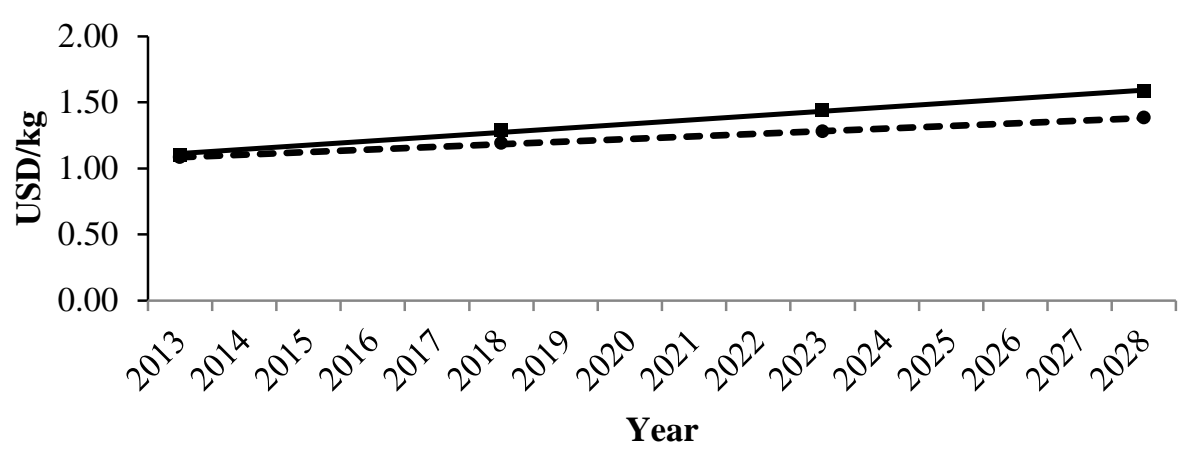

— Pangasius price for RAS - - - Pangasius price for traditional system

Yield projection from 2013 to 2028

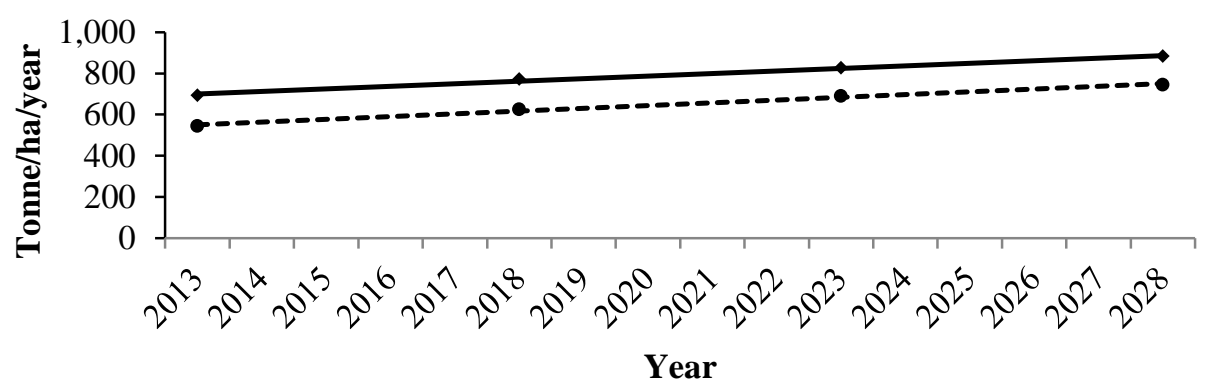

— Pangasius yield for RAS ----- Pangasius yield for traditional system

Figure 3.3 Projection (2013-2028) of prices and yields for the traditional system and RAS

\section{Net present value (NPV) calculation}

Capital budgeting is an appropriate approach for assessing and comparing the economic feasibility of the two pangasius farming systems. The net present value (NPV) method was used in this study because it considers cash inflows and outflows over the whole lifetime of the investment. An investment's NPV is defined according to the following equation (Barry and Ellinger 2010; Kay et al. 2012): 
$N P V=-I N V+\sum_{t=1}^{T} \frac{N C F_{t}}{(1+i)^{t}}+\frac{V_{T}}{(1+i)^{T}}$

where $I N V$ is the initial investment, $N C F$ is the annual net cash flow, which equals annual cash inflow (annual revenues) minus annual operating cash expenses (sum of annual variable costs and annual fixed costs excluding annual depreciation and interest), $V$ is terminal value, $i$ is the discount rate, and $T$ is the lifetime of the investment.

The lifetime of the investment in a pond was assumed to be 15 years for both the traditional system and the RAS. A salvage value of 0 USD was used for all equipment (including the pond) at the end of the investment horizon. The monthly salary for hired labor in the aquaculture sector was used as the opportunity cost to quantify the expense of family labor. All expenses were assumed to increase by $2 \%$ per year due to inflation, based on the producer price indexes for agricultural, forestry, and fishery products in the fourth quarter of 2012 (General Statistics Office Of Vietnam 2012). Price projections (Figure 3.3) were assumed to include a similar inflation percentage. The discount rate was $20 \%$, incorporating $8 \%$ opportunity cost of capital (Agribank 2014), a risk premium of 10\% (De Ionno et al. 2006), and inflation of $2 \%$. Straight line depreciation was assumed for all equipment and storage houses.

\section{Monte Carlo simulation}

\section{Simulation model}

Investment cost, pangasius yields, market prices, and the operating expenses are uncertain. In order to assess the risk associated with these uncertain variables, a Monte Carlo simulation was developed. The outcomes of the simulation provide information about the likelihood that investing in RAS versus the traditional system is economically viable. In addition, the simulation results show whether a range (a, b) of NPV likely falls within a confidence interval (Gebrezgabher et al. 2012), such that:

$$
\int_{a}^{b} f\left(N P V_{1} \ldots N P V_{k}\right) d N P V=\operatorname{probability}(a \leq N P V \leq b)
$$


where $f$ denotes the probability function based on the NPV input data. The Oracle ${ }^{\circledR}$ Crystal Ball software was used to simulate NPV and profit using 1,000 iterations (Engle 2010). The stochastic input variables were initial investment cost, annual yields, annual prices, and annual expenses, i.e. costs of fingerling, feed, labor, veterinary services, land use, sludge discharge, energy, repair and maintenance, and annual interest.

RAS is costly and thus adoption is more likely by medium and large farms. Simulations were carried out for these farms (not for small farms). Normal distributions were used to describe uncertain annual prices and annual yields of pangasius farming. Initial investment cost and annual operating expenses were specified as triangular distributions. Similar distributions were used by Valderrama and Engle (2001) for shrimp farming, and Gebrezgabher et al. (2012) for biogas systems.

The parameterization of the distributions is shown in Table 3.2 and 3.3. For normal distributions we used the mean and standard deviation (assumed to be constant over the investment horizon of 15 years). For triangular distributions, we used the minimum, maximum, and most likely values, which were derived from the minimum, maximum, and mean values, respectively (Vose 2008). The 2014-2028 price and yield projections for each farm size were derived by using the relative changes over time (for all farms, as shown in Figure 3.3) with the price and yield values for the starting year for each farm size (Table 3.2 and 3.3). Correlations were applied between feed costs and yields ( $\mathrm{r}=0.9)$, and between fingerling costs and yields $(\mathrm{r}=0.7)$, the latter only for medium farms. The correlations $(\mathrm{P} \leq$ 0.05 ) were estimated from data from the survey of farms with the traditional system (Table 3.2) and were assumed to be similar for RAS.

\section{Sensitivity analysis}

To obtain insight in the stochastic input variables in the simulation that have an important impact on the NPV, the Spearman rank correlation coefficients between NPV and the variables were computed. The higher the value of the Spearman rank correlation coefficient, the higher the correlation between a variable and the NPV, and the stronger the association between them. 


\section{Results}

\section{Economic performance of RAS}

Table 3.4 presents the mean economic performance of the traditional system and RAS. The average annual profit for the traditional system ranges from 97,000 USD/ha (medium farms) to $177,000 \mathrm{USD} /$ ha (large farms). After implementing RAS, the average annual profit is expected to increase to $228,000 \mathrm{USD} / \mathrm{ha}$ and $306,000 \mathrm{USD} / \mathrm{ha}$ for medium and large farms. In addition, when shifting from the traditional system to RAS, the mean NPV/ha increases from 262,000 USD to 539,000 USD for medium farms, and from 589,000 USD to 916,000 USD for large farms.

Table 3.4 Mean economic performance of the traditional system and RAS by farm size, simulated results from 1000 iterations

\begin{tabular}{lrrrr}
\hline Item & $\begin{array}{c}\text { Traditional } \\
\text { Medium farm }\end{array}$ & $\begin{array}{r}\text { Large } \\
\text { farm }\end{array}$ & $\begin{array}{r}\text { Redium farm } \\
\text { Large } \\
\text { farm }\end{array}$ \\
\hline i) Initial investment (1,000 USD/ha) & & 97.2 & 326.0 & 338.0 \\
ii) Revenues & 82.0 & & & \\
Price (USD/kg) & & & 1.32 & 1.35 \\
Yield (ton/ha/yr) & 1.22 & 1.25 & 730.0 & 825.2 \\
Total (1,000 USD/ha/yr) & 658.1 & 707.1 & 963.6 & $1,114.0$ \\
iii) Variable costs & 802.9 & 883.9 & & \\
Pond preparation & & & 1.2 & 1.4 \\
Fingerling & 1.3 & 1.6 & 60.0 & 67.0 \\
Feed (farm, extruded pellets) & 52.1 & 52.3 & 604.3 & 670.0 \\
Labor (family, hired) & 592.0 & 605.0 & 6.1 & 5.7 \\
Veterinary services & 10.2 & 11.1 & 12.1 & 10.0 \\
Sludge discharge & 21.1 & 18.2 & 1.2 & 1.3 \\
Energy (electricity, fuel) & 2.3 & 2.6 & 13.0 & 14.1 \\
Repair and maintenance & 4.9 & 2.3 & 2.9 & 1.9 \\
Total (1,000 USD/ha/yr) & 0.8 & 1.1 & 700.8 & 771.4 \\
iv) Fixed costs & 684.7 & 694.2 & & \\
Depreciation & & & 17.5 & 20.0 \\
Land use & 5.4 & 6.7 & 1.6 & 1.7 \\
Interest paid & 1.7 & 1.4 & 22.4 & 27.5 \\
Total (1,000 USD/ha/yr) & 20.2 & 15.7 & 41.5 & 49.2 \\
Mean profit (1,000 USD/ha/yr) & 27.3 & 23.8 & 228 & 306 \\
Mean NPV (1,000 USD/ha) & 97 & 177 & 539 & 916 \\
\hline
\end{tabular}


In addition to average performance, the robustness of the outcomes is also relevant for decision makers. Table 3.5 shows the variation in profitability and NPV for each farm size. Results illustrate that there is more variation in the performance of the RAS, as shown by the increased standard deviation of profitability and NPV. At the same time, however, the performance of RAS is generally better, both for annual profitability and NPV.

Table 3.5 Simulation results from 1000 iterations for profitability and NPV for traditional and RAS systems by farm size

\begin{tabular}{lrrrr}
\hline & \multicolumn{2}{c}{ Traditional system } & \multicolumn{2}{c}{ RAS } \\
& Medium farm & Large farm & Medium farm & Large farm \\
\hline Profit (1,000 USD/ha/yr) & & & & \\
Mean & 97 & 177 & 228 & 306 \\
Standard deviation & 23 & 40 & 31 & 68 \\
$5^{\text {th }}$ percentile & 59 & 110 & 177 & 194 \\
$95^{\text {th }}$ percentile & 138 & 244 & 278 & 420 \\
Probability (Profit $>$ 0) (\%) & 99 & 99 & 99 & 99 \\
NPV (1,000 USD) & & & & \\
Mean & 262 & 589 & 539 & 916 \\
Standard deviation & 131 & 227 & 180 & 374 \\
$5^{\text {th }}$ percentile & 57 & 223 & 244 & 310 \\
95 & 486 & 997 & 839 & 1,512 \\
Probability (NPV > 0) $(\%)$ & 98 & 99 & 99 & 99 \\
\hline
\end{tabular}

\section{Sensitivity analysis}

Table 3.6 shows the highest Spearman rank correlation coefficients between NPV and the stochastic input variables. Associations are generally stronger for RAS than for the traditional system. Outcomes show that an increase in initial investment cost significantly lowers the NPV in the case of RAS, i.e. $r=-0.38$ and -0.15 for medium and large farms respectively. The highest association is found for yields, especially with RAS in large farms $(\mathrm{r}=0.90)$. The association between NPV and feed costs is highest for large farms as well $(\mathrm{r}=0.77)$. 
Table 3.6 Spearman rank correlation coefficients between NPV and input variables for the traditional system and RAS, by farm size

\begin{tabular}{lrrrr}
\hline \multirow{2}{*}{ Variable } & \multicolumn{2}{c}{ Traditional system } & \multicolumn{2}{c}{ RAS } \\
& Medium farm & Large farm & Medium farm & Large farm \\
\hline $\begin{array}{l}\text { i) Initial investment } \\
\text { ii) Revenues }\end{array}$ & -0.19 & -0.07 & -0.38 & -0.15 \\
Price & & & & \\
Pangasius yield & 0.41 & 0.20 & 0.42 & 0.19 \\
iii) Variable costs & 0.64 & 0.81 & 0.78 & 0.90 \\
Fingerling & & & & \\
Feed & 0.42 & -0.14 & 0.52 & 0.65 \\
& 0.38 & 0.56 & 0.64 & 0.77 \\
\hline
\end{tabular}

\section{Discussion and conclusions}

This study shows that farmers are generally positive about the economic performance of RAS. Based on the perceptions of farmers and experts, the NPV of investment in RAS substantially increases for both medium and large farms. Crucial factors leading to the improved economic performance are improved yields and prices. The increase in profitability due to RAS found in this study is in line with studies by Kupren et al. (2008) on asp (Aspius Aspius) production, and Ali (2012) and Appiah-Kubi (2012) on tilapia (Oreochromis niloticus) production, although the latter only found positive effects for large farms.

This study assesses the economic feasibility of an innovation based on the perception of farmers and experts. Our arguments for the validity of this approach are as follows. First, this approach is currently the only possible approach for assessing RAS in pangasius production in Vietnam, as this system is currently only used in a pilot project. Hence, farmlevel economic information on yields, prices and costs for pangasius cultivation with RAS are not available. Second, respondents were well-informed before they started completing the questionnaires. The workshop was organized at the pilot facility and the system was elaborately shown and explained by the aquaculture expert responsible for running the pilot facility prior to completion of the questionnaire. Third, the elicited values at the workshop are generally in line with our expectations, e.g. with regard to increased stocking densities 
and costs of energy. Fourth, the number of outliers was found to be fairly limited. With regard to the elicited data for the traditional system, positive net farm incomes were also found by Kam et al. (2012), although their scenarios predicted negative results after 2015 (coastal zones) and 2018 (inland pangasius farms).

Outcomes of this study can be used by policy makers (such as the Ministry of Agriculture and Rural Development of Vietnam) and private sectors (retailers and farmers) to assess the robustness of the economic performance of RAS for Vietnamese pangasius farms. The key variables influencing the profitability of RAS provide a basis for policy recommendations. For instance, to help farmers cope with the relatively high initial investment costs for setting up RAS, governments could provide free-interest loan programs to pangasius farmers who are willing to implement RAS on their farms. Furthermore, farmers who implement RAS expect a price premium for their product and higher yield to partially compensate for the high investments. Private sectors (retailers) could provide a price premium for ASC certified pangasius products. 


\section{CHAPTER 4}

\section{Adoption of Recirculating Aquaculture System in Large Pangasius Farms: A Choice Experiment}

Pham Thi Anh $\operatorname{Ngoc}^{\mathrm{a}, \mathrm{c}}$, Miranda P. M. Meuwissen ${ }^{\mathrm{a}}$, Tru Cong Le $^{c}$, Roel H. Bosma ${ }^{b}$, Johan Verreth ${ }^{\mathrm{b}}$, and Alfons Oude Lansink ${ }^{\mathrm{a}}$

${ }^{a}$ Business Economics Group, Wageningen University, P.O. Box 81306700 EW Wageningen, The Netherlands

${ }^{\mathrm{b}}$ Aquaculture and Fisheries Group, Wageningen University, P.O. Box 338, 6700 AH Wageningen, The Netherlands

${ }^{\mathrm{c}}$ Economics Faculty, Nong Lam University, Linh Trung Ward, Thu Duc district, Ho Chi Minh City, Vietnam 


\begin{abstract}
In response to increasing concerns about sustainable production, a growing number of European customers expect seafood products to be certified, e.g. by ASC certification. A possible answer to achieve environmental sustainability of Vietnamese pangasius farming is to apply recirculating aquaculture system (RAS) at the farm. However, RAS requires relatively high initial investments and therefore its adoption depends largely on the economic feasibility in the Vietnamese farming context. The latter includes not only economic factors but also socio-demographic characteristics of the farmers. This study uses a choice experiment to measure farmers' preferences for RAS in pangasius production in Vietnam.
\end{abstract}

Findings show that the probability of adopting RAS is positively associated with expected higher yields and ASC certification with a price premium, whereas it is negatively associated with the initial investment. Location of a farm is also important, i.e. farmers in salt water intrusion areas are more likely to implement RAS compared to those in fresh water areas. Other variables significantly associated with the probability of adopting RAS are age, education, gender, and household income. The overall probability of adopting RAS was low; the main constraints for adoption of RAS were farmers' uncertainty about the performance of RAS, lack of access to finance and lack of certainty about receiving the ASC price premium.

To stimulate the adoption of RAS, we recommend that policy makers target farmers with farms located in salt water intrusion areas. We further recommend policies that link access to credit with investments in sustainability, and the establishment of pioneer RAS farms as a way to disseminate information about RAS and reduce farmers' uncertainty. Lastly, we recommend that retailers guarantee price premiums for ASC-certified pangasius.

Keywords: Pangasius, choice experiment, recirculating aquaculture system, ASC certification, price premium. 


\section{Introduction}

Pangasius has become one of the most important export products of Vietnam. In 2013, exports of pangasius were valued around 1.5 billion USD; $24 \%$ of exports were to EU markets (Globefish 2013). In recent years, the sustainability of pangasius production has been increasingly questioned due to disease outbreaks (Phan et al. 2009; Le and Cheong 2010), water pollution (Bosma et al. 2009; Anh et al. 2010) and antibiotic pollution from the discharge of untreated effluents into surrounding aquatic ecosystems (Rico and Van den Brink 2014; Andrieu et al. 2015). Furthermore, retailers and buyers in the EU increasingly demand pangasius products from environmentally sustainable and socially equitable production systems, such as those with Aquaculture Stewardship Council (ASC) certification (Bush and Duijf 2011; Little et al. 2012; Halls and Johns 2013).

To mitigate sustainability concerns and to keep up with the increasing demand for ASCcertified pangasius, water purification technologies such as re-use and recycling of waste materials or the treatment of waste streams could be applied to reduce water pollution from pangasius farming (Anh et al. 2010). Recirculating aquaculture system (RAS) was suggested as a potential solution to reduce waste discharge and to improve water quality in fish ponds as a response to environmental regulations (Martins et al. 2010).

Traditional pangasius farms usually operate one or several 3 to 5 meter deep fish pond(s) with one or two sluice gates, and a feed storage. In the past, the majority of the farmers applied chlorine, lime, benzalkonium chloride and salt for water purification. Stocking densities vary from 5 to $31 \mathrm{fish} / \mathrm{m} 3$, depending on the size, availability of fingerlings and the financial capacity of farmers to purchase feedstock (Phan et al. 2009). More recently, most pangasius farmers use extruded pellets, except for a few small farms in traditional pangasius areas, such as An Giang, where extruded pellets are used together with farmmade feed. Most farms use river water in the fish ponds and discharge waste water directly into channels leading to the Mekong River. Water exchange is done using pumping or gravity from the tides (Ngoc et al. 2016b). 
The application of RAS in pangasius farms requires additional investment in a moving bed bio-filter, filter media, septic tank, pumps and pipes for water movement and aeration (Ngoc et al. 2016b). In aquaculture, several RAS designs can be used, varying from an indoor, high-tech installation, for example, in European eel farming, to an in-pond configuration with a nitrification reactor and some devices for sludge separation. The current study focuses on the latter in-pond configuration. In this system, RAS separates solids (i.e. waste and sludge discharge) from the bio-filter into septic tanks, thereby improving the water quality inside the ponds and reducing effluent discharge, while supplying additional oxygen for the fish. Stocking densities are 76 fish/m3 and only extruded pellets are used with RAS (Nhut et al. 2013). Potential advantages are reduced disease infections and use of less antibiotics and chemicals (Gutierrez-Wing and Malone 2006). However, the recirculation leads to high energy consumption either in the form of electricity or fuel for circulating in-pond water (d'Orbcastel et al. 2009).

RAS has been successfully implemented in many countries in Europe for different fish species, such as salmon in France, sea bass in the UK and trout in Denmark (see Martins et al. (2010) for a review and Badiola et al. (2012)) and also for low-value fishes such as tilapia in North America (Bunting et al. 2005) and African catfish in The Netherlands (Eding and Kamstra 2002). As a response to sustainability concerns, the Vietnamese government wishes to stimulate ASC certification and compliance, in which RAS can play an important role. Recently, RAS has been implemented in a farm-scale pilot project for Vietnamese pangasius production. Based on the perceptions of farmers, Ngoc et al. (2016b) showed that farmers from large farms (greater than or equal to 3 ha) are generally positive about the expected economic performance of RAS. However, the adoption of RAS faces some constraints. Initial investment costs for RAS are relatively high Ngoc et al. (2016b). Furthermore, future yields, prices and operating costs for RAS are still fairly uncertain. This uncertainty combined with the high initial investment costs means that the economic feasibility is also uncertain and this may constrain the adoption of these modern production systems (Ngoc et al. 2016b).To the best of the authors' knowledge, no previous studies have evaluated the willingness of farmers to adopt RAS or explored the factors that might influence this willingness. 
The objective of this paper is to investigate the key determinants influencing the adoption of RAS by Vietnamese pangasius farmers. Given the high initial investment, we focus on large farms as these are more likely to adopt RAS due to their relative cost advantage (Pannell et al. 2006). In Vietnamese aquaculture, farms equal to or greater than 3 ha are considered as large farms. We defined key decision attributes and analysed decisions using a choice experiment. We expect the outcomes of this paper to provide useful insights to policy makers, which can be used to design policies and strategies that provide incentives for RAS adoption. The outcomes are relevant to policy makers from the Directorate of Fisheries, Ministry of Agriculture and Rural Development, and Local Aquaculture Departments in Vietnam, and to retailers and buyers in the EU.

This paper proceeds with the conceptual framework, presents the data collection, design of the choice experiment and the empirical model. This is followed by the presentation of results and discussion, conclusions and policy implications.

\section{Conceptual framework}

This paper is based on the expected utility theory, which postulates that within a set of choices, an investor will opt for the choice that maximizes her or his own expected utility (Fishburn 1970). Expected utility is generally regarded as a function of profitability, implying that the investor's goal is to maximize utility by choosing the investment that offers the highest net profitability. Net Present Value (NPV) is the most complete and widely used investment appraisal method to assess profitability of an investment (Kay et al. 2012). The decision to invest is made when the expected present value of the investment cash inflows exceeds the investment cash outflows, i.e. the NPV is positive. NPV is defined by Kay et al. (2012) as:

$N P V=-I N V+\sum_{t=1}^{T} \frac{N C F_{t}}{(1+i)^{t}}+\frac{V_{T}}{(1+i)^{T}}$ 
where $I N V$ is the initial investment, $N C F$ is the annual net cash flow, which equals annual cash inflow (i.e. annual revenues) minus annual operating cash expenses, $V$ is the terminal value, $i$ is the discount rate and $T$ is the lifetime of the investment. Discount rates contain three components: inflation, opportunity costs of capital and a premium for the level of risk embodied in the investment (Kay et al. 2012). We regard the NPV parameters in (4.1) as crucial for adoption decisions, and hence they form the key attributes in the conceptual framework of the choice experiment. The relevance of the NPV attributes for adoption decisions is supported by literature. For instance, Pannell et al. (2006) concluded in an extensive review on adoption decisions in agriculture that a higher initial investment negatively associates with the likelihood of adoption. With regard to the annual net cash flows, the literature shows positive associations between the likelihood of adoption and future yields, output prices (Pannell et al. 2006) and a price premium for environmentally certified products (Aguilar and Vlosky 2007; Espinosa-Goded et al. 2010). With regard to the discount rate, Pannell et al. (2006) also confirmed that innovations subject to much uncertainty (i.e. reflected in a relatively high discount factor) are less likely to be adopted.

The literature provides evidence that socio-economic variables, including farmer demographics and farm characteristics, can also affect the NPV in (4.1). A number of variables can affect net cash flows, including farm size, farm location and extension services. Regarding farm size, larger farms have more potential to achieve economies of scale (Pannell et al. 2006; Gebrezgabher et al. 2015). As a result, larger farms tend to achieve a lower long run average cost than smaller farms. Likewise, farm locations, which capture regional differences in environmental conditions and infrastructure, are expected to influence expenses and returns generated from an investment (Khanna 2001). Furthermore, the availability of information provided by private or public extension services enhances the technical performance of innovations, which has a direct impact on the net cash flows (Oude Lansink et al. 2003; Pannell et al. 2006).

The discount rate in (4.1) can also be affected by socioeconomic variables, including credit accessibility, education, learning effects from neighbours, household income and gender. 
Credit accessibility refers to the ease or difficulty in acquiring credit, which will affect the opportunity costs of capital (Ismael 2013). With regard to education, Knight et al. (2003), Marra et al. (2003) and Prokopy et al. (2008) concluded that more educated farmers are better able to access and understand new information, likely reducing the risk associated with the adoption of a technological innovation. Similarly, learning effects from neighbours may eliminate the riskiness related to the innovation, when the neighbours have sufficient experience to make adoption profitable (Mercer 2004). Additionally, the level of household income may have a risk-reducing effect in adopting innovations, as more financial resources imply enhanced opportunities to frequently consult with extension services (Marra et al. 2003; Pannell et al. 2006). A further risk-related socioeconomic characteristic is gender, as men are generally more willing than women to take risks in investment decisions (Knight et al. 2003). Gillespie et al. (2007) argued that this is why male farmers were found to more likely adopt best management practices in the beef cattle industry.

Another demographic characteristic, which is likely to affect the NPV in (4.1) is age. Oude Lansink et al. (2003) and Koundouri et al. (2006) found that younger farmers tend to have a longer planning horizon, thereby potentially extending the lifetime of an investment.

\section{Materials and methods}

\section{Choice experiment}

To evaluate the role of different variables in the adoption of RAS, a choice experiment was designed and administered to pangasius farmers. A choice experiment, i.e. a stated preference valuation method, is a known approach to measure the degree of preferences of respondents to a particular product that is not traded in the real market (Louviere et al. 2000). An example among aquaculture studies is that Grimsrud et al. (2013) used a choice experiment to estimate the average annual willingness to pay for improved welfare of farmed salmon. A choice experiment involves the following steps: determining attributes and their levels, designing choice cards and collecting data. 


\section{Developing attributes and attribute levels}

For the selection of attributes, we first created a long-list of attributes from the NPV framework presented in section of conceptual framework. Second, four experts from the SUPA project ${ }^{1}$ selected key attributes from this list and were asked to add additional attributes if deemed necessary. The experts had different disciplinary backgrounds, such as economics or aquaculture, and were all knowledgeable on pangasius farming and RAS.

The four SUPA experts selected eight attributes from the NPV framework, i.e. initial investment, yields, price premium, uncertainty, farm size, the availability of extension services, access to credit and neighbours. Two additional attributes were added, which covered fish quality and the opportunity to acquire ASC certification.

In the third step, we reworked these ten attributes into statements about RAS adoption (Table 4.1). Statements were evaluated by twenty-nine pangasius farmers and six experts (local aquaculture specialists and aquaculture researchers) during a workshop, which was organised to inform pangasius farmers about RAS and to discuss economic prospects. The workshop took place at the pilot RAS facility in Tien Giang in December 2013. The majority of farmers present at the workshop were from medium and large farms: four small (<1ha), eleven medium (1-3ha) and fourteen large farms (>3ha). Statements were evaluated using Likert scales from 1 (strongly disagree) to 5 (strongly agree). Results in Table 4.1 show that participants had doubts about the RAS-induced improvement in fish quality (i.e. only $30 \%$ gave a score of 4 or 5) and the spill-over effects from neighbours (17\% gave a score of 4 or 5 ). The relatively low scores for these two attributes could be because RAS is currently still at the pilot stage in Vietnam. Additionally, learning from neighbours is generally more important for small-scale farms (Pannell et al. 2006).

\footnotetext{
${ }^{1}$ SUPA (Improving waste management for pangasius culture in the Mekong Delta of Vietnam), a public-private project funded by the Dutch Ministry of Economics, the Vietnamese Ministry of Agriculture and Rural Development and private companies, such as Queens, Marine Harvest, Vinh Hoan and Provimi.
} 
Table 4.1 Attributes, the corresponding statements about RAS, and the percentage of respondents for each level of agreement with the statement, where 1 is strongly disagree and 5 is strongly agree $(n=35)$

\begin{tabular}{|c|c|c|c|c|c|c|}
\hline Attribute & Statement & 1 & 2 & 3 & 4 & 5 \\
\hline Initial investment & I expect that RAS adoption costs are too high & 0 & 0 & 3 & 49 & 31 \\
\hline Yields & $\begin{array}{l}\text { With RAS, I expect higher yields due to a } \\
\text { decreased fish mortality rate }\end{array}$ & 0 & 0 & 3 & 60 & 20 \\
\hline Price premium & $\begin{array}{l}\text { I expect that with RAS I will receive a price } \\
\text { premium }\end{array}$ & 0 & 0 & 3 & 57 & 23 \\
\hline Uncertainty & I believe that the RAS investment is too risky & 0 & 6 & 3 & 57 & 17 \\
\hline Farm size & My farm is too small to adopt RAS & 0 & 9 & 6 & 49 & 20 \\
\hline Extension services & $\begin{array}{l}\text { I expect that extension services will help me } \\
\text { in working with RAS }\end{array}$ & 0 & 0 & 0 & 71 & 11 \\
\hline Access to credit & $\begin{array}{l}\text { I cannot invest in RAS due to insufficient } \\
\text { access to credit }\end{array}$ & 3 & 0 & 12 & 60 & 8 \\
\hline Neighbour effect & $\begin{array}{l}\text { I will invest in RAS if other farms have } \\
\text { applied RAS successfully }\end{array}$ & 14 & 40 & 11 & 17 & 0 \\
\hline Fish quality & With RAS, I expect better pangasius quality & 3 & 30 & 20 & 9 & 21 \\
\hline ASC certification & $\begin{array}{l}\text { I expect that by adopting RAS, I am better } \\
\text { able to fulfil ASC requirements }\end{array}$ & 0 & 2 & 6 & 58 & 17 \\
\hline
\end{tabular}

In the fourth step, we defined the final list of attributes. We followed the recommendation of Abiiro et al. (2014), i.e. a relatively low number of attributes keeps the number of choice cards manageable for respondents. The final list contained attributes for which at least $75 \%$ of participants gave a score of 4 or 5 (Table 4.1): initial investment, yields, price premium, extension services and ASC certification). Uncertainty, although very close to this threshold (74\% of respondents gave a score of 4or 5), was excluded as an attribute due to overlap with yields, price premium and initial investment, each of which already includes a degree of uncertainty. Furthermore, ASC certification and price premium were considered to be related and therefore these two attributes were merged into a single variable, as RAS might contribute to fulfilling the requirements of ASC certification and hence the achievement of a price premium. Keeping them as separate variables would conflict with the requirement in choice experiments to have variables that are mutually exclusive. The final list of attributes 
contained (1) initial investment, (2) yields, (3) extension services and (4) ASC certification with price premium.

We next defined attribute levels for each of the selected attributes. We followed the recommendation of Bateman et al. (2002) that the attribute levels should be realistic, span the range of individuals' expectations and practically achievable. Extreme values for levels were selected, in order to ensure tradeoffs between attributes while remaining acceptable for the respondent (Kløjgaard et al. 2012).

For the situation with RAS, attribute levels for initial investment and expected yields were derived from Ngoc et al. (2016b), who studied the economic feasibility of RAS in Vietnamese pangasius farms. For extension services, fees were determined in consultation with local aquaculture departments. Free services were provided by government whereas private service costs were 800 USD per month. Attribute levels for price premium were derived from literature. At farm level, Ngoc et al.(2016b) found a price premium of $3 \%$ for ASC certified pangasius, whereas Beukers et al. (2013) found premiums of $10 \%$ and $20 \%$. The latter two values for price premiums were selected as attribute levels, as these were considered to be the most extreme values.

The traditional system was used as the reference situation. For this situation, attribute levels for initial investment and yields were taken from Ngoc et al. (2016b). For extension services we assumed that government services were free. For ASC certification with price premium, a $0 \%$ price premium was assumed. The final attributes and their levels for both situations are reported in Table 4.2. 
Economic analysis of technological innovations to improve sustainability of pangasius production in Vietnam

Table 4.2 Final attributes and levels for the traditional system and RAS

\begin{tabular}{|c|c|c|c|}
\hline Attribute & Unit & $\begin{array}{l}\text { Traditional system } \\
\text { (reference situation) }\end{array}$ & RAS \\
\hline Initial investment & $\begin{array}{l}1,000 \text { USD per } \\
\text { ha }\end{array}$ & 110 & $180 ; 380 ; 720$ \\
\hline Yields & $\begin{array}{l}\text { Tonne per ha } \\
\text { per year }\end{array}$ & 650 & $360 ; 790 ; 2,000$ \\
\hline $\begin{array}{l}\text { Extension } \\
\text { services }\end{array}$ & USD per month & For free & 800 ; for free \\
\hline $\begin{array}{l}\text { ASC with price } \\
\text { premium }\end{array}$ & $\%$ & $\begin{array}{l}\text { ASC with } 0 \% \text { price } \\
\text { premium }\end{array}$ & $\begin{array}{l}\text { ASC with } 10 \% \text { price } \\
\text { premium; ASC with } 20 \% \\
\text { price premium }\end{array}$ \\
\hline
\end{tabular}

\section{Generation of choice cards}

A combination of two attributes with three levels, and two attributes with two levels resulted in a full factorial design with thirty-six profiles. We considered it unreasonable to ask each respondent to evaluate thirty-six profiles. Hence, an orthogonal fractional factorial design (Addelman 1972) was implemented, using SPSS software, to generate eighteen calibration profiles. This enabled the unconfounded estimation of the main effects (no interaction was assumed). In addition, four holdout profiles were included. Holdout profiles are exact duplicates of the calibration profiles, used to check the consistency of respondents. The holdout profiles were randomly mixed with other profiles. The profiles were presented as choice cards, for which farmers were asked to choose either (1) the traditional system or (2) in-pond RAS. Table 4.3 shows an example of a choice card presented to respondents. 
Table 4.3 Example of a choice card

Question: Which of the two farming situations below do you prefer most? (Tick your option)

\begin{tabular}{|c|c|c|}
\hline Attribute & Traditional system & In-pond RAS \\
\hline Initial investment & 110 (1,000 USD per ha) & $180(1,000$ USD per ha) \\
\hline Yields & 650 (tonne per ha per year) & 790 (tonne per ha per year) \\
\hline Extension services & For free & 800 (USD per month) \\
\hline ASC with price premium & ASC with $0 \%$ price premium & $\begin{array}{l}\text { ASC with } 10 \% \text { price } \\
\text { premium }\end{array}$ \\
\hline $\begin{array}{l}\text { Please select the option } \\
\text { you prefer most }\end{array}$ & $\square$ & $\square$ \\
\hline
\end{tabular}

\section{Data collection}

Choice experiments were conducted during three workshops, attended by a total of ninetyfive farmers with a large farm ( $\geq 3$ ha). Data were collected using a structured questionnaire, which covered: (i) introductory questions (e.g. general information on the ASC certification status of each farm, how respondents perceived the water quality of their current fish ponds and questions on information about RAS), (ii) choice cards, (iii) questions on socioeconomic characteristics and (iv) statements to further clarify the adoption decision. The statements for additional clarification were organised as two sets of seven statements each. A farmer was asked to answer the first set if (s)he mostly (>11 choice cards) chose RAS, otherwise the farmer was asked to answer the second set. In case of equal preference, the farmer was free to choose either of the sets. Statements were derived from the NPV framework and were generally similar for both sets. The statements are shown in Table 4.6.

Participants were randomly selected with the help of local aquaculture officers and were from representative pangasius farming regions, including An Giang, Dong Thap, Can Tho, Vinh Long (the main pangasius fresh water production region) and Soc Trang provinces (a newly developed salt water intrusion region). The selection was based on the lists of pangasius farmers of Aquaculture Department in each province. The farms participating in 
the workshop covered $12 \%$ of the total pangasius farming area in the Mekong River Delta. Respondents in the workshops were in a position to make investment decisions for their farms, and were either managers or key technicians.

The questionnaire was pre-tested with two farmers to ensure that the questions were clear and the choice tasks were manageable. The first workshop took place in Can Tho and included participants from Can Tho, Vinh Long and Soc Trang provinces. The other two workshops were held in An Giang and Dong Thap. An Giang, Dong Thap, Can Tho and Vinh Long are located in the main pangasius production region, which is a fresh water region. Soc Trang is a newly developed, salt water intrusion region. All workshops took place in September 2014.

The information presented to the workshop participants included two blocks. The first block covered the background of our research and provided information about the establishment and operating mechanisms of RAS. This was followed by twenty minutes for further questioning and discussion to enhance the understanding about RAS. The second block contained the choice experiment and used the structured questionnaire in small groups of eight respondents with one enumerator per group. Enumerators asked and explained the questions one by one to ensure all respondents in the group could give a thoughtful answer. Respondents answered questionnaires individually.

\section{Sample description}

The statistical description of the sample of farms and the socioeconomic characteristics of farmers is shown in Table 4.4. The average age of farmers was fairly young, fourty-three years old, with completed high school education and an average household income of about 844 USD per month (applied exchange rate: 1 USD equals 20,000 VND). Farmers were mainly male (80\%), and mostly originated from a fresh water region (89\%). Fourteen per cent of the farms already had ASC certification and received an average price premium of 0.04 USD per kilogram of pangasius fillet, i.e. the $3 \%$ premium. A further $17 \%$ of farms were in the application process for ASC certification. Most farmers (63\%) perceived that the water quality in their current fish pond was at a neutral level. A neutral level of water 
quality may hamper the ability to currently achieve ASC certification, as certification requires a high level of water quality. The majority of farmers did not have ASC certification (69\%), and $62 \%$ of respondents had no prior knowledge of RAS.

Table 4.4 Summary statistics of respondents' socioeconomic and farm characteristics $(n=95)$

\begin{tabular}{|c|c|c|c|c|c|}
\hline Characteristic & Mean & $\begin{array}{l}\text { Frequency } \\
(\%)\end{array}$ & $\begin{array}{l}\text { Standard } \\
\text { deviation }\end{array}$ & Minimum & Maximum \\
\hline Age (years) & 42.6 & & 12.1 & 24 & 70 \\
\hline Education (years) & 12.6 & & 3.9 & 5 & 16 \\
\hline Household income (USD/month) & 844 & & 524 & 250 & 1,750 \\
\hline Male (dummy, 1 if male) & 0.8 & & 0.3 & 0 & 1 \\
\hline Farm size (ha) & 5.8 & & 4.7 & 3 & 20 \\
\hline Farms in fresh water region & & 89 & & & \\
\hline Farms in salt water intrusion region & & 11 & & & \\
\hline $\begin{array}{l}\text { ASC certification status ( } \% \text { of } \\
\text { respondent) } \\
\text { - ASC certification } \\
\text { - No ASC certification } \\
\text { - In ASC certification application } \\
\text { process }\end{array}$ & & $\begin{array}{l}14 \\
69 \\
17\end{array}$ & & & \\
\hline $\begin{array}{l}\text { Current price premium with ASC } \\
\text { (USD/kg) }\end{array}$ & 0.04 & & 0.02 & 0.02 & 0.05 \\
\hline $\begin{array}{l}\text { In-pond water quality status of own } \\
\text { farm } \\
\text { - Very bad } \\
\text { - Bad } \\
\text { - Neutral } \\
\text { - Good } \\
\text { - Very good }\end{array}$ & & $\begin{array}{r}0 \\
3 \\
63 \\
32 \\
2\end{array}$ & & & \\
\hline $\begin{array}{l}\text { Information about RAS } \\
\text { - Never heard about RAS } \\
\text { - Have some information about RAS } \\
\text { - Have enough information about } \\
\text { RAS }\end{array}$ & & $\begin{array}{r}62 \\
38 \\
0\end{array}$ & & & \\
\hline
\end{tabular}

\section{Binary probit model}

A binary probit model was used to estimate the probability that respondents choose the traditional system or RAS. The model was estimated using EVIEWS version 6 . The probit 
model has been used in a number of adoption studies, for example Gracia and de Magistris (2008) and Keelan et al. (2009). Choice models are typically based on the theory of utility maximization of Lancaster (1966). Let $U_{i j}$ represent the utility of respondent $i(i=1,2, \ldots, I)$ for $\operatorname{system} j$ ( $j=1$ for traditional system and $j=2$ for RAS). The linear random utility model is then:

$U_{i j}=x_{i j}^{\prime} \beta_{k j}^{\prime}+\varepsilon_{i j}$

where $x_{i}^{\prime}$ are the observable vectors representing the choice experiment attributes and key farm and farmer characteristics: initial investment (10,000 USD/ha), yields (10 tonne/ha/year), extension services (1,000 USD/month), ASC with price premium (\%), location (1 if salt water intrusion region, 0 if fresh water region), education (years), income (1,000 USD/month), gender (1 if female, 0 if male), age (years), age (years) and farm with $A S C$ ( 1 if yes, 0 if no). We used the quadratic form for the age variable $\left(a g e^{2}\right)$ to capture the nonlinear impact of age on the probability of adopting RAS. In the binary probit model the dummy variable farm with ASC was additionally included to examine whether there was a difference in the willingness to adopt RAS between farms with ASC and farms without ASC. Farmers already having ASC creditation may still want to adopt RAS to improve water quality and disease control.

$\beta_{k}^{\prime}$ are the vectors of estimated parameters in the model $(k=1,2, \ldots, 11)$. The random error terms, $\varepsilon_{i j}$, are assumed to be normally distributed and representing unobservable variables, measurement errors and specification errors.

In the choice decision, a respondent selects the option that maximizes her/his utility (Louviere et al. 2000). We denoted the respondent choosing to adopt RAS by $Y_{i}=1$; $Y_{i}=0$ indicated a respondent choosing the traditional system. The probability of a respondent choosing to adopt RAS, inferring $U_{2}>U_{1}$, is:

$$
\begin{aligned}
& \operatorname{Prob}\left(Y_{i}=1 \mid x_{i}^{\prime}\right)=F\left(x_{i}^{\prime} \beta_{k}^{\prime}\right) \\
& \operatorname{Prob}\left(Y_{i}=0 \mid x_{i}^{\prime}\right)=1-F\left(x_{i}^{\prime} \beta_{k}^{\prime}\right)
\end{aligned}
$$


$F$ is the standard normal cumulative distribution function, for which values range from 0 to 1. As binary choice models are estimated using maximum likelihood estimation, the signs of estimated parameters can be directly interpreted but not the magnitude of the estimated coefficients. For interpretation purposes, the marginal effect is preferred. The marginal effect of a change in variable $x_{i k}$ on the probability that $Y_{i}=1$ was computed as the partial derivative of the probit function with respect to $x_{i}$ :

$\frac{\partial F\left(x_{i}^{\prime} \beta_{k}\right)}{\partial x_{k}}=F^{\prime}\left(x_{i}^{\prime} \beta_{k}^{\prime}\right) * \beta_{k}$

For the variable age, which contains a linear and a quadratic term, the composite marginal effect at average age was estimated as:

$\frac{\partial F\left(x_{i}^{\prime} \beta\right)}{\partial a g e}=F^{\prime}\left(x_{i}^{\prime} \beta_{k}^{\prime}\right) *\left(\beta_{k-1}+2 \beta_{k} a g e\right)$

\section{Results and discussion}

\section{Factors affecting RAS adoption}

The regression results of the binary probit model and the marginal effects of the independent variables are shown in Table 4.5. The goodness-of-fit is reflected in the Pseudo- $\mathrm{R}^{2}(0.21)$ at the $1 \%$ significance level, with an overall correct prediction rate of $78.4 \%$, suggesting the model is well fitted and the independent variables in the model have a reasonable prediction power. The probit model predicts $23 \%$ of all respondents opting for RAS, which is somewhat lower than observed in the choice experiment (26\%). The relatively low adoption may relate to uncertainty attributed to the economic feasibility of RAS. Overall, the results of the binary probit model show that all parameters are statistically significant at either the $1 \%, 5 \%$ or $10 \%$ significance level, except for extension services and farm with ASC. 
The attribute initial investment has a negative effect on RAS adoption. The marginal effect indicates that a one unit increase in initial investment decreases the probability of adopting RAS by $0.5 \%$. Innovations with high initial investment are less attractive to farmers, as investing in a new technology entails sunk costs related to irreversibility (Koundouri et al. 2006; Pannell et al. 2006). Similarly, the result by Murray et al. (2014) and Schneider et al. (2006) showed that the high initial investment costs is also an important factor leading to slow adoption of RAS in Europe. In contrast, yields and ASC certification with price premium have a positive effect on RAS adoption. The probability of RAS adoption increases by $0.2 \%$ for a one unit increase in yields and by $1.2 \%$ for a one unit increase in ASC with price premium. In RAS, high stocking densities and production levels are required to be able to cover investment costs (Martins et al. 2010). This is in accordance with Ngoc et al. (2016b), who found that higher yields and a price premium are positively associated with the profitability of RAS. A study of Wetengere (2011) also suggested that farmers are more likely to adopt fish farming technology if the introduced system is expected to be profitable.

Farm-specific characteristics also impact on the likelihood of RAS adoption. For instance, there is a positive relationship between the dummy variable location and RAS adoption, suggesting that farmers with farms located in a salt water intrusion region are $22 \%$ more willing to adopt RAS than those in a fresh water region. This in line with our prior expectation that farmers with farms located in the salt water intrusion region are more likely to adopt RAS, as RAS reduces fresh water requirements.

In terms of farmer-specific characteristics, education has a positive effect on adoption. Results show that an additional year of education increases the probability of adopting RAS by $0.6 \%$. This result reveals that education plays a role in increasing the probability of farmers adopting RAS. Prokopy et al. (2008) and Gebrezgabher et al. (2015) suggest that higher educated farmers may have a more open mind towards new technological information as well as better capability to access and process such information.

Another farmer characteristic with a positive effect on the adoption of RAS is household income; a one unit increase in household income leads to a $7 \%$ increase in the likelihood of 
RAS adoption. This provides support for the observation that even when new technologies require large amounts of money initially, wealthy farmers still readily adopt them (Ofuoku et al. 2008; Bosma et al. 2012). The positive relationship between RAS adoption and household income is in line with our expectations, based on Marra et al. (2003) and Pannell et al. (2006).

We found gender to be negatively related to RAS adoption, consistent with our expectations. This indicates that the probability of male farmers adopting RAS is $8 \%$ higher than the probability of female famers adopting RAS. This result is consistent with the findings of Adelaja (2013) and Brummett et al. (2010) who pointed out that fishery activities are mostly dominated by men.

The compositepiled marginal effect of age (i.e. age and $a g e^{2}$ ) has a significantly negative effect on RAS adoption, indicating that a farmer is more likely to adopt RAS up to the age of 32 years (i.e. by solving age in (5)) at which time the farmer begins to decrease adoption by $0.9 \%$ with each additional year. Younger farmers may have longer planning horizons and are therefore more likely to accept the risks associated with innovations, thus confirming the findings of Oude Lansink et al. (2003), Asfaw and Admassie (2004) and Koundouri et al. (2006).

The non-significance of extension services suggests that farmers may rely on their own experience, or may have sufficiently large farms to employ qualified staff themselves. It might also relate to a lack of trust in public and private extension programs (Pannell et al. 2006). In contrast to our results, aquaculture extension and training of fish farmers stimulated the adoption of technology innovations in Ghana (Nwaobiala 2014) and in Bangladesh (Sakib and Afrad 2014). We also found that farm with ASC has no significant effect on RAS adoption. This implies that there is no difference between farms with ASC and farms without ASC in the probability of RAS adoption. This confirms our prior hypothesis that farms with ASC may still consider adopting RAS to improve water quality and disease control. 
To check for the consistency of respondents, the Pearson correlation coefficient of individual respondents was estimated using the holdout profiles. The mean of the individual-level Pearson correlation coefficients was relatively high, 0.68, implying that respondents were mainly consistent in their choices.

Table 4.5 Parameter estimates from the binary probit model and calculated marginal effects on the probability of RAS adoption

\begin{tabular}{|c|c|c|c|c|}
\hline Variable & Coefficient & Marginal effect & $\begin{array}{r}\text { Standard } \\
\text { error }^{\mathrm{a}}\end{array}$ & P value $^{\mathrm{a}}$ \\
\hline Constant & $-2.140 k * *$ & & & \\
\hline \multicolumn{5}{|l|}{ Attribute } \\
\hline Initial investment & $-0.017 * * *$ & -0.005 & 0.000 & 0.000 \\
\hline Yields & $0.008 * * *$ & 0.002 & 0.000 & 0.000 \\
\hline Extension services & -0.053 & -0.018 & 0.031 & 0.563 \\
\hline ASC with price premium & $0.039 * * *$ & 0.012 & 0.002 & 0.000 \\
\hline \multicolumn{5}{|l|}{ Farmers and farms variable } \\
\hline Location & $0.627 * * *$ & 0.215 & 0.040 & 0.000 \\
\hline Education & $0.018 * *$ & 0.006 & 0.003 & 0.040 \\
\hline Income & $0.230 * * *$ & 0.070 & 0.020 & 0.001 \\
\hline Gender & $-0.275 * *$ & -0.077 & 0.029 & 0.016 \\
\hline Age & $0.035 *$ & $-0.009^{b}$ & $0.023^{\mathrm{b}}$ & $0.069^{\mathrm{b}}$ \\
\hline $\mathrm{Age}^{2}$ & $-0.000 * *$ & & & \\
\hline Farm with ASC & 0.160 & 0.050 & 0.035 & 0.144 \\
\hline Log-likelihood & -788.4 & & & \\
\hline$\chi^{2}$ & $447.78 * * *$ & & & \\
\hline Pseudo- $\mathrm{R}^{2}$ & 0.22 & & & \\
\hline $\begin{array}{l}\text { Calculated probability } \\
(\mathrm{Y}=1)\end{array}$ & $23 \%$ & & & \\
\hline Overall correctly predicted & $78.4 \%$ & & & \\
\hline Total \# observations & 1710 & & & \\
\hline
\end{tabular}

$* * *$ Values significant at $1 \%$ level; **Values significant at $5 \%$ level; *Values significant at

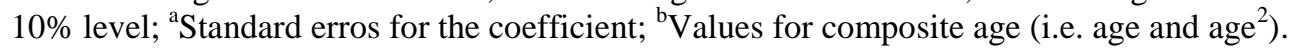

\section{Additional clarification of adoption decisions}

Findings from the choice experiment show a relatively low overall preference to adopt RAS. This is supported by the answers to the statements, which aimed to clarify the choice to either adopt RAS or maintain the traditional system (Table 4.6). For instance, in order to adopt RAS, farmers perceived ASC with price premium as the most important attribute 
(Table 4.5). Statements in Table 4.6 however, demonstrate that farmers' trust in price premiums is very low. Only $32 \%$ of adopters expected to receive a premium (implying $68 \%$ have doubts about this), and $60 \%$ of non-adopters did not believe that they would receive a price premium. The reason for the low trust of farmers in obtaining a price premium is that an explicit price premium has not been offered so far by processing companies for Global G.A.P certified pangasius products (Ngoc et al. 2016b). Thus, farmers believe that price premiums for ASC certified pangasius products are not guaranteed, although price premiums are provided at retail level for other certified fishes, for example, ecolabelled fish in Sweden (Blomquist et al. 2015) and Marine Stewardship Council (MSC) certified frozen processed Alaska pollock products in UK (Roheim et al. 2011). The question remains however whether price increases at retail level are fully transmitted to the farm level. As such, there is a need for further research in price transmission along the Vietnamese pangasius chain in international trading. From the choice experiment we also found that the level of the initial investment is important. Table 4.6 shows that a lack of access to credit may inhibit costly investments. A study of Mityata and Manatunge (2004) on factors influencing adoption of floating net aquaculture in Indonesia also showed that access to credit is an important factor limiting the adoption of the innovation, particularly for financially constrained farms in developing countries. For instance, only $16 \%$ of adopters indicated that they have the financial capacity to invest in RAS. Among non-adopters, $46 \%$ perceived their access to finance as inadequate.

We furthermore found yields to be an important attribute determining RAS adoption. Table 4.6 shows that farmers do believe that RAS improves in-pond water quality (52\%) and controls disease outbreaks $(36 \%)$, and therefore might increase yields. The relatively low percentages may represent a high degree of uncertainty among farmers about the actual performance of RAS. This might also be reflected in the modest belief in a successful implementation of the system (12\%), questions about actual reductions of discharge volumes (32\%), and the perception that the system uses a lot of electricity (43\%). 
Table 4.6 Statements describing the motivation for choosing RAS or the traditional system and the percentage of respondents in agreement

\begin{tabular}{ll}
\hline Statement of reason & \% \\
\hline Adopting $R A S$ (n=25) & 16 \\
a) I have the financial capacity to adopt RAS & 32 \\
b) I expect ASC-certified pangasius will get a price premium & 52 \\
c) I expect that with RAS, the water quality in my fish pond will substantially improve & 36 \\
d) I expect that by adopting RAS, I am better able to fulfil ASC requirements & 12 \\
e) I believe that RAS would be successful on my farm & 36 \\
f) RAS may help reduce discharge volumes, leading to lower environmental taxes in & 32 \\
g) I expect that with RAS, disease can be controlled & \\
Not adopting RAS (maintain traditional system) (n=70) & 46 \\
a) I don't have the financial capacity to adopt RAS & 60 \\
b) I don't think I will get a price premium with ASC-certified pangasius & 10 \\
c) I don't see any concerns regarding the water quality in my pangasius pond & \\
d) I don't believe that RAS would help me to fulfil the requirements of ASC & 26 \\
e) RAS uses a lot of electricity & 43 \\
f) I don't care about obtaining ASC certification & 34 \\
g) Establishing and operating RAS seems complex to me & 20 \\
\hline
\end{tabular}

${ }^{1}$ Chosen by a farmer if (s)he preferred RAS in most of the choice cards (> 11); otherwise a farmer was required to choose the second set (maintain traditional system). In case of indifference, a farmer could select either set.

\section{Conclusions and policy implications}

Adoption of water purification technology, such as RAS, is considered to be an important step to achieve compliance with sustainability certifications and disease control in pangasius farming. In this study, we analysed the attributes and socioeconomic variables affecting the intention to adopt RAS using a choice experiment, conducted among ninetyfive large pangasius farms.

Results suggest that RAS with lower initial investment, expected higher yields and a guarantee of a price premium for ASC-certified pangasius is likely to encourage farmers to adopt RAS, especially in areas suffering from salt intrusion and among younger farmers with a higher level of education and a higher household income. In general however, we 
found a relatively low preference to adopt RAS. Lack of trust in receiving a price premium, inadequate access to finance and uncertainty about the actual performance of RAS seem to be constraints for the adoption of RAS.

The findings of the choice experiment and additional clarifications are regarded as fairly robust due to the set-up of the workshops, i.e. with in-depth elaboration on RAS, the presence of multiple enumerators and the clarification of questions in small groups. We also found a relatively large consistency across answers in profiles, as illustrated by the high correlation between calibration and holdout profiles, and the answers to the additional statements provided. At the time of the study, fish in in-pond pilot RAS was already harvested. If respondents could have personally visited the pilot RAS demonstration site, robustness of results might have further improved.

If the adoption of RAS is to be enhanced, policy makers can stimulate the introduction of RAS by targeting male farmers younger than thirty-two years old with higher education levels, higher household income and with farms located in salt water intrusion regions. In addition, given the importance of the size of the initial investment and the perceived limitations with regard to access to finance, credit programs might be established that link access to credit with farm investments targeting sustainability. Furthermore, policy makers could improve the dissemination of information about technological innovations in pangasius farming by establishing pioneer farms demonstrating the use of RAS, accumulating of sufficient local technical capacity of RAS, and conducting technical training on RAS using the existing extension system in the Mekong Delta area. All of these would certainly help to reduce farmers' uncertainty about the system and hence, increase the chance to adopt RAS. Our results suggest that if the adoption of RAS is to be increased, it is crucial that processors and retailers provide and guarantee a price premium for certified pangasius. 


\section{CHAPTER 5}

\section{Price transmission along the Vietnamese pangasius export chain}

Pham Thi Anh Ngoc ${ }^{\mathrm{a}, \mathrm{c}}$, Miranda P. M. Meuwissen ${ }^{\mathrm{a}}$, Tru Cong

Le $^{\mathrm{c}}$, Roel H. Bosma ${ }^{\mathrm{b}}$, Johan Verreth ${ }^{\mathrm{b}}$, and Alfons Oude Lansink ${ }^{\mathrm{a}}$

${ }^{\text {a }}$ Business Economics Group, Wageningen University, P.O. Box 81306700 EW Wageningen, The Netherlands

${ }^{\mathrm{b}}$ Aquaculture and Fisheries Group, Wageningen University, P.O. Box 338, 6700 AH Wageningen, The Netherlands

${ }^{c}$ Economics Faculty, Nong Lam University, Linh Trung Ward, Thu Duc district, Ho Chi Minh City, Vietnam 


\begin{abstract}
Symmetric price transmission in international chains is important to ensure that price premiums paid by consumers for environmental sustainability labels are transmitted upstream to farmers. This facilitates investment in sustainable aquaculture systems. This study analyses the price transmission from the Polish retail stage to the Vietnamese farm, focusing on frozen pangasius fillets. We used monthly nominal prices at farm and export stages in Vietnam, and at wholesale and retail stages in Poland for the period from August 2010 to December 2014. Price signals at the Polish retail stage were found to transmit back to the wholesale, export, and farm stages. Moreover, price transmission from wholesale to export and from export to farm is characterized by both short- and long-run symmetries. In the short run, retailers tend to transmit only wholesale price increases to their customers and wholesalers transmit only retail price increases to exporters. A long-run relationship between retailers and wholesalers is absent, thereby reducing the ability of chain actors to respond to all market signals, including downward changes.
\end{abstract}

Given the delay in price transmission in the short run, the introduction of business-tobusiness electronic trading or auction markets might reduce this delay along the retail, wholesale, export, and farm stages. To enhance the long-run price relationship in the wholesale-retail market, more retailers should enter the pangasius market. The transmission of price changes from Polish markets back to Vietnamese pangasius farmers is a positive signal for farmers to invest in sustainable production methods, as consumer price premiums likely flow back to the farm.

Key words: price transmission, bargaining power, pangasius, Vietnam, sustainability certification 


\section{Introduction}

Fish is highly traded in the international market; $38 \%$ of world fish production was exported in 2010 (Msangi et al. 2013). Developed countries are the largest market for fish exports from developing countries, accounting for $67 \%$ of these exports (Msangi et al. 2013). Vietnam is the world's largest producer of pangasius. The European Union (EU) is the largest export market for pangasius, and accounts for $22 \%$ of the value of exported Vietnamese frozen pangasius fillets (EUMOFA 2014). Although it is the largest export market, EU imports of frozen pangasius fillets decreased from $€ 370$ million in 2010 (EUMOFA 2014) to $€ 275$ million in 2014 (CBI 2015). This decline could be a consequence of recent claims about the negative environmental impacts of pangasius production and food safety issues (Bush and Duijf 2011; Little et al. 2012; Rico and Van den Brink 2014). Furthermore, retailers and customers increasingly demand labelled pangasius, such as pangasius with the Aquaculture Stewardship Council (ASC) certification, to ensure that pangasius products are sourced from environmentally sustainable and socially equitable production systems (Bush and Duijf 2011; Little et al. 2012).

Labelling requirements raise compliance costs, e.g. because of additional investments and the costs of auditing (Ngoc et al. 2016a; Ngoc et al. 2016b). These costs are typically passed on to the consumers (Boyd and McNevin 2012). However, under asymmetric price transmission, price increases at the downstream stages, i.e. international wholesale and retail stages, are transmitted slowly and possibly not fully to the upstream stages, i.e. domestic export and farm stages (Meyer and von Cramon-Taubadel 2004; Vavra and Goodwin 2005). As a consequence, sufficient capital may not be allocated to meet the required standards.

Among the explanations in the literature, market power in the downstream stages of the supply chain has been identified as the most important reason for asymmetric price transmission (Meyer and von Cramon-Taubadel 2004; Vavra and Goodwin 2005; Frey and Manera 2007; Acharya et al. 2011). The exercise of market power at downstream stages may result in weaker bargaining power at upstream stages (Fałkowski 2010; Assefa et al. 
2014), thus farmers may fail to negotiate a price premium to partially offset the high costs of labelling compliance.

Literature on the degree of price transmission along international supply chains trade is limited and generally focuses on trade within developed countries, such as the salmon chain from Norway to France (Asche et al. 2007), the Israeli grapefruit chain to the EU (Goetz et al. 2008), and the Dutch fresh vegetable supply chain (Verreth et al. 2015). For international trade from developed to developing countries, several studies have investigated price transmission issues. These studies mostly focus on agricultural products, however they do not cover all stages of the chain, i.e. producer, processor/exporter, wholesaler/importer, and retailer (Krivonos 2004; Minot 2010; Rapsomanikis and Mugera 2011; John 2014). In international seafood trade, to the best of our knowledge, no study has addressed price transmission along all stages of the chain. This lack of insight into price transmission along international seafood chains might hamper the switch to a more sustainable aquaculture sector in developing countries.

The objective of this paper was to analyse the price transmission along the international supply chain for frozen pangasius fillets. We selected Poland to represent the international retail stage. Poland is the 7th largest market in the EU for Vietnamese frozen pangasius fillets, accounting for $4.5 \%$ of the value in 2013. The Vietnam to Poland chain is the only international pangasius chain with full price data available for all stages in the same period. The outcomes of this study can provide a better understanding of the market mechanisms in the supply chain; this information is valuable for policy makers to help identify ways of increasing the sustainability of the Vietnamese pangasius sector.

This paper proceeds with a brief description of the supply chain for frozen pangasius fillets from Vietnam to Poland, the data collection, and the price transmission models, and finally it presents the results and discussion, conclusion and policy implications. 


\section{Materials and Methods}

\section{The supply chain for frozen pangasius fillets from Vietnam to Poland}

The supply chain for frozen pangasius fillets from Vietnam to Poland consists of four stages, i.e. farmers and exporters on the Vietnamese side and wholesalers and retailers on the Polish side. The linking markets can be described as follows: (i) farmers sell live pangasius that meet export requirements directly to processing factories, which are also the exporting companies (Khoi 2007; Loc et al. 2010), (ii) at the processing/exporting factories, fish are filleted, frozen, packed, and then exported to the wholesaler in Poland, and finally (iii) the products are distributed to retailers and final consumers.

Vietnamese pangasius production is characterized by an elastic supply. In other words, the supply of Vietnamese pangasius is very sensitive to the market price of live pangasius. For example, when the price is high, farmers will quickly increase their production in the next crop or prolong the sale (Khoi 2007; Bush and Belton 2011; Trifković 2014). This often leads to live pangasius output exceeding the processing capacity of the industry in the following crop. This oversupply of pangasius inevitably drives the price down. In contrast, when the price is low, famers will reduce production in the next crop. Some famers even temporarily stop raising pangasius, resulting in a shortage in the supply of live pangasius in the following crop, which drives the price upwards again (Rapsomanikis et al. 2006; Khoi 2007; Phan et al. 2009).

At the exporter stage, there were approximately 291 Vietnamese pangasius exporters who exported to EU markets in 2010 (van Duijn et al. 2012). Vietnamese pangasius exporters mostly have their own farms; the exporter-owned farms are on average larger than household-owned farms (van Duijn et al. 2012; Trifković 2014).

In Poland, 91\% of total frozen pangasius fillets originated from Vietnam (Pieniak et al. 2011; EUMOFA 2014; VASEP 2014). Fish is sold in specialized stores, supermarkets, hypermarkets, and small independent groceries. Small retailers source fish products from 
wholesalers. The largest retail chains such as hypermarkets and supermarkets are the leading distribution channel for seafood products in Poland (Jesús 2011; Piotr 2015).

\section{Data collection}

We used monthly nominal prices of Vietnamese pangasius at the farm, export, wholesale, and retail stages for the period from August 2010 to December 2014. As export prices and retail prices were in euros, we also converted farm and wholesale prices into euros. For farm prices (VND/EUR), monthly exchange rates were used from www.ozforex.com.au. For wholesale prices (PLN/EUR), exchange rates from www.X-rate.com were used.

The farm prices for live pangasius were retrieved from four Departments of Aquaculture that represent the two main regions for production, i.e. An Giang, Dong Thap, and Vinh Long (main fresh water production region) and Tra Vinh provinces (newly developed salt water intrusion region). An average of Vietnamese farm prices was then calculated for the analysis.

We used Polish import prices as a proxy for Vietnamese export prices. Import prices were derived from monthly import values and quantities of frozen pangasius fillets, both obtained from LEI Wageningen UR.

With respect to Polish wholesale prices for frozen pangasius fillets, average prices from all wholesalers in Poland were collected from www.portalspozywczy.pl. Polish retail prices were retrieved from www.ec.europa.eu. Weekly retail prices were converted into monthly prices by a simple average of four-weekly prices.

\section{Data description}

Figure 5.1 shows the farm, export, wholesale, and retail prices for the period from August 2010 to December 2014. The prices for the farm, export, wholesale, and retail stages appear to follow a fairly similar pattern throughout the period. The sudden jump in export prices in August 2013 is likely associated with the shortage of live pangasius for processing, caused by low prices in the previous months, which in turn were linked to negative media coverage 
by the World Wide Fund for Nature (WWF) in late 2010 (see Little et al. (2012) for a discussion of the pangasius claims in the EU).

Table 5.1 presents the descriptive statistics of the farm, export, wholesale, and retail prices and exchange rates. The fluctuation in retail prices is relatively low, with a coefficient of variation $(\mathrm{CV})$ of 0.04 , compared with the fluctuation in farm prices ( $\mathrm{CV}$ of 0.10$)$, export prices (0.09), and wholesale prices (0.11). Prices at the retail stage generally adjust slowly due to menu costs and the perishable characteristics of products (Vavra and Goodwin 2005; Guillén and Artés 2015).

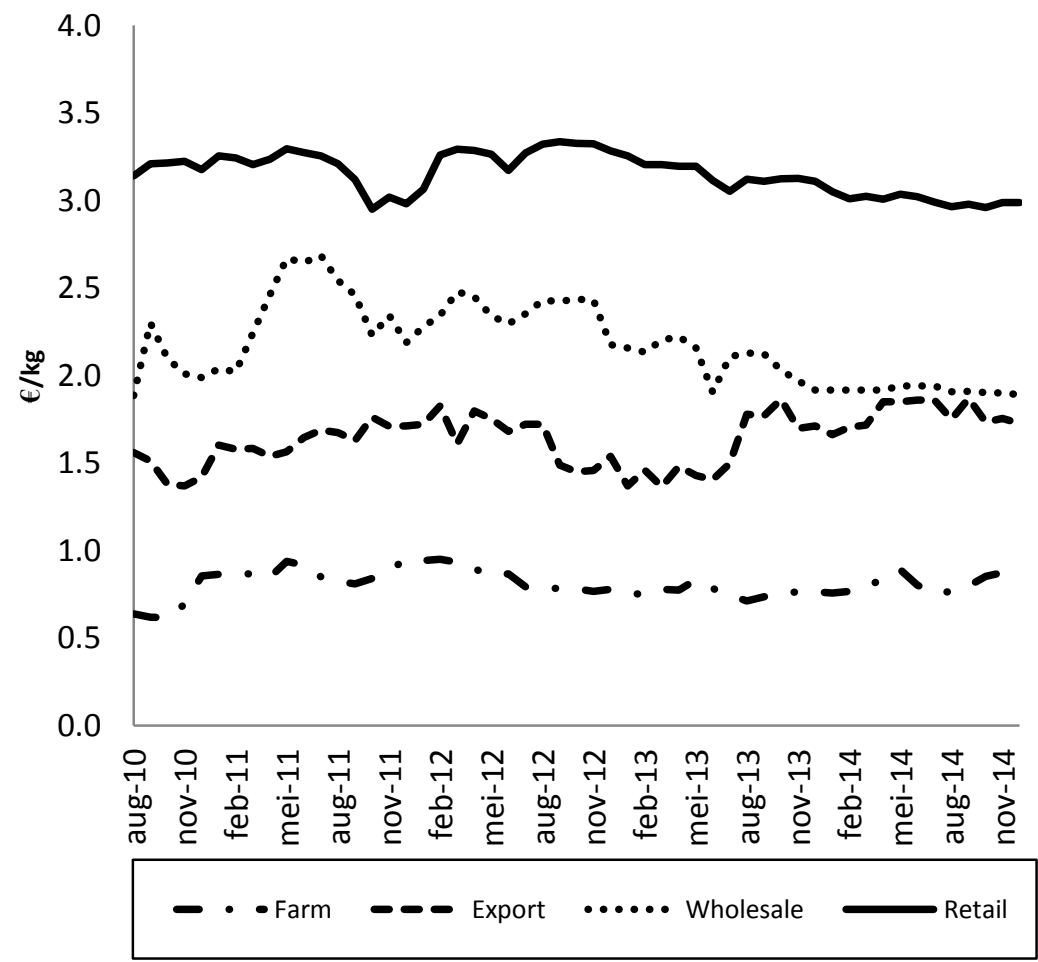

Figure 5.1 The evolution of monthly price series 
Table 5.1 Descriptive statistics of price series and exchange rates

\begin{tabular}{|c|c|c|c|c|c|}
\hline Price (EUR/month) & Mean & SD & $\mathbf{C V}$ & $5 \%$ & $95 \%$ \\
\hline Farm $^{1}$ & 0.81 & 0.08 & 0.10 & 0.63 & 0.94 \\
\hline Export $^{2}$ & 1.64 & 0.15 & 0.09 & 1.37 & 1.86 \\
\hline Wholesale $^{3}$ & 2.18 & 0.23 & 0.11 & 1.90 & 2.65 \\
\hline Retail $^{4}$ & 3.15 & 0.12 & 0.04 & 2.96 & 3.32 \\
\hline \multicolumn{6}{|l|}{ Exchange rate } \\
\hline $\begin{array}{l}\text { VND/EUR } \\
(1,000 \mathrm{VND} / \text { month })^{5}\end{array}$ & 27.71 & 1.20 & 0.04 & 25.59 & 29.65 \\
\hline PLN/EUR (PLN/month) ${ }^{6}$ & 4.15 & 0.12 & 0.03 & 3.93 & 4.39 \\
\hline
\end{tabular}

Data source: ${ }^{1}$ Departments of Aquaculture in An Giang, Dong Thap,and Vinh Long (fresh water area) and Tra Vinh (salt water intrusion area). A weighted average of farm prices was calculated;

${ }^{2}$ Willem van der Pijl from LEI Wageningen UR;

${ }^{3}$ www.Portalspozywczy.pl;

4ec.europa.eu;

${ }^{5}$ www.ozforex.com.au;

${ }^{6}$ www.X-rate.com.

\section{Asymmetric price transmission analysis}

To analyze the price transmission along the stages of the Vietnamese pangasius supply chain, we followed the vector autoregressive error correction model (VECM) framework (see Frey and Manera (2007) for a review). The price transmission analysis involved two main steps: (i) testing the stationarity of price series and the cointegration of pair-wise price series and (ii) testing for asymmetric price transmission.

\section{Testing for stationarity}

The first step of the price transmission analysis was to examine the stationarity of the time series data to avoid a spurious regression (Asteriou and Hall 2007). We used the DickeyFuller GLS (DF-GLS) and Phillips-Perron (PP) tests to test the stationarity of each price series (Asteriou and Hall 2007). The null hypothesis for both tests is that each price series is non-stationary. For the DF-GLS test, the lag length was selected using the Akaike information criterion (AIC). 


\section{Testing for cointegration}

Next, we used the Johansen (1991) approach to test for the cointegration of pair-wise prices; cointegration implies a causal long-run relationship between pair-wise prices, i.e. farmexport, export-wholesale, and wholesale-retail. The criterion of selecting lag length for cointegration tests was based on the three of the following five statistical tests: AIC, Schwarz Bayesian Criterion (SBC), Hannan-Quin, likelihood ratio, and final predictor error points at the same lag length. This criterion is frequently used as suggested by Asteriou and Hall (2007), Fałkowski (2010), and Serra and Goodwin (2003). 2.4.3. Asymmetric price transmission models

The second step was to check for asymmetric price transmission and quantify the price adjustment. We used the VECM for the cointegrated pair-wise prices and the Houck (1977) and Ward (1982) model for non-cointegrated pair-wise prices (von Cramon-Taubadel 1998; Bakucs et al. 2012; Verreth et al. 2015). Literature has acknowledged the importance of the exchange rate in international trade (Tveteras and Asche 2008; Larsen and Kinnucan 2009; Asche et al. 2014). Therefore, to capture the effect of the exchange rate on the price transmission mechanism, our asymmetric price transmission model included a variable exchange rate.

a. The vector error correction model (VECM)

Following von Cramon-Taubadel (1998), our asymmetric VECM model for cointegrated pair-wise prices was specified as:

$$
\begin{aligned}
& \Delta \mathrm{P}_{1, \mathrm{t}}=\gamma_{0}+\sum_{\mathrm{i}=1}^{\mathrm{n}} \gamma_{1, \mathrm{i}} \Delta \mathrm{P}_{1, \mathrm{t}-\mathrm{i}}+\sum_{\mathrm{i}=0}^{\mathrm{n}} \gamma_{2, \mathrm{i}}^{+} \Delta \mathrm{P}_{2, \mathrm{t}-\mathrm{i}}^{+}+\sum_{\mathrm{i}=0}^{\mathrm{n}} \gamma_{2, \mathrm{i}}^{-} \Delta \mathrm{P}_{2, \mathrm{t}-\mathrm{i}}^{-}+\sum_{\mathrm{i}=0}^{\mathrm{n}} \gamma_{3, \mathrm{i}} \Delta \mathrm{EX}_{\mathrm{VND}, \mathrm{t}-\mathrm{i}}+ \\
& \gamma_{4}^{+} \mathrm{ECT}_{\mathrm{t}-1}^{+}+\gamma_{4}^{-} \mathrm{ECT}_{\mathrm{t}-1}^{-}+\varepsilon_{\mathrm{t}}
\end{aligned}
$$

where $\Delta$ is the first difference operator (e.g. $\Delta \mathrm{P}_{1}=\mathrm{P}_{1, \mathrm{t}}-\mathrm{P}_{1, \mathrm{t}-1}$ ), $\mathrm{n}$ is the lag length, and $\mathrm{EX}_{\mathrm{VND}, \mathrm{t}}$ stands for the exchange rate from VND to EUR. For the exchange rate from PLN to EUR, we replaced $\mathrm{EX}_{\mathrm{VND}, \mathrm{t}}$ by $\mathrm{EX}_{\mathrm{PLN}, \mathrm{t}}$. The cointegrtation relation is given as: $\mathrm{P}_{1, \mathrm{t}}=\gamma_{0}+\gamma_{1} \mathrm{P}_{2, \mathrm{t}}+\gamma_{2} \mathrm{EX}_{\mathrm{t}}+\varepsilon_{\mathrm{t}}$. The error correction term $\mathrm{ECT}_{\mathrm{t}-1}$ is the first lagged 
residual of the long-run relationship of pair-wise prices: $\mathrm{ECT}_{\mathrm{t}-1}=\varepsilon_{\mathrm{t}-1}=\mathrm{P}_{1, \mathrm{t}}-\gamma_{0}-$ $\gamma_{1} P_{2, t}-\gamma_{2} E_{t}$. To capture the short- and long-run asymmetry in price transmission, $\Delta \mathrm{P}_{2}$ and ECT are split into their positive (+) and negative (-) components respectively. The parameters $\gamma_{1, i}, \gamma_{2, i}, \gamma_{3, i}$ represent the speed of adjustment, showing how quickly $P_{1, t}$ is corrected in the short run in response to a change in lagged $\mathrm{P}_{1, \mathrm{t}}, \mathrm{P}_{2, \mathrm{t}}$, and exchange rate $\mathrm{EX}_{\mathrm{VND}, \mathrm{t}}$ or $\mathrm{EX}_{\mathrm{PLN}, \mathrm{t}}$. Similarly, the parameters $\gamma_{4}$ represent the speed of adjustment of the price $\mathrm{P}_{1, \mathrm{t}}$ towards the long-run equilibrium price.

The following rules were applied in calculating the negative and positive components of the split independent variables of $\Delta \mathrm{P}_{2, \mathrm{t}}$ and $\mathrm{ECT}_{\mathrm{t}}$ :

$$
\begin{aligned}
& \mathrm{ECT}_{t}^{+}=\left\{\begin{array}{cl}
\mathrm{ECT}_{\mathrm{t}} & \text { if } \mathrm{ECT}_{\mathrm{t}}>0 \\
0 & \text { otherwise }
\end{array} \quad \text { and } \quad \mathrm{ECT}_{\mathrm{t}}^{-}=\left\{\begin{array}{cc}
\mathrm{ECT}_{\mathrm{t}} & \text { if } \mathrm{ECT}_{\mathrm{t}}<0 \\
0 & \text { otherwise }
\end{array}\right.\right. \\
& \Delta \mathrm{P}_{2 \mathrm{t}}^{+}=\left\{\begin{array}{cc}
\Delta \mathrm{P}_{2 \mathrm{t}} \text { if } \Delta \mathrm{P}_{2 \mathrm{t}}>0 \\
0 & \text { otherwise }
\end{array} \quad \text { and } \quad \Delta \mathrm{P}_{2 \mathrm{t}}^{-}=\left\{\begin{array}{cc}
\Delta \mathrm{P}_{2 \mathrm{t}} \text { if } \Delta \mathrm{P}_{2 \mathrm{t}}<0 \\
0 & \text { otherwise }
\end{array}\right.\right.
\end{aligned}
$$

When price transmission in pair-wise prices is asymmetric in the short run (SR) and longrun equilibrium (LR), the F-test should reject the following hypothesis:
$\mathrm{H}_{0, \mathrm{SR}}: \sum_{\mathrm{i}=0}^{\mathrm{n}} \gamma_{2, \mathrm{i}}^{+}=\sum_{\mathrm{i}=0}^{\mathrm{n}} \gamma_{2, \mathrm{i}}^{-}$
and
$\mathrm{H}_{0, \mathrm{LR}}: \gamma_{4}^{+}=\gamma_{4}^{-}$

Next, we followed Boswijk and Urbain (1997) to test whether $P_{1, t}$ is driven by $P_{2, t}$ with respect to the short-run parameters in Equation 5.1. The marginal model for $\mathrm{P}_{2}$ takes the form (von Cramon-Taubadel 1998):

$\Delta \mathrm{P}_{2, \mathrm{t}}=\mu_{0}+\sum_{\mathrm{i}=1}^{\mathrm{n}} \mu_{1} \Delta \mathrm{P}_{1, \mathrm{t}-\mathrm{i}}+\sum_{\mathrm{i}=1}^{\mathrm{n}} \mu_{2} \Delta \mathrm{P}_{2, \mathrm{t}-\mathrm{i}}+\varepsilon_{\mathrm{t}}$ 
b. The Houck (1977) and Ward (1982) model

Following the Houck (1977) and Ward (1982) approach for non-cointegrated pair-wise prices, the response of a price $\mathrm{P}_{1, \mathrm{t}}$ to $\mathrm{P}_{2, \mathrm{t}}$ in the short run can be expressed as (Frey and Manera 2007; Verreth et al. 2015):

$\mathrm{P}_{1, \mathrm{t}}^{*}=\alpha_{0}+\sum_{\mathrm{i}=0}^{\mathrm{n}} \alpha_{1, \mathrm{i}}^{+} \Delta \mathrm{P}_{2, \mathrm{t}-\mathrm{i}}^{+}+\sum_{\mathrm{i}=0}^{\mathrm{n}} \alpha_{1, \mathrm{i}}^{-} \Delta \mathrm{P}_{2, \mathrm{t}-\mathrm{i}}^{-}+\sum_{\mathrm{i}=0}^{\mathrm{n}} \alpha_{2, \mathrm{i}} \Delta \mathrm{EX}_{\mathrm{VND}, \mathrm{t}-\mathrm{i}}+\varepsilon_{\mathrm{t}}$

where the superscript $*$ denotes cumulative values from the starting value $\mathrm{P}_{1,0}^{*}$ (i.e. $\mathrm{P}_{1, \mathrm{t}}-\mathrm{P}_{1,0}^{*}$. Equation (5.3) considers the impact of positive $(+)$ and negative (-) variations of $\mathrm{P}_{2, \mathrm{t}}$ and exchange rate $\mathrm{EX}_{\mathrm{VND}, \mathrm{t}}$ on $\mathrm{P}_{1, \mathrm{t}}$, cumulated from the required lags up to the current period $(\mathrm{i}=0)$. For the exchange rate from PLN to EUR, we replaced $\mathrm{EX}_{\mathrm{VND}, \mathrm{t}}$ by $\mathrm{EX}_{\mathrm{PLN}, \mathrm{t}}$. If a serial correlation problem existed in the estimated equation, we used the Cochrane-Orcutt procedure to correct the problem (Pindyck and Rubinfeld 1998).

When price transmission in pair-wise prices is asymmetric in the short run, the F-test should reject the following hypothesis: $\mathrm{H}_{0}: \sum_{\mathrm{i}=0}^{\mathrm{n}} \alpha_{1, \mathrm{i}}^{+}=\sum_{\mathrm{i}=0}^{\mathrm{n}} \alpha_{1, \mathrm{i}}^{-}$.

\section{Results and discussion}

A summary of the results of price transmission along the Vietnamese pangasius chain is presented in Figure 5.2. This section starts with the results of the stationarity tests of the price series, followed by the cointegration tests of pair-wise prices, and the results of the price transmission analysis. 


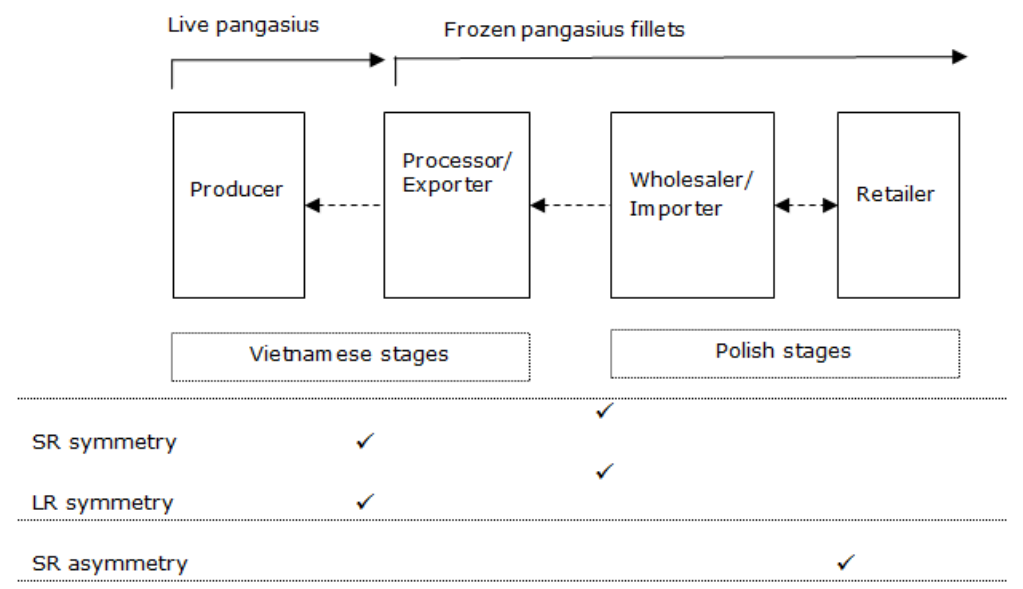

Notes: Dashed arrows show the directions of price relationship; SR (short run) and LR (long run)

Figure 5.2 Summary of findings for price transmission along the supply chain for frozen pangasius fillets from Vietnam to Poland.

\section{Results of the stationarity tests}

Table 5.2 reports the results of the DF-GLS and PP tests, which show that we failed to reject all the null hypotheses of non-stationarity for export, wholesale, and retail prices and exchange rates at the $1 \%, 5 \%$, or $10 \%$ critical levels. Only farm prices are stationary at the $10 \%$ critical level. However, both tests of the price series in their first difference form robustly rejected the null hypothesis of non-stationarity at the $1 \%$ critical level for all price series. Therefore, we conclude that farm, export, wholesale, and retail prices, and exchange rates are all stationary in the first difference form. 
Table 5.2 Results of stationarity tests

\begin{tabular}{|c|c|c|c|c|c|}
\hline Variable & Test & $\begin{array}{r}\text { Non- } \\
\text { differenced }\end{array}$ & Lag & First difference & Lag \\
\hline Farm price $^{1}$ & $\begin{array}{l}\text { DF-GLS } \\
\text { PP }\end{array}$ & $\begin{array}{l}-1.862^{*} \\
-2.626^{*}\end{array}$ & 0 & $\begin{array}{l}-5.209^{\text {***** }} \\
-5.252^{\text {***** }}\end{array}$ & 0 \\
\hline Export price $^{2}$ & $\begin{array}{l}\text { DF-GLS } \\
\text { PP }\end{array}$ & $\begin{array}{l}-2.159 \\
-2.775\end{array}$ & 1 & $\begin{array}{l}-9.271^{* * *} \\
-9.549^{* * *}\end{array}$ & 0 \\
\hline Wholesale price ${ }^{2}$ & $\begin{array}{l}\text { DF-GLS } \\
\text { PP }\end{array}$ & $\begin{array}{l}-2.127 \\
-3.279^{*}\end{array}$ & 0 & $\begin{array}{l}-2.283^{* * * *} \\
-7.890^{* * *}\end{array}$ & 0 \\
\hline Retail price $^{2}$ & $\begin{array}{l}\text { DF-GLS } \\
\text { PP }\end{array}$ & $\begin{array}{l}-2.423 \\
-2.504\end{array}$ & 1 & $\begin{array}{l}-5.825^{* * * *} \\
-6.128^{* * * *}\end{array}$ & 0 \\
\hline $\begin{array}{l}\text { Exchange rate (EX) } \\
\text { VND/EUR }^{2}\end{array}$ & DF-GLS & -2.978 & 1 & $-5.235^{* * *}$ & 1 \\
\hline & PP & -2.146 & & $-5.060^{* * *}$ & \\
\hline PLN/EUR $^{1}$ & $\begin{array}{l}\text { DF-GLS } \\
\text { PP }\end{array}$ & $\begin{array}{l}-2.396 \\
-1.800\end{array}$ & 3 & $\begin{array}{l}-4.483^{* * * *} \\
-4.518^{* * *}\end{array}$ & 0 \\
\hline
\end{tabular}

${ }^{1}$ The DF-GLS test includes an intercept; ${ }^{2}$ The DF_GLS test includes an intercept and trend at non-differenced; ***Values significant at $1 \%$ level and $*$ at $10 \%$ level.

\section{Results of the cointegration tests for a long-run equilibrium relationship}

Table 5.3 presents the results of the Johansen cointegration test. With respect to the farmexport market, both trace and maximal eigenvalue statistics indicate one cointegration vector, implying the existence of a long-run relationship between farm and export prices. The null hypothesis that the factor loading in the equation for export prices equals 0 is not rejected, implying that farm prices are driven by export prices in the long run. This likely reflects the close cooperation between exporters and pangasius farmers, for example through training programs to ensure fish quality and safety for export to the EU market (Bush and Belton 2011; Khoi 2011; Trifković 2014). This close cooperation confirms the unidirectional causality from export to farm prices. These results are in line with findings of Ohen et al. (2007) and Asche et al. (2007) who also found the long-run relationship 
between farmers and exporters in live catfish in Nigeria, and Salmon in Norway, respectively.

Regarding the export-wholesale market, both trace and maximal eigenvalue statistics suggest one cointegration vector between export and wholesale prices. The null hypothesis that the factor loading in the equation for wholesale prices equals 0 is not rejected, implying that export prices are driven by wholesale prices. This is consistent with the findings of Khoi (2007) and Khoi (2011), who indicated that Vietnamese pangasius exporters want to establish long-run relationships with international wholesalers. Exporters usually set their prices based on international import market prices, thus confirming the unidirectional causality from wholesale to export prices.

In contrast, with respect to the wholesale-retail market, both trace and maximal eigenvalue statistics suggest that the null hypothesis of zero cointegration vectors cannot be rejected. The non-cointegration of wholesale and retail prices could be attributed to private label products introduced by retailers (Bukeviciute et al. 2009) together with the consolidation in retail chains (Wilkin et al. 2007; Fałkowski 2010). These in turn might influence the movement of prices, especially weakening the role of wholesalers, thus leading to the possible absence of a long-run relationship between wholesale and retail prices. 
Table 5.3 Results of Johansen cointegration tests

\begin{tabular}{|c|c|c|c|c|c|c|}
\hline Linking market & $\begin{array}{c}\text { Lag } \\
\text { length }\end{array}$ & $\begin{array}{l}\text { Hypothesized } \\
\text { number of } \\
\text { cointegration } \\
\text { vectors }\end{array}$ & $\begin{array}{r}\text { Trace } \\
\text { statistic }\end{array}$ & P-value & $\begin{array}{r}\text { Maximal } \\
\text { eigenvalue } \\
\text { statistic }\end{array}$ & P-value \\
\hline Farm-Export & 1 & $\begin{array}{c}\text { None } \\
\text { At most } 1\end{array}$ & $\begin{array}{r}27.823 \\
6.475\end{array}$ & $\begin{array}{r}0.028^{* *} \\
0.402\end{array}$ & $\begin{array}{r}21.348 \\
6.475\end{array}$ & $\begin{array}{r}0.025^{* * *} \\
0.402\end{array}$ \\
\hline Export-Wholesale & 2 & $\begin{array}{c}\text { None } \\
\text { At most } 1\end{array}$ & $\begin{array}{r}21.995 \\
3.070\end{array}$ & $\begin{array}{r}0.028 * * \\
0.567\end{array}$ & $\begin{array}{r}18.924 \\
3.070\end{array}$ & $\begin{array}{r}0.016^{* *} \\
0.567\end{array}$ \\
\hline Wholesale-Retail & 1 & $\begin{array}{c}\text { None } \\
\text { At most } 1 \\
\end{array}$ & $\begin{array}{r}10.721 \\
3.721 \\
\end{array}$ & $\begin{array}{l}0.569 \\
0.455 \\
\end{array}$ & $\begin{array}{l}6.999 \\
3.721 \\
\end{array}$ & $\begin{array}{l}0.669 \\
0.455 \\
\end{array}$ \\
\hline \multicolumn{7}{|c|}{$\begin{array}{r}{ }^{\mathrm{i} F a c t o r} \text { loading }\left(\mathrm{P}_{\mathrm{f}}, \mathrm{P}_{\mathrm{e}}\right): \mathrm{a}=(-0.397 ; 0.283), \mathrm{H}_{0}: \alpha_{2}=0 ; \chi^{2} \text {-statistic }=(4.670 ; 1.219), \chi_{.050}^{2}=3.841 \\
\left(\mathrm{P}_{\mathrm{e}}, \mathrm{P}_{\mathrm{w}}\right): \mathrm{a}=(-0.507 ; 0.047), \mathrm{H}_{0}: \alpha_{2}=0 ; \chi^{2} \text {-statistic }=(4.526 ; 0.299), \chi_{.050}^{2}=3.841\end{array}$} \\
\hline
\end{tabular}

** Values significant at $5 \%$ level; ${ }^{\text {iT }}$ The null hypothesis that the factor loading equals 0 in the equations for $\mathrm{P}_{\mathrm{e}}$ and $\mathrm{P}_{\mathrm{w}}$ is not rejected.

\section{Results of the price transmission analysis}

This section presents the outcomes of the VECM for cointegrated pair-wise prices of the farm-export and export-wholesale markets, and The Houck (1977) and Ward (1982) model for non-cointegrated wholesale-retail prices.

\section{Farm-export market}

The results of the asymmetric VECM with farm prices as dependent variable are shown in Table 5.4. The non-significant residuals in the variable addition test from the marginal model (Equation 5.2) of the VECM (Equation 5.1) confirm that farm prices are driven by export prices. The R-squared coefficient is 0.28 and the equation is significant at the $10 \%$ critical level, indicating that $28 \%$ of the variation in farm prices is explained by the model. 
Results in Table 5.4 suggests that changes in export prices, previous farm prices, and exchange rates take one month to transmit to farm prices. The coefficient of the lagged farm prices is positive and statistically significant at the $1 \%$ critical level. The estimated coefficient is 1.76 (greater than one), indicating that farm prices respond very quickly to a change in the previous month's farm price. When the farm price increases during the previous month, farmers expect a price increase in the upcoming month. They may then wait a while before selling in order to sell their fish for higher prices (Khoi 2007; Phan et al. 2009).

The coefficient of the lagged exchange rate (VND/EUR) is negative and statistically significant at the $10 \%$ critical level, with a magnitude of 0.02 . This result has two implications. First, the magnitude suggests that farm prices respond slowly to a change in exchange rates. Second, the negative sign of the lagged exchange rate (VND/EUR) implies that farm prices decrease as the exchange rate increases. This might be because of foreign currency speculation by the Vietnamese exporter. Exporters who directly sell frozen pangasius fillets to Poland might wait until the exchange rate is more favorable before converting to the euro. At the same time, an increase in the exchange rate (VND/EUR) might increase the fuel prices, which might influence the operation costs for exporters, such as transportation costs. Consequently exporters may assign a temporarily lower farmer price to compensate for the increased costs. This result is opposite to our prior expectation. In principle, a depreciation of the domestic currency will boost exports, creating pressure on the domestic price to increase due to higher demand for domestic goods (Rapsomanikis et al. 2006; Lee and Gomez 2011).

The non-significance of current and lagged export prices suggests that a change in export price does not affect farm prices. One of the possible reasons is that most of the large farms are owned and operated by exporters, who are able to temporarily supply live pangasius themselves (Phan et al. 2009; Beukers et al. 2015).

In the long-run equilibrium, the error correction terms $\mathrm{ECT}^{+}$and $\mathrm{ECT}^{-}$are significant at the $1 \%$ and $5 \%$ critical levels, respectively. The two ECT coefficients suggest that adjustments are relatively fast, i.e. even more than $100 \%$ of the divergence from the long-run 
equilibrium is corrected during the next month. For instance, the estimated coefficient of $\mathrm{ECT}^{+}$implies that if the farm price increases by $€ 1.00$ in the long-run equilibrium with the export price, the farm price would be expected to decrease by $€ 1.85$ in the next month. Similarly, ECT $^{-}$suggests that farm prices would be expected to increase by $€ 1.38$ in the next month when the farm price decreases in the long-run equilibrium with the export price.

With regard to asymmetry in price transmission, Wald tests with a null hypothesis of symmetric price transmission could not be rejected at the $1 \%, 5 \%$, or $10 \%$ critical levels, suggesting that a change in export price is fully transmitted to the farm price. Results imply that even though exporters can set the farm price, farmers can still negotiate the prices. It is possible that farmers with larger farms who can provide quality fish and fulfil the certification requirements are able to negotiate prices with exporters. Exporters set prices based on the fish quality at the end of production cycle (Khoi 2011; Trifković 2014). 
Table 5.4 Results for price transmission in the farm-export market

\begin{tabular}{|c|c|c|}
\hline \multirow[b]{2}{*}{ Independent variables } & \multicolumn{2}{|c|}{ Dependent variable } \\
\hline & $\begin{array}{l}\text { Estimated } \\
\text { coefficient }\end{array}$ & P-value \\
\hline Constant & 0.017 & 0.225 \\
\hline$\Delta \mathrm{P}_{\mathrm{f}, \mathrm{t}-1}$ & 1.761 & $0.002 * *$ \\
\hline$\Delta \mathrm{P}_{\mathrm{e}, \mathrm{t}}^{+}$ & -0.075 & 0.466 \\
\hline$\Delta \mathrm{P}_{\mathrm{e}, \mathrm{t}-1}^{+}$ & 0.086 & 0.397 \\
\hline$\Delta \mathrm{P}_{\mathrm{e}, \mathrm{t}}^{-,}$ & 0.062 & 0.591 \\
\hline$\Delta \mathrm{P}_{\mathrm{e}, \mathrm{t}-1}^{-}$ & 0.096 & 0.419 \\
\hline$\Delta \mathrm{EX}_{\mathrm{VND}, \mathrm{t}}$ & 0.007 & 0.367 \\
\hline$\Delta \mathrm{EX}_{\mathrm{VND}, \mathrm{t}-1}$ & -0.023 & $0.060^{*}$ \\
\hline $\mathrm{ECT}_{\mathrm{t}-1}^{+}$ & -1.851 & $0.004 * * *$ \\
\hline $\mathrm{ECT}_{\mathrm{t}-1}^{-}$ & -1.385 & $0.029 * *$ \\
\hline R-squared & 0.283 & - \\
\hline F-statistic & 1.798 & $0.098^{*}$ \\
\hline Residual tests & F-statistic & \\
\hline No serial correlation & 0.375 & 0.543 \\
\hline Homoscedasticity & 1.161 & 0.344 \\
\hline Normal distribution & - & $0.000 * * *$ \\
\hline $\begin{array}{l}\text { Variable addition test for residual in } \\
\text { Equation } 2\end{array}$ & 0.006 & 0.928 \\
\hline \multicolumn{3}{|l|}{ Asymmetry tests } \\
\hline Short run & 0.326 & 0.571 \\
\hline Long run & 0.962 & 0.332 \\
\hline
\end{tabular}

$* * *$ Values significant at $1 \%$ level, $* *$ at $5 \%$ level, and * at $10 \%$ level; LM test for autocorrelation; Breusch-Pagan-Godfrey test for heteroskedasticity; Histogram for normality test.

\section{Export-wholesale market}

The estimation results of the VECM with export prices as the dependent variable are presented in Table 5.5. The non-significant residuals in the variable addition test from Equation 5.2 in the VECM (Equation 5.1) confirm that export prices are driven by wholesale prices. The R-squared coefficient is 0.44 at the $5 \%$ critical level, showing that $44 \%$ of the variation in export prices is explained by the equation.

A lag length of two was selected based on the outcomes of the AIC, Hannan-Quin, and final predictor error tests. In the export-wholesale market, the lags are slightly longer than 
in the farm-export market. This might reflect that the transaction costs for adjusting prices are possibly higher in international trading than in domestic trading.

The non-significance of lagged export prices, lagged wholesale prices, and lagged exchange rates (PLN/EUR) indicates that changes in the previous month's export prices, wholesale prices, and exchange rates do not transmit to export prices. This might be related to the expiry date of pangasius export contracts, which may affect the length of time needed for price adjustments to be incorporated. Larsen and Asche (2011) suggested that export price movements are limited by the use of fixed price contracts in Norwegian salmon exports to France.

In the long-run equilibrium, $\mathrm{ECT}^{+}$and $\mathrm{ECT}^{-}$are both statistically significant at the $10 \%$ critical level. Adjustments are less responsive in the export-wholesale market than in the farm-export market. For example, if export prices increase/decrease by $€ 1.00$ in the longrun equilibrium relationship with wholesale prices, exporters decrease/increase their prices by $€ 1.03 / € 0.95$ in the next month.

With respect to asymmetry in price transmission, the Wald tests with a null hypothesis of symmetry in the short run and long run could not be rejected at the $1 \%, 5 \%$, or $10 \%$ critical levels. This symmetry in price transmission likely implies that exporters can attain privileged market access by being able to comply with required standards. 
Table 5.5 Results for price transmission in the export-wholesale market

\begin{tabular}{|c|c|c|}
\hline \multirow[b]{2}{*}{ Independent variables } & \multicolumn{2}{|c|}{$\begin{array}{c}\text { Dependent variable } \\
\Delta \boldsymbol{P}_{\rho t}\end{array}$} \\
\hline & $\begin{array}{l}\text { Estimated } \\
\text { coefficient }\end{array}$ & P-value \\
\hline Constant & 0.023 & 0.459 \\
\hline$\Delta \mathrm{P}_{\mathrm{e}, \mathrm{t}-1}$ & 0.540 & 0.245 \\
\hline$\Delta \mathrm{P}_{\mathrm{e}, \mathrm{t}-2}$ & 0.097 & 0.512 \\
\hline$\Delta \mathrm{P}_{\mathrm{w}, \mathrm{t}}^{+}$ & -0.230 & 0.369 \\
\hline$\Delta \mathrm{P}_{\mathrm{w}, \mathrm{t}-1}^{+}$ & 0.130 & 0.626 \\
\hline$\Delta \mathrm{P}_{\mathrm{w}, \mathrm{t}-2}^{+}$ & -0.021 & 0.911 \\
\hline$\Delta \mathrm{P}_{\mathrm{w}, \mathrm{t}}^{-}$ & 0.170 & 0.433 \\
\hline$\Delta \mathrm{P}_{\mathrm{w}, \mathrm{t}-1}^{-}$ & 0.233 & 0.584 \\
\hline$\Delta \mathrm{P}_{\mathrm{w}, \mathrm{t}-2}^{-}$ & -0.340 & 0.137 \\
\hline$\Delta \mathrm{EX}_{\mathrm{PLN}, \mathrm{t}}$ & -0.112 & 0.377 \\
\hline$\Delta \mathrm{EX}_{\mathrm{PLN}, \mathrm{t}-1}$ & 0.045 & 0.801 \\
\hline$\Delta \mathrm{EX}_{\mathrm{PLN}, \mathrm{t}-2}$ & -0.048 & 0.726 \\
\hline $\mathrm{ECT}_{\mathrm{t}-1}^{+}$ & -1.039 & $0.076^{*}$ \\
\hline $\mathrm{ECT}_{\mathrm{t}-1}^{-}$ & -0.953 & $0.095^{*}$ \\
\hline R-squared & 0.449 & 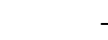 \\
\hline F-statistic & 2.263 & $0.026 * *$ \\
\hline Residual tests & F-statistic & \\
\hline No serial correlation & 0.403 & 0.671 \\
\hline Homoscedasticity & 0.941 & 0.522 \\
\hline Normal distribution & - & 0.703 \\
\hline $\begin{array}{l}\text { Variable addition test for residual in } \\
\text { Equation } 2\end{array}$ & 0.634 & 0.431 \\
\hline \multicolumn{3}{|l|}{ Asymmetry tests } \\
\hline Short run & 0.077 & 0.782 \\
\hline Long run & 0.027 & 0.870 \\
\hline
\end{tabular}

**Values significant at 5\% level and * at 10\% level; LM test for autocorrelation; BreuschPagan-Godfrey test for heteroskedasticity; Histogram for normality test.

\section{Wholesale-retail market}

The Houck and Ward models with dependent variables of (i) wholesale prices and (ii) retail prices both have R-squared coefficients around 0.85 and significant at the $1 \%$ critical level, suggesting that wholesale prices influence retail prices and vice versa. Results of the two models are shown in Table 5.6. A lag length of one was selected based on the SBC, Hannan-Quin, and likelihood ratio tests. 
In the first model, where the retail price drives the wholesale price, only the positive cumulative coefficient of current retail price is statistically significant at the $1 \%$ critical level. The estimated coefficient is 1.22 , implying that wholesale prices respond quickly to an increase in retail prices. Similarly, in the model where the wholesale price drives the retail price, only the positive cumulative coefficient of current wholesale price is statistically significant at the $1 \%$ critical level. The estimated coefficient of 0.26 suggests that retail prices respond slowly to an increase in wholesale prices; this might be due to the existence of menu costs at the retail stage (Vavra and Goodwin 2005; Guillén and Artés 2015).

In both models, the non-significance of the exchange-rate (PLN/EUR) and its lags suggests that a change in exchange rates in the previous month does not affect wholesale or retail prices. This is understandable as the transaction between wholesalers and retailers has been made in the Polish currency (PLN), not in euros.

With regard to asymmetric price transmission, the Wald test in the first model where the retail price drives the wholesale price with a null hypothesis of symmetry was rejected at the 5\% critical levels, suggesting asymmetric price transmission between wholesalers and retailers. Several studies have also shown that retailers use their market power to transmit price decreases more than price increases to upstream stages (Fałkowski 2010; Assefa et al. 2014; Sapkota et al. 2015). In addition, our findings in the model where the wholesale price drives the retail price show that wholesale prices could also respond to retail price increases. Poor transportation and perishability of the product might affect the leadership of retail prices over wholesale prices in the short run (Sapkota et al. 2015). 
Table 5.6 Results for price transmission in the wholesale-retail market

\begin{tabular}{|c|c|c|c|c|}
\hline \multirow{3}{*}{ Independent variables } & \multicolumn{4}{|c|}{ Dependent variable } \\
\hline & \multicolumn{2}{|c|}{$\mathbf{P}_{\mathrm{w}, \mathrm{t}}^{*}$} & \multicolumn{2}{|l|}{$\mathbf{P}_{\mathrm{r}, \mathrm{t}}^{*}$} \\
\hline & $\begin{array}{c}\text { Estimated } \\
\text { coefficient }\end{array}$ & P-value & $\begin{array}{c}\text { Estimated } \\
\text { coefficient }\end{array}$ & P-value \\
\hline Constant & 0.198 & $0.066^{*}$ & -0.100 & $0.033 * *$ \\
\hline$\Delta \mathrm{P}_{\mathrm{r}, \mathrm{t}}^{+}$ & 1.226 & $0.002 * * *$ & - & - \\
\hline$\Delta \mathrm{P}_{\mathrm{r}, \mathrm{t}-1}^{+}$ & 0.216 & 0.636 & - & - \\
\hline$\Delta \mathrm{P}_{\mathrm{r}, \mathrm{t}}^{-}$ & 0.690 & 0.125 & - & - \\
\hline$\Delta \mathrm{P}_{\mathrm{r}, \mathrm{t}-1}^{-}$ & -0.364 & 0.579 & - & - \\
\hline$\Delta \mathrm{P}_{\mathrm{w}, \mathrm{t}}^{+}$ & & & 0.266 & $0.000 * * *$ \\
\hline$\Delta \mathrm{P}_{\mathrm{w}, \mathrm{t}-1}^{+}$ & & & 0.112 & 0.112 \\
\hline$\Delta \mathrm{EX}_{\mathrm{PLN}, \mathrm{t}}$ & -0.095 & 0.585 & 0.038 & 0.691 \\
\hline$\Delta \mathrm{EX}_{\mathrm{PLN}, \mathrm{t}-1}$ & 0.035 & 0.841 & -0.009 & 0.945 \\
\hline $\mathrm{AR}(1)$ & 0.859 & $0.000 * * *$ & 0.833 & $0.000 * * *$ \\
\hline $\mathrm{R}$-squared & 0.870 & - & 0.854 & - \\
\hline F-statistic & 35.280 & $0.000 * * *$ & 43.143 & $0.000 * * *$ \\
\hline Residual tests & F-statistic & & F-statistic & \\
\hline No serial correlation & - & - & - & . \\
\hline Homoscedasticity & 0.856 & 0.534 & 1.785 & 0.147 \\
\hline Normal distribution & - & $0.021 * *$ & - & $0.005 * * *$ \\
\hline Asymmetry tests & & & - & - \\
\hline Short run & 4.816 & $0.033 * *$ & & \\
\hline
\end{tabular}

$* * *$ Values significant at $1 \%$ level, ** at 5\% level, and * at $10 \%$ level; LM test for autocorrelation; Breusch-Pagan-Godfrey test for heteroskedasticity; Histogram for normality test.

\section{Conclusion and policy implications}

This study contributes to the literature on price transmission in aquaculture by providing an empirical analysis of the price relationships along all stages of an international supply chain from a developing to a developed country. Specifically, we have investigated how prices transmit from the Polish retail stage to Vietnamese pangasius farms and vice versa.

From our findings, we conclude that price changes at the Polish retail stage do transmit to wholesale, export, and Vietnamese pangasius farm stages with some delay (a month for both farm-export and wholesale-retail markets, and two months for the export-wholesale market). Moreover, price transmissions from wholesale to export and from export to farm 
are characterized by both short- and long-run symmetries. In the short run, retailers tend to transmit only wholesale price increases to their customers and wholesalers transmit only retail price increases to exporters. In addition, a long-run relationship between wholesalers and retailers is absent, thereby reducing the ability of chain actors to respond to all market signals, including downward changes.

Our findings have important policy implications. Given the delay in price transmission among market stages, policies could introduce business-to-business electronic trading or auction markets with more flexible pricing. In addition, if more retailers enter the pangasius market, the market power at the retail level would decrease, likely improving the long-run relationship in the wholesale-retail market. Lastly, the transmission of price changes from EU markets back to developing country producers is a positive signal for policy makers to stimulate local aquaculture farmers to invest in sustainable production methods, as consumer price premiums paid for sustainable fish likely flow back to the farm level. 
Chapter 5 


\section{CHAPTER 6}

\section{General Discussion}




\section{Introduction}

World markets increasingly require seafood products to be produced in a sustainable way (Bush and Duijf 2011; Beukers et al. 2015). Certification systems such as the Aquaculture Stewardship Council (ASC) provide the consumers a guarantee that the product is produced in an environmentally sustainable way (Bush and Belton 2011; Little et al. 2012; Bush et al. 2013; CBI 2015). As a response to the quest for environmental sustainability, RAS could be an opportunity for Vietnamese pangasius production. However, investing in such technical innovations is costly. In order to provide useful insights to consider investment in RAS, the overall objective of this thesis was to perform an economic analysis of technological innovations such as RAS to improve the sustainability of pangasius production in Vietnam. The overall objective was split into four sub-objectives. Chapter 2 estimated the input- and output-specific technical and scale inefficiency of Vietnamese pangasius farmers in the traditional system. Chapter 3 analysed the profitability of RAS and compared it with the profitability of the traditional system. Chapter 4 investigated factors influencing the likelihood of RAS adoption and, finally Chapter 5 analysed the price transmission along the Vietnamese pangasius supply chain to export markets.

This concluding chapter synthesizes the results of the four sub-objectives, discusses the methodological and data issues, presents the implications of the thesis to business and policy makers, and finally it provides suggestions for future research and the main conclusions of the thesis.

\section{Synthesis of results}

In this thesis, the analyses of technical and scale inefficiency, profitability, and the adoption of RAS focused on the farm stage where farmers are the decision makers. The analysis of 
price transmission on the other hand covered all stages along the pangasius supply chain to export markets.

Chapter 2 analysed the technical and scale inefficiency of the Vietnamese pangasius farmers in the traditional system. The study concluded that technical inefficiency is mainly associated with inefficient use of capital, as indicated by a capital-specific technical inefficiency of $42 \%$, and low fish yield, as indicated by fish yield-technical inefficiency of $30 \%$. The inefficiency in the use of capital is explained by its quasi-fixed nature, i.e. capital is not easily adjusted from one year to the other. In practice, it is costly to upscale or downscale the investments in machinery, equipment or pond construction. RAS separates solids (i.e. waste and sludge discharge) from the bio-filter into septic tanks, thereby improving the water quality inside the ponds and reducing effluent discharge, while supplying additional oxygen for the fish. Potential advantages are reduced risks for diseases and enabling higher stocking densities (Gutierrez-Wing and Malone 2006; Martins et al. 2010). In this way, RAS may help the pangasius farmers to improve their farm management, thereby achieving higher fish yields. Chapter 3 suggested that pangasius farmers are generally positive about the economic performance of RAS. When shifting from the traditional system to RAS, the net present value (NPV) of investment in RAS was expected to substantially increase, for both medium (1-3 ha) and large ( $>3$ ha) farms. RAS applied in asp (Aspius Aspius) production (Kupren et al. 2008) and in tilapia (Oreochromis niloticus) production (Ali 2012; Appiah-Kubi 2012) was also found to increase profitability, although the latter study only found positive effects for large farms.

Results in Chapter 4 showed that RAS with lower initial investments, higher expected yields and a guaranteed price premium for ASC-certified pangasius is likely to encourage farmers with large farms ( $\geq 3$ ha) to adopt RAS. Initial investments, pangasius yields, and pangasius price were also found to be crucial parameters determining the profitability of RAS investment as shown in Chapter 3. Farmers are more likely to adopt fish farming technology if the introduced system is expected to be profitable (Wetengere 2011). The result by Murray et al. (2014) and Schneider et al. (2006) showed that the high initial investment costs are also an important factor leading to slow adoption of RAS technology 
in Europe. In RAS, high stocking densities and production levels are required in order to cover investment costs (Martins et al. 2010). Similarly, Valeeva et al. (2006) suggested the need for a price premium to compensate the extra costs of additional food safety measures in the dairy chain.

Results of Chapter 2 and 4 provided evidence that socio-economic variables, including farmer demographics such as the level of education and years of experience of farmers and farm characteristics such as farm locations can also affect the technical inefficiency of pangasius farmers, both in the traditional system and RAS. Chapter 2 suggested that farmers with a higher education level and more years of experience are generally better in managing the pond area, the use of fish feed and the production of fish yield. Farmers farming in areas suffering from salt water intrusion are associated with a lower technical inefficiency in the use of capital assets and other variable inputs; they are on the other hand associated with a higher technical inefficiency in the production of fish yields. In Chapter 4, higher educated farmers were also found to be more likely to adopt RAS in pangasius farming as they may have a more open mind towards new technological information. Likewise, farmers farming in salt water intrusion region are more willing to adopt RAS than those in a fresh water region possibly because RAS reduces fresh water requirements.

In Chapter 4, price premiums were found to be among the most important factors influencing the adoption of RAS, i.e. the probability of RAS adoption increased by $1.2 \%$ for a one unit increase in price premiums with ASC-certified pangasius products. Chapter 5 suggested that price signals at the Polish retail stage tend to transmit back to wholesale, export and Vietnamese pangasius farms. The transmission of price changes from Polish markets back to Vietnamese pangasius farmers might provide a positive signal for farmers to invest in more sustainable production methods, because an increase in Polish retail prices is likely to transmit back to Vietnamese pangasius farmers. On the other hand, according to Beukers et al. (2013), certification is used effectively as a 'licence to operate' instead of as a tool to generate price premiums. As such RAS may contribute to gain the "licence" to access the export markets. 
In general, this thesis proposed a framework to perform an economic analysis of technological innovations before the actual implementation. Findings are useful for policy makers and private sectors including farmers to identify potential areas for improvement in the current production systems and to assess potential implications of technological innovations. More specifically, the input- and output-specific technical inefficiency of farmers in the traditional system provides the specific areas of performance improvement in which technological innovations might play an important role. In addition, an investment appraisal of technological innovations and an analysis of the willingness to adopt technological innovations are essential to provide new insights for farmers to consider to invest in this new technology and in the factors influencing this investment decision. Also, future prices, yields, and operating expenses for technological innovations are uncertain. Consequently, the economic feasibility of technological innovations is also uncertain and this may constrain the adoption of technological innovations. Furthermore, price transmission analysis along the supply chain provides information of whether price signals at the retail stage transmit back to farms to invest in technological innovations.

\section{Methodological and data issues}

A variety of methods and data sources were used to achieve the specific objectives of this thesis. This section presents a brief discussion on the methodologies and data used in the four research chapters.

\section{Methodological issues}

A variety of analytical methods including mathematical programming (Chapter 2), econometric models (Chapter 2, 4 and 5), simulation (Chapter 2 and 3), and investment appraisal (Chapter 3) were applied in this thesis.

In Chapter 2, the input- and output-specific technical and scale inefficiency were measured using Data Envelopment Analysis (DEA), a non-parametric technique. The advantage of 
DEA over a parametric approach such as stochastic frontier analysis is that it does not impose any specific functional form on the production technology (Fried et al. 2008; Iliyasu et al. 2014; Skevas and Oude Lansink 2014). DEA is also useful for the efficiency analysis in the presence of multiple inputs and outputs (Fried et al. 2008). In addition, the bootstrap truncated regression model was used to assess the impacts of farmers' demographics and farm characteristics on input- and output-technical and scale inefficiency scores. Simar and Wilson (2007) noted that traditionally used approaches such as censored regression are invalid due to serial correlation of non-parametrically derived inefficiency estimates. The Simar and Wilson bootstrap approach corrects for this serial correlation.

In Chapter 3, the aim was to analyse the economic feasibility of RAS. NPV method, which is the most complete and widely used investment appraisal method, was used to assess the profitability of an investment. This considers cash inflows and outflows over the whole lifetime of an investment (Barry and Ellinger 2010; Kay et al. 2012). NPV was also used to analyse the economic feasibility of RAS in other studies on fish production, such as Murray cod in Australia (De Ionno et al. 2006), asp (Aspius Aspius) and ide (Leuciscus idus) in Poland (Kupren et al. 2008), and tilapia (Oreochromis niloticus) in Egypt (Ali 2012). However, the investment appraisal does not take into account the uncertainties associated with investment costs, pangasius yields, market prices and the operating expenses. Therefore, a Monte Carlo simulation was used to capture the effect of the stochastic variables on the profitability of an investment. Past economic feasibility assessments of investments in aquaculture production have not accounted for variation of input parameters using Monte Carlo simulation, except for a study of Valderrama and Engle (2001).

Chapter 4 and 5 used two different econometric models for investigating the key determinants influencing the adoption of RAS and for analysing the price transmission along the international supply chain for frozen pangasius fillets, respectively. In Chapter 4, a binary probit model was used to estimate the probability that respondents choose the traditional system or RAS. The probit model has been used in a number of adoption studies, for example Gracia and de Magistris (2008) and Keelan et al. (2009). The advantages of this discrete choice model are (i) it can predict the probability that respondents choose the 
current system or technological innovations, and (ii) it can provide estimates of effects of attributes, farmers' demographics, and farm characteristics on the probability of technological innovations adoption (Louviere et al. 2000). In Chapter 5, the aim was to investigate whether price increases for certified pangasius products at the Polish retail stage are transmitted fully to the stage of Vietnamese pangasius farms. Given the unavailability of information of the price premiums for certified pangasius products, the vector autoregressive error correction model (VECM) framework was employed to analyse the price transmission between pair-wise prices in the chain using monthly prices of Vietnamese pangasius at the farm, export, wholesale, and retail stages. Results of VECM provide insight into transmission of price shocks which may not be the same as the transmission of a potential structural price change as a result of certification.

\section{Data issues}

The data sources used in this thesis were a structured survey among farmers (Chapter 2 and 3), workshops with farmers (Chapter 2, 3 and 4) and experts (Chapter 3 and 4), and timeseries data (Chapter 5).

Chapter 2 used data from a structured survey and workshop with farmers, whereas Chapter 3 also used data from workshop with experts. A survey was conducted to collect data on the traditional system (Chapter 2 and 3) and a workshop was conducted to obtain data on the expected performance of RAS (Chapter 3). The workshop was also used (1) to increase the number of observations on the traditional system for large farms (Chapter 2 and 3), and (2) to elicit future projections of pangasius prices and yields for both traditional and RAS systems (Chapter 3). As RAS in pangasius production was only used in a pilot project at the time of the study, farm-level economic information on yields, prices and costs for pangasius cultivation with RAS were not available. Therefore, in Chapter 3, the perceived revenues and costs by pangasius farmers were the only possible data that could be collected. Previous studies of economic feasibility of pilot RAS in some fish species production used data from the pilot facility (Kupren et al. 2008; Appiah-Kubi 2012). These studies also found that RAS investments are profitable, although the latter only found positive effects for large 
farms. In Chapter 3, to reduce the possible bias from the perceived data, prior to completion of the questionnaire in a workshop: (i) respondents were well-informed, (ii) the workshop was organized at the pilot facility and RAS was elaborately shown and explained by the aquaculture expert responsible for running the pilot facility.

In Chapter 4, the technique of a choice experiment is a known approach to measure the degree of preferences of respondents to a particular product that is not traded in the real market (Louviere et al. 2000). The validity of a choice experiment depends on the appropriate specification of the attributes and their levels (Abiiro et al. 2014). Therefore, a systematic process of developing and selecting the final short-list of attributes about RAS adoption was designed. To ensure the reliability of choice experimental data collection, the workshops for choice experiment were well-prepared, i.e. with in-depth elaboration on RAS, the presence of multiple enumerators, and the clarification of questions in small groups. Respondents were asked additional questions for clarifications of adoption decisions.

Furthermore, the elicitation of expert opinions was used to predict and find consensus about the future prices and yields for both traditional system and RAS. Expert elicitation also was used to score the long-list of attributes in the choice experiment. Experts were local aquaculture specialists in Mekong River Delta area and aquaculture researchers in Chapter 3, whereas in Chapter 4, experts were from the SUPA project. The project's experts had different disciplinary backgrounds, such as economics or aquaculture, and were all knowledgeable on pangasius farming and RAS. The elicitation from experts is a widely used method, e.g. to assess the improvement of seed potato systems in Ethiopia (Hirpa et al. 2012), to perceive issues of the price volatility and management strategies in European food supply chains (Assefa et al. 2014), to characterize the relative ecological risks associated with salmon practices in British Columbia (McDaniels et al. 2006), and to estimate the impacts of plastic pollution on marine wildlife (Wilcox et al. 2016).

Chapter 5 analysed the price transmission along the chain which required time-series data. In this chapter, the availability of price data at various stages posed challenges. For instance, export prices and export quantities of Vietnamese pangasius products to EU markets have 
not been assembled for specific countries. Therefore, import prices for specific import country such as Poland were used as a proxy for Vietnamese export prices. Moreover, very limited historical pangasius data in international trade is also another challenge for price transmission analysis. Hence, prices of Vietnamese pangasius at various stages along the supply chain were only available from August 2010 onwards. The lack of insight into price premiums for certified pangasius products is another challenge to analyse if the price increases at the retail stage are transmitted to the farm stage.

\section{Implications of the study}

\section{Business implications}

Findings of this thesis are useful for farmers (Chapter 2 and 3), other stages in the chain (Chapter 4 and 5), and service providers (Chapter 4).

At the farm stage, the results from Chapter 2 imply that pangasius farmers can improve their capital management skills by e.g. better estimating the amount of required capital, the time replacing capital assets, and monitoring the use of capital assets. In addition, the implementation of water purification system in pangasius production such as RAS could potentially increase the pangasius yields. For the potential RAS investors, the implication of the results from the economic analysis of RAS investment is that probability of profitable investment RAS is $99 \%$ for both medium and large farms. The key variables influencing the profitability of RAS include the improved yields and prices.

Farmers who implement RAS expect a price premium for their product and higher yields to compensate for the high investments. Therefore, other stages in the chain such as the international retailers could provide a price premium for ASC-certified pangasius products. Moreover, Chapter 5 suggested that price changes are transmitted from the Polish retail stage back to Vietnamese pangasius farmers with some delay (a month for both farm-export and wholesale-retail markets, and two months for the export-wholesale market). Given the 
delay in price transmission among market stages, wholesalers and retailers could use a business-to-business electronic trading or auction market system with more flexible pricing to stimulate the pass-through of the price changes through the chain.

Service providers such as extension officers and banks can also use results of Chapter 4 to stimulate the adoption of RAS by Vietnamese pangasius farmers. For instance, extension officers could disseminate the information about RAS by conducting technical training on the system. This would help to reduce farmers' uncertainty about the performance of the system and hence, increase the chance to adopt RAS. In addition, given the perceived limitations with regard to access to finance credit programs might also be established that link access to credit for farm investments targeting sustainability.

\section{Policy implications}

Findings of this thesis are useful for policy makers in Vietnam (Chapter 2, 3 and 4). Given the inefficiency in producing fish of Vietnamese pangasius farmers, as indicated by fish yield-technical inefficiency of $30 \%$, policy makers could introduce RAS allowing for higher stocking densities and better quality of pond water to increase the pangasius yields. Moreover, given the importance of the size of the initial investment of RAS and the perceived limitations with regard to access to finance, credit programs might be established that link access to credit with farm investments targeting sustainability. Policy makers could also reduce farmers' uncertainty about RAS and increase the chance to adopt RAS by establishing pioneer farms demonstrating the use of RAS, accumulating sufficient local technical capacity of RAS, and conducting technical training on RAS using the existing extension system in the Mekong River Delta area. In addition, policies for reducing technical inefficiency could target farmers with farms located in salt water intrusion region who are also more likely to adopt RAS. 


\section{Implications for further research}

This thesis performed an economic analysis of technological innovations such as RAS to improve the sustainability of pangasius production in Vietnam. The findings of this thesis demonstrate that given the importance of the size of the initial investment and the perceived limitations with regard to access to finance, credit programs might be established that link access to credit with farm investments targeting sustainability. However, in order to engage the financial providers to invest in such technological innovations, it is necessary to investigate how the new technologies contribute to the improvement of the sustainability of pangasius production in Vietnam. Therefore, there is a need for further assessment in the sustainability performance of RAS in pangasius production, concerning economic, social, and social sustainability. At the time of the study, RAS was only used in a pilot project. Farm-level economic information on yields, prices and costs for pangasius cultivation with RAS were not available. Therefore, the analyses of economic feasibility and the adoption of RAS have used stated preferences of pangasius farmers about the economic feasibility and the adoption of RAS. If data of RAS at farm-level are available, research can be further extended to study the actual cost-effectiveness and the actual investment decisions of RAS.

The price premiums for certified pangasius products highly determine the profitability of RAS, and thus likely the encouragement of farmers to adopt RAS. However, farmers' trust in receiving price premiums for certified products was found to be relatively low. Therefore, issues such as how much the international consumers are willing to pay for certified pangasius products should be further studied. 


\section{Main conclusions}

The following main conclusions are derived from this thesis:

1. The Inadequate management skills in using capital assets, as indicated by a capital-specific technical inefficiency of $42 \%$, and improper methods for producing fish, as indicated by fish yield-technical inefficiency of $30 \%$, are the main challenges for enhancing the performance of Vietnamese pangasius production (Chapter 2).

2. The probability of RAS being a profitable investment is $99 \%$ for both medium (13 ha) and large farms (> 3 ha) (Chapter 3 ).

3. Crucial factors leading to improved economic performance of RAS compared to traditional system are the improved pangasius yields and pangasius prices (Chapter 3).

4. Main constraints for adoption of RAS are the lack of trust in receiving a price premium, lack of access to finance, and uncertainty about the performance of RAS (Chapter 4).

5. Younger and more educated farmers with higher household incomes and with farms in salt water intrusion areas are more likely to adopt RAS (Chapter 4).

6. In the Vietnamese-Polish pangasius supply chain, price signals at retail stage transmit back to wholesale, export and Vietnamese pangasius farms (Chapter 5).

7. International retailers can provide a price premium for certified pangasius to compensate for the high investments in RAS and increase the likelihood of adoption of RAS (Chapter 3 and 4). 
SUMMARY 


\section{Summary}

Pangasius has become one of the most important export products of Vietnam. In 2015, exports of pangasius were valued around 1.5 billion USD; $24 \%$ of exports were to EU markets. In recent years, the sustainability of pangasius production has been increasingly questioned due to disease outbreaks, water pollution, and antibiotic pollution from the discharge of untreated effluents into surrounding aquatic ecosystems. Furthermore, retailers and buyers in the EU increasingly demand pangasius products from environmentally sustainable and socially equitable production systems, such as those with Aquaculture Stewardship Council (ASC) certification. As a response to the quest for environmental sustainability, Recirculating Aquaculture System (RAS) could be an opportunity not only to reduce waste discharge and to improve water quality in the fish ponds, but also to contribute to a reduction in the occurrence of fish diseases and thus to decreased mortality and lower use of medicines. RAS has recently been established at a pilot facility at Cai Be station in the Tien Giang province in order to test its presumed benefits as outlined above.

Traditional pangasius farms usually operate one or several 3 to 5 meter deep fish pond(s) with one or two sluice gates, and a feed storage. Stocking densities vary from 5 to 31 fish $/ \mathrm{m}^{3}$, depending on the size, availability of fingerlings and the financial capacity of farmers to purchase feedstock. Most farms use river water in the fish ponds and discharge waste water directly into channels leading to the Mekong River. RAS can be applied in an existing pond or a completely new pond. The application of in-pond RAS in pangasius farms requires additional investments in a moving bed bio-filter, filter media, septic tank, pumps and pipes for water movement and aeration. Stocking densities are $76 \mathrm{fish} / \mathrm{m}^{3}$ and only extruded pellets are applicable used with RAS. Investing in RAS at farm scale is costly. Also, future prices, yields, and operating expenses for RAS are uncertain. This uncertainty combined with the high initial investment costs means that the economic feasibility is also uncertain and this may constrain the adoption of RAS. Hence, the overall objective of this thesis was to perform an economic analysis of technological innovations such as RAS to improve the sustainability of pangasius production in Vietnam. 
Chapter 2 measured input- and output-specific technical and scale inefficiency of Vietnamese pangasius farmers with a traditional system and to assess the impact of farmers' demographics and farm characteristics on these technical and scale inefficiencies. For this, a non-radial directional input-output distance function was first used to estimate the inputand output-specific technical and scale inefficiency. Second, a bootstrap truncated regression was used to analyse the farmers' demographics and farm characteristics influencing the input- and output-specific technical and scale inefficiency. Data were collected from the survey and a workshop. The workshop was used to increase the number of observations on the traditional system for large farms (larger than 3 ha). Eighty-two surveyed farmers and fourteen additional farmers from large farms in the workshop came from two representative pangasius farming regions, including the main pangasius fresh water production and newly developed salt water intrusion region. Results suggested that inadequate management skills in using capital assets, as indicated by a capital-technical inefficiency of $42 \%$, and improper methods for producing fish, as indicated by fish yieldtechnical inefficiency of $30 \%$, are the main challenges for enhancing the performance of Vietnamese pangasius production. Moreover, technical inefficiency was found to be negatively associated with the age, experience and education level of pangasius farmers. Location of the farm in a salt-water intrusion area was positively associated with inefficiency of producing fish. As described above, the introduction of technological innovations such as RAS allowing for higher stocking densities and better quality of pond water would potentially increase the pangasius yields, and thus improve the performance of Vietnamese pangasius farms.

Chapter 3 analysed the economic feasibility of RAS in Vietnamese pangasius farming. This study used a capital budgeting approach and accounts for uncertainty in key parameters. Stochastic simulation was used to simulate the economic performance of medium (1-3 ha) and large farms operating with a traditional system or RAS. Data for traditional system were obtained from the same sample as in Chapter 2. Data for the expected performance of RAS were also obtained from the same workshop as in Chapter 2. However, participants in the workshop also included twenty-nine farmers with small (smaller than $1 \mathrm{ha}$ ), medium and large farms, and six experts. Experts were local aquaculture specialists and aquaculture 
researchers. The workshop was also used to elicit future projections of pangasius prices and yields for both traditional and RAS systems. The perceived costs and revenues of RAS were assessed based on the previously filled information on the traditional system. Results show that farmers were generally positive about the economic performance of RAS. Based on the perceptions of farmers and experts, the net present value (NPV) of investment in RAS substantially increases, for both medium and large farms. With RAS, the crucial parameters determining profitability are initial investments, pangasius yields, and pangasius price.

Chapter 4 investigated key determinants influencing the adoption of RAS by Vietnamese pangasius farmers. Given the high initial investment, this study focused on large farms (equal to or greater than $3 \mathrm{ha}$ ) as these are more likely to adopt RAS due to their relative cost advantage. To evaluate the role of different variables in the adoption of RAS, a choice experiment was designed and administered to pangasius farmers. Choice experiments were conducted during three workshops, attended by a total of ninety-five farmers with large farms. Results suggested that lower initial investment, higher expected yields and a guaranteed price premium for ASC-certified pangasius are likely to encourage farmers to adopt RAS; also adoption is more likely in areas suffering from salt intrusion and by younger farmers with a higher level of education and a higher household income. In general however, this study found the relatively low probability to adopt RAS is explained by the lack of trust in receiving a price premium, inadequate access to finance and uncertainty about the actual performance of RAS.

Chapter 5 analysed price transmission along the international supply chain of pangasius. This study used the vector autoregressive error correction model (VECM) to investigate this relationship. Results showed that price changes at the Polish retail stage do transmit to wholesale, export, and Vietnamese pangasius farm stages with some delay (a month for both farm-export and wholesale-retail markets, and two months for the export-wholesale market). Moreover, price transmissions from wholesale to export and from export to farm are characterized by both short- and long-run symmetries. In the short run, retailers tend to transmit only wholesale price increases to their customers and wholesalers transmit only 
retail price increases to exporters. In addition, a long-run relationship between wholesalers and retailers is absent, thereby reducing the ability of chain actors to respond to all market signals.

Finally, Chapter 6 provided a synthesis of the main findings, and a reflection on the methodologies and data used in the Chapters 2-5 as well as a discussion of the implications for business, policy and future studies. The main conclusions of this thesis are summarized as follows:

1. The inadequate management skills in using capital assets, as indicated by a capitalspecific technical inefficiency of $42 \%$, and improper methods for producing fish, as indicated by fish yield-technical inefficiency of $30 \%$, are the main challenges for enhancing the performance of Vietnamese pangasius production (Chapter 2).

2. The probability of RAS being a profitable investment is $99 \%$ for both medium (13 ha) and large farms (greater than 3 ha) (Chapter 3).

3. Crucial factors leading to improved economic performance of RAS compared to traditional system are the improved pangasius yields and pangasius prices (Chapter 3).

4. Main constraints for adoption of RAS are the lack of trust in receiving a price premium, lack of access to finance, and uncertainty about the performance of RAS (Chapter 4).

5. Younger and more educated farmers with higher household incomes and with farms in salt water intrusion areas are more likely to adopt RAS (Chapter 4).

6. In the Vietnamese-Polish pangasius supply chain, price signals at retail stage transmit back to wholesale, export and Vietnamese pangasius farms (Chapter 5).

7. International retailers can provide a price premium for certified pangasius to compensate for the high investments in RAS and increase the likelihood of adoption of RAS (Chapter 3 and 4). 


\section{REFERENCES}




\section{References}

Abiiro, G. A., G. Leppert, G. B. Mbera, P. J. Robyn and M. De Allegri (2014). "Developing attributes and attribute-levels for a discrete choice experiment on micro health insurance in rural Malawi." BMC Health Services Research 14(1): 235.

Acharya, R. N., H. W. Kinnucan and S. B. Caudill (2011). "Asymmetric farm-retail price transmission and market power: a new test." Applied Economics 43(30): 47594768.

Addelman, S. (1972). "Recent developments in the design of factorial experiments." Journal of the American Statistical Association 67(337): 103-111.

Adelaja, O. (2013). "Limitations to the Adoption of Recommended Aquaculture Production Technologies by Small Scale Fish Farmers in Oyo State Nigeria." GJSFR-D: Agriculture and Veterinary 13(9).

Aguilar, F. X. and R. P. Vlosky (2007). "Consumer willingness to pay price premiums for environmentally certified wood products in the U.S." Forest Policy and Economics 9(8): 1100-1112.

Alam, F. (2011). "Measuring technical, allocative and cost efficiency of pangas (Pangasius hypophthalmus: Sauvage 1878) fish farmers of Bangladesh." Aquaculture Research 42(10): 1487-1500.

Ali, S. A. (2012). "A Techno-Financial Analysis of Tilapia Production in the Recirculating Aquaculture Systems." Journal of Agricultural Engineering 29(4): 1583-1602.

Amos, T. (2007). "Production and productivity of crustacean in Nigeria." J. Soc. Sci 15(3): 229-233.

Andrieu, M., A. Rico, T. M. Phu, D. T. T. Huong, N. T. Phuong and P. J. Van den Brink (2015). "Ecological risk assessment of the antibiotic enrofloxacin applied to Pangasius catfish farms in the Mekong Delta, Vietnam." Chemosphere 119: 407414.

Anh, N. L., V. B. T. Pham, R. H. Bosma, J. A. J. Verreth, R. Leemans, D. S. Silva and A. G. J. M. Oude Lansink (2015). Impact of climate change on the technical efficiency of striped catfish (pangasianodon hypophthalmus) farming in the Mekong Delta, Vietnam. Fishery and Aquaculture. The Netherlands, Wageningen University. PhD. 
Anh, P. T., C. Kroeze, S. R. Bush and A. P. Mol (2010). "Water pollution by Pangasius production in the Mekong Delta, Vietnam: causes and options for control." Aquaculture Research 42(1): 108-128.

Anh, P. T., C. Kroeze, S. R. Bush and A. P. J. Mol (2010). "Water pollution by Pangasius production in the Mekong Delta, Vietnam: causes and options for control." Aquaculture Research 42(1): 108-128.

Appiah-Kubi, F. (2012). An economic analysis of the use of recirculating aquaculture systems in the production of Tilapia. Department of Animal and Aquaculture Sciences. Norway, Norwegian University of Life Sciences. Master.

Asche, F., R. E. Dahl, D. Valderrama and D. Zhang (2014). "Price transmission in new supply chains - The case of salmon in France." Aquaculture Economics \& Management 18(2): 205-219.

Asche, F., S. Jaffry and J. Hartmann (2007). "Price transmission and market integration: vertical and horizontal price linkages for salmon." Applied Economics 39(19): 2535-2545.

Asfaw, A. and A. Admassie (2004). "The role of education on the adoption of chemical fertiliser under different socioeconomic environments in Ethiopia." Agricultural Economics 30(3): 215-228.

Assefa, T. T., W. E. Kuiper and M. P. Meuwissen (2014). "The Effect of Farmer Market Power on the Degree of Farm Retail Price Transmission: A Simulation Model with an Application to the Dutch Ware Potato Supply Chain." Agribusiness 30(4): 424437.

Assefa, T. T., M. P. M. Meuwissen and A. G. J. M. Oude Lansink (2014). "Price volatility perceptions and management strategies in European food supply chains." Scientific Paper (6).

Asteriou, D. and S. G. Hall (2007). Applied econometrics: A modern approach using eviews and microfit revised edition. London, Palgrave Macmillan.

Badiola, M., D. Mendiola and J. Bostock (2012). "Recirculating Aquaculture Systems (RAS) analysis: Main issues on management and future challenges." Aquacultural Engineering 51: 26-35.

Bakucs, Z., J. Falkowski and I. Ferto (2012). "Price transmission in the milk sectors of Poland and Hungary." Post-Communist Economies 24(3): 419-432.

Barry, P. J. and P. N. Ellinger (2010). Financial Management in Agriculture. New Jersey, Prentice Hall. 
Bateman, I. J., R. T. Carson, B. Day, M. Hanemann, N. Hanley, T. Hett, M. Jones-Lee, G. Loomes, S. Mourato and E. Özdemiroglu (2002). Economic valuation with stated preference techniques: a manual. Massachusetts, Edward Elgar.

Belton, B., M. M. Haque, D. C. Little and L. X. Sinh (2011). "Certifying catfish in Vietnam and Bangladesh: Who will make the grade and will it matter?" Food Policy 36(2): 289-299.

Beukers, R., W. v. d. Pijl and A. P. v. Duijn (2013). Prospects for the position of (ASCcertified) pangasius in the EU retail and food service sector. Wageningen, The Netherlands, LEI Wageningen UR.

Beukers, R., W. v. d. Pijl and A. P. v. Duijn (2015). Pangasius in the EU market; Prospects for the position of (ASC-certified) pangasius in the EU retail and food service sector. The Hague, CBI (Centre for the promotion of imports from developing countries).

Blomquist, J., V. Bartolino and S. Waldo (2015). "Price Premiums for Providing Ecolabelled Seafood: Evidence from MSC-certified Cod in Sweden." Journal of Agricultural Economics 66(3): 690-704.

Bosma, R. H., C. T. Hanh, J. Potting and P. A. Dung (2009). Environmental impact assessment of the pangasius sector in the Mekong Delta. Wageningen, Wageningen University.

Bosma, R. H., D. K. Nhan, H. M. J. Udo and U. Kaymak (2012). "Factors affecting farmers' adoption of integrated rice-fish farming systems in the Mekong delta, Vietnam." Reviews in Aquaculture 4(3): 178-190.

Boyd, C. E. and A. A. McNevin (2012). "An early assessment of the effectiveness of aquaculture certification and standards." The Roles and Limitations of Certification: 35 .

Brummett, R. E., J. Youaleu, A. M. TIANI and M. M. Kenmegne (2010). "Women's traditional fishery and alternative aquatic resource livelihood strategies in the Southern Cameroonian Rainforest." Fisheries Management and Ecology 17(3): 221-230.

Bukeviciute, L., A. Dierx, F. Ilzkovitz and G. Roty (2009). Price transmission along the food supply chain in the European Union. 113th seminar of the European Association of Agricultural Economists, Chania, Crete, Greece.

Bunting, S. W., D. C. Little, B. Costa-Pierce, A. Desbonnet, P. Edwards and D. Baker (2005). "The emergence of urban aquaculture in Europe." Urban Aquaculture. CABI Publishing, Wallingford, Cambridge: 119-135. 
Bush, S. R. and B. Belton (2011). Out of the factory and into the fish pond: Can certification transform Vietnamese Pangasius. Food practices in transitionChanging food consumption, retail and production in the age of reflexive modernity. G. Spaargaren, P. Oosterveer and A. Loeber. New York, London, Taylor \& Francis.

Bush, S. R., B. Belton, D. Hall, P. Vandergeest, F. J. Murray, S. Ponte, P. Oosterveer, M. S. Islam, A. P. Mol and M. Hatanaka (2013). "Certify Sustainable Aquaculture?" Science 341(6150): 1067-1068.

Bush, S. R. and M. Duijf (2011). "Searching for (un)sustainabilty in pangasius aquaculture: A political economy of quality in European retail." Geoforum 42(2): 185-196.

CBI (2015). Exporting pangasius to Europe. Market information. The Hague, The Netherlands, Centre for the Promotion of Imports from developing countries,.

CBI (2015). What competition do I face on the European frozen white fish market? Frozen white fish products. The Hague, The Netherlands, Centre for the Promotion of Imports from developing countries.

Charnes, A., W. W. Cooper and E. Rhodes (1978). "Measuring the efficiency of decision making units." European journal of operational research 2(6): 429-444.

Chiang, F.-S., C.-H. Sun and J.-M. Yu (2004). "Technical efficiency analysis of milkfish (Chanos chanos) production in Taiwan - an application of the stochastic frontier production function." Aquaculture 230(1): 99-116.

d'Orbcastel, E. R., J.-P. Blancheton and J. Aubin (2009). "Towards environmentally sustainable aquaculture: Comparison between two trout farming systems using Life Cycle Assessment." Aquacultural Engineering 40(3): 113-119.

De Ionno, P. N., G. L. Wines, P. L. Jones and R. O. Collins (2006). "A bioeconomic evaluation of a commercial scale recirculating finfish growout system-An Australian perspective." Aquaculture 259(1): 315-327.

Dey, M. M., F. J. Paraguas, N. Srichantuk, Y. Xinhua, R. Bhatta and L. Thi Chau Dung (2005). "Technical efficiency of freshwater pond polyculture production in selected Asian countries: estimation and implication." Aquaculture Economics \& Management 9(1-2): 39-63.

Eding, E. H. and A. Kamstra (2002). "Netherlands farms tune recirculation systems to production of varied species." Global Aquaculture Advocate 5(3): 52-55.

Ekunwe, P. A. and C. O. Emokaro (2009). "Technical efficiency of catfish farmers in Kaduna, Nigeria." Journal of Applied Sciences Research 5(7): 802-805. 
Engle, C. R. (2010). Aquaculture economics and financing: management and analysis. Ames, Iowa, Wiley-Blackwell Scientific Publications.

Espinosa-Goded, M., J. Barreiro-Hurlé and E. Ruto (2010). "What do farmers want from Agri-environmental scheme design? A choice experiment approach." Journal of Agricultural Economics 61(2): 259-273.

EUMOFA (2014). Pangasius importd in the EU. Monthly Highlights No4/2014. Brussel, Belgium, European Market Observatory for Fisheries and Aquaculture Products.

Fałkowski, J. (2010). "Price transmission and market power in a transition context: evidence from the Polish fluid milk sector." Post-communist economies 22(4): 513-529.

Färe, R. and S. Grosskopf (2010). "Directional distance functions and slacks-based measures of efficiency." European journal of operational research 200(1): 320-322.

Färe, R., S. Grosskopf and C. A. Pasurka (2007). "Environmental production functions and environmental directional distance functions." Energy 32(7): 1055-1066.

Farrell, M. J. (1957). "The measurement of productive efficiency." Journal of the Royal Statistical Society. Series A (General) 120(3): 253-290.

Fishburn, P. C. (1970). Utility theory for decision making, DTIC Document.

Frey, G. and M. Manera (2007). "Econometric models of asymmetric price transmission." Journal of Economic surveys 21(2): 349-415.

Fried, H. O., C. A. K. Lovell and S. S. Schmidt (2008). The measurement of productive efficiency and productivity growth. New York, Oxford University Press.

Gaitán-Cremaschi, D., F. K. van Evert, M. P. M. Meuwissen and A. G. J. M. Oude Lansink (2015). "Integrated indicators for benchmarking agricultural production systems: the case of specialized potato farms in North-Western Europe." Sustainability metrics for agri-food supply chains, Business Economics Group. Wageningen, The Netherlands, Wageningen University. PhD.

Gebrezgabher, S. A., M. P. M. Meuwissen and A. G. J. M. Oude Lansink (2012). "Energyneutral dairy chain in the Netherlands: An economic feasibility analysis." Biomass and Bioenergy 36: 60-68.

Gebrezgabher, S. A., M. P. M. Meuwissen, G. Kruseman, D. Lakner and A. G. J. M. Oude Lansink (2015). "Factors influencing adoption of manure separation technology in the Netherlands." Journal of environmental management 150: 1-8.

General Statistics Office Of Vietnam (2012). Socio-Economic situation in 2012. General Statistics Office, Hanoi, Vietnam. 
Gillespie, J., S. Kim and K. Paudel (2007). "Why don't producers adopt best management practices? An analysis of the beef cattle industry." Agricultural Economics 36(1): 89-102.

Goetz, L., S. von Cramon-Taubadel and Y. Kachel (2008). Measuring Price Transmission in the International Fresh Fruit and Vegetable Supply Chain: The Case of Israeli Grapefruit Exports to the EU, Discussion Paper No. 10-08.

Gracia, A. and T. de Magistris (2008). "The demand for organic foods in the South of Italy: A discrete choice model." Food Policy 33(5): 386-396.

Grimsrud, K., H. Nielsen, S. Navrud and I. Olesen (2013). "Households' willingness-to-pay for improved fish welfare in breeding programs for farmed Atlantic salmon." Aquaculture 372: 19-27.

Guillén, J. and R. F. Artés (2015). "Price transmission and volatility along the Spanish fresh fish market chain." New medit: Mediterranean journal of economics, agriculture and environment $=$ Revue méditerranéenne d'economie, agriculture et environment 14(1): 4-11.

Gutierrez-Wing, M. T. and R. F. Malone (2006). "Biological filters in aquaculture: Trends and research directions for freshwater and marine applications." Aquacultural Engineering 34(3): 163-171.

Halls, A. and M. Johns (2013). "Assessment of the vulnerability of the Mekong Delta Pangasius catfish industry to development and climate change in the Lower Mekong Basin." Report prepared for the Sustainable Fisheries Partnership.

Hirpa, A., M. P. M. Meuwissen, I. A. Van der Lans, W. J. Lommen, A. G. J. M. Oude Lansink, A. Tsegaye and P. C. Struik (2012). "Farmers' opinion on seed potato management attributes in Ethiopia: A conjoint analysis." Agronomy Journal 104(5): 1413-1424.

Houck, J. P. (1977). "An approach to specifying and estimating nonreversible functions." American Journal of Agricultural Economics 59(3): 570-572.

Iliyasu, A., Z. A. Mohamed, M. M. Ismail and A. M. Abdullah (2014). "A meta-analysis of technical efficiency in aquaculture." Journal of Applied Aquaculture 26(4): 329339.

Iliyasu, A., Z. A. Mohamed, M. M. Ismail, A. M. Abdullah, S. M. Kamarudin and H. Mazuki (2014). "A review of production frontier research in aquaculture (20012011)." Aquaculture Economics \& Management 18(3): 221-247. 
Ismael, B. (2013). "Credit Terms, Credit Accessibility and Performance of Agricultural Cooperatives in Rwanda." Journal of Emerging Issues in Economics, Finance and Banking 1(6): 554-570.

Jesús, I. M. (2011). Fisheries in Poland. Fisheies. P. D. o. S. a. C. Policies. Brussels, European Parliament.

Johansen, S. (1991). "Estimation and hypothesis testing of cointegration vectors in Gaussian vector autoregressive models." Econometrica: Journal of the Econometric Society: 1551-1580.

John, A. (2014). "Price relations between international rice markets." Agricultural and Food Economics 2(1): 1-16.

Kaliba, A. R. and C. R. Engle (2006). "Productive efficiency of Catfish farms in Chicot county, Arkansas." Aquaculture Economics \& Management 10(3): 223-243.

Kam, Badjeck, Teh and Tran (2012). Autonomous adaptation to climate change by shrimp and catfish farmers in Vietnam's Mekong River delta. Penang, Malaysia, WorldFish: 1-24.

Kareem, R., A. Aromolaran and A. Dipeolu (2009). "Economic Efficiency Of Fish Farmingin Ogun State, Nigeria." Aquaculture Economics \& Management 13(1): $39-52$.

Kay, R. D., W. M. Edwards and P. A. Duffy (2012). Farm management. New York, McGraw-Hill

Keelan, C., F. S. Thorne, P. Flanagan, C. Newman and E. Mullins (2009). "Predicted willingness of irish farmers to adopt GM technology." AgBioForum 12(3\&4): 394-403.

Khanna, M. (2001). "Sequential Adoption of Site-Specific Technologies and its Implications for Nitrogen Productivity: A Double Selectivity Model." American Journal of Agricultural Economics 83(1): 35-51.

Khoi, L. N. D. (2007). "Description of the Pangasius value chain in Vietnam." Centre for ASEAN Studies (CAS), Centre for International Management and Development Antwerp (Cimda) and School of Economics and Business Administration, Can Tho University, Can Tho City, Vietnam.

Khoi, L. N. D. (2011). Quality Management in the Pangasius Export Supply Chain in Vietnam: The Case of Small-Scale Pangasius Farming in the Mekong River Delta, University of Groningen Groningen.

Kløjgaard, M. E., M. Bech and R. Søgaard (2012). "Designing a stated choice experiment: the value of a qualitative process." Journal of Choice Modelling 5(2): 1-18. 
Knight, J., S. Weir and T. Woldehanna (2003). "The role of education in facilitating risktaking and innovation in agriculture." The Journal of Development Studies 39(6): $1-22$.

Koundouri, P., C. Nauges and V. Tzouvelekas (2006). "Technology adoption under production uncertainty: Theory and application to irrigation technology." American Journal of Agricultural Economics 88(3): 657-670.

Krivonos, E. (2004). "The impact of coffee market reforms on producer prices and price transmission." World Bank Policy Research Working Paper(3358).

Kupren, K., K. Turkowski, D. Kucharczyk, S. Krejszeff, D. Żarski, A. Hakuć-Błażowska, K. Targońska, M. Kwiatkowski, M. Jamróz and T. Czarkowski (2008). "Economic aspects of rearing larval asp, Aspius aspius (L.), and ide, Leuciscus idus (L.), in closed recirculating systems." Archives of Polish Fisheries 16(4): 413-420.

Lancaster, K. J. (1966). "A new approach to consumer theory." The journal of political economy: 132-157.

Larsen, T. A. and F. Asche (2011). "Contracts in the salmon aquaculture industry: An analysis of Norwegian salmon exports." Marine Resource Economics 26(2): 141150.

Larsen, T. A. and H. W. Kinnucan (2009). "The effect of exchange rates on international marketing margins." Aquaculture Economics \& Management 13(2): 124-137.

Le, T. C. and F. Cheong (2010). "Perceptions of risk and risk management in Vietnamese catfish farming: An empirical study." Aquaculture Economics \& Management 14(4): 282-314.

Lee, J. and M. I. Gomez (2011). Price Transmission Asymmetries and Nonlinearities in the International Coffee Supply Chain. 2011 Annual Meeting, July 24-26, 2011, Pittsburgh, Pennsylvania, Agricultural and Applied Economics Association.

Little, D. C., S. R. Bush, B. Belton, N. T. Phuong, J. A. Young and F. J. Murray (2012). "Whitefish wars: Pangasius, politics and consumer confusion in Europe." Marine Policy 36(3): 738-745.

Little, D. C., S. R. Bush, B. Belton, N. Thanh Phuong, J. A. Young and F. J. Murray (2012). "Whitefish wars: Pangasius, politics and consumer confusion in Europe." Marine Policy 36(3): 738-745.

Loc, V. T. T., S. R. Bush and N. T. Khiem (2010). "High and low value fish chains in the Mekong Delta: challenges for livelihoods and governance." Environment, Development and Sustainability 12(6): 889-908. 
Louviere, J. J., D. A. Hensher and J. D. Swait (2000). Stated choice methods: analysis and applications. Cambridge, Cambridge University Press.

Mahlberg, B. and B. K. Sahoo (2011). "Radial and non-radial decompositions of Luenberger productivity indicator with an illustrative application." International Journal of Production Economics 131(2): 721-726.

Marra, M., D. J. Pannell and A. Abadi Ghadim (2003). "The economics of risk, uncertainty and learning in the adoption of new agricultural technologies: where are we on the learning curve?" Agricultural systems 75(2-3): 215-234.

Martins, C. I., D. Ochola, S. S. Ende, E. H. Eding and J. A. Verreth (2009). "Is growth retardation present in Nile tilapia Oreochromis niloticus cultured in low water exchange recirculating aquaculture systems?" Aquaculture 298(1): 43-50.

Martins, C. I. M., E. H. Eding, M. C. J. Verdegem, L. T. N. Heinsbroek, O. Schneider, J. P. Blancheton, E. R. d'Orbcastel and J. A. J. Verreth (2010). "New developments in recirculating aquaculture systems in Europe: A perspective on environmental sustainability." Aquacultural Engineering 43(3): 83-93.

McDaniels, T. L., P. L. Keen and H. Dowlatabadi (2006). "Expert judgments regarding risks associated with salmon aquaculture practices in British Columbia." Journal of Risk Research 9(7): 775-800.

Mercer, D. E. (2004). "Adoption of agroforestry innovations in the tropics: a review." Agroforestry systems 61(1-3): 311-328.

Meyer, J. and S. von Cramon-Taubadel (2004). "Asymmetric Price Transmission: A Survey." Journal of Agricultural Economics 55(3): 581-611.

Minot, N. (2010). Transmission of world food price changes to markets in Sub-Saharan Africa. Washington, DC, International Food Policy Research Institute.

Mityata, S. and J. Manatunge (2004). "Knowledge sharing and other decision factors influencing adoption of aquaculture in Indonesia." International Journal of Water Resources Development 20(4): 523-536.

Msangi, S., M. Kobayashi, M. Batka, S. Vannuccini, M. Dey and J. Anderson (2013). "Fish to 2030: Prospects for fisheries and aquaculture." World Bank Report(83177GLB).

Murray, F., J. Bostock and D. Fletcher (2014). Review of recirculation aquaculture system technologies and their commercial application. Aquaculture Research Reports, Highlands and Islands Enterprise. University of Stirling Aquaculture. 
Ngoc, P. T. A., M. P. M. Meuwissen, T. C. Le, R. H. Bosma, J. A. J. Verreth and A. G. J. M. Oude Lansink (2016a). "Adoption of recirculating aquaculture systems in large pangasius farms: A choice experiment." Aquaculture 460: 90-97.

Ngoc, P. T. A., M. P. M. Meuwissen, T. C. Le, J. A. J. Verreth, R. H. Bosma and A. G. J. M. Oude Lansink (2016b). "Economic Feasibility of Recirculating Aquaculture Systems in Pangasius Farming " Aquaculture Economics \& Management 20(2): 185-200.

Nhut, N., H. N. Van, R. H. Bosma, E. H. Eding, J. A. J. Verreth and M. C. J. Verdegem (2013). Recirculation Aquaculture System applied in pangasius farming. Annual meeting of SuPa project, Ho Chi Minh, Vietnam, Wageningen University.

Nwaobiala, C. U. (2014). "The Influence of Socio-Economic Factors on Adoption of Fish Production Technologies among Community-Based Farmers in Cross River State, Nigeria." International Journal of Agricultural Science, Research and Technology in Extension and Education Systems (IJASRT in EESs) 4(3): 131-135.

OECD (2010). Globalisation in fisheries and aquaculture: opportunities and challenges. Paris, OECD Publishing.

Ofuoku, A., N. Olele and G. Emah (2008). "Determinants of adoption of improved fish production technologies among fish farmers in Delta state, Nigeria." Journal of agricultural education and extension 14(4): 297-306.

Ohen, S., S. Abang and I. Idiong (2007). "Price transmission and market integration: vertical and horizontal price linkages for live catfish in Nigeria." Journal of Agriculture and Social Science 3(3): 79-82.

Onumah E.E., Brümmer B. and Hörstgen-Schwark G. (2010). "Elements which delimitate technical efficiency of fish farms in Ghana." Journal of the World Aquaculture Society 41(4): 506-518.

Onumah E.E., Brümmer B. and Hörstgen-Schwark G. (2010). "Productivity of the hired and family labour and determinants of technical inefficiency in Ghana's fish farms." Agricultural Economics-Chech 56(2): 79-88.

Oude Lansink, A. G. J. M., M. van den Berg and R. B. M. Huirne (2003). "Analysis of strategic planning of Dutch pig farmers using a multivariate probit model." Agricultural systems 78(1): 73-84.

Pannell, D. J., G. R. Marshall, N. Barr, A. Curtis, F. Vanclay and R. Wilkinson (2006). "Understanding and promoting adoption of conservation practices by rural landholders." Animal Production Science 46(11): 1407-1424. 
Peter Boswijk, H. and J.-P. Urbain (1997). "Lagrance-multiplier tersts for weak exogeneity: a synthesis." Econometric Reviews 16(1): 21-38.

Phan, L. T., T. M. Bui, T. T. T. Nguyen, G. J. Gooley, B. A. Ingram, H. V. Nguyen, P. T. Nguyen and S. S. De Silva (2009). "Current status of farming practices of striped catfish, Pangasianodon hypophthalmus in the Mekong Delta, Vietnam." Aquaculture 296(3-4): 227-236.

Pieniak, Z., M. Kołodziejczyk, B. Kowrygo and W. Verbeke (2011). "Consumption patterns and labelling of fish and fishery products in Poland after the EU accession." Food Control 22(6): 843-850.

Pindyck, R. S. and D. L. Rubinfeld (1998). Econometric models and economic forecasts, Irwin/McGraw-Hill Boston.

Piotr, R. (2015). Fish and seafood market in Poland. Fishery products. Warsaw, Poland, USDA, American Embassy, Foreign Agricultural Service.

Prokopy, L., K. Floress, D. Klotthor-Weinkauf and A. Baumgart-Getz (2008). "Determinants of agricultural best management practice adoption: Evidence from the literature." Journal of Soil and Water Conservation 63(5): 300-311.

Rapsomanikis, G., D. Hallam and P. Conforti (2006). "Market integration and price transmission in selected food and cash crop markets of developing countries: review and applications." Agricultural Commodity Markets and Trade, Edward Elgar, Cheltenham, UK: 187-217.

Rapsomanikis, G. and H. Mugera (2011). Price transmission and volatility spillovers in food markets of developing countries. Methods to Analyse Agricultural Commodity Price Volatility, Springer: 165-179.

Rico, A. and P. J. Van den Brink (2014). "Probabilistic risk assessment of veterinary medicines applied to four major aquaculture species produced in Asia." Science of the Total Environment 468: 630-641.

Rico, A. and P. J. Van den Brink (2014). "Probabilistic risk assessment of veterinary medicines applied to four major aquaculture species produced in Asia." Science of The Total Environment 468-469: 630-641.

Roheim, C. A., F. Asche and J. I. Santos (2011). "The Elusive Price Premium for Ecolabelled Products: Evidence from Seafood in the UK Market." Journal of Agricultural Economics 62(3): 655-668.

Sahota, A., B. Haumann, H. Givens and C. Baldwin (2009). Ecolabeling and Consumer Interest in Sustainable Products. Sustainability in the Food Industry. Iowa, A John Wiley \& Sons, Ltd.: 159-184. 
Sakib, M. H. and M. S. I. Afrad (2014). "Adoption of modern aquaculture technologies by the fish farmers in Bogra district of Bangladesh." International Journal of Agriculture Innovations and Research 3(2): 414-421.

Sapkota, P., M. M. Dey, M. F. Alam and K. Singh (2015). "Price transmission relationships along the seafood value chain in Bangladesh: Aquaculture and capture fisheries." Aquaculture Economics \& Management 19(1): 82-103.

Schneider, O., J. Blancheton, L. Varadi, E. Eding and J. Verreth (2006). Cost price and production strategies in European recirculation systems. Conference: Aqua 2006: Linking Tradition \& Technology Highest Quality for the Consumer, Firenze (Florence), Italy, 9-13 May 2006.

Seafish (2015). Responsible sourcing guide: farmed pangasius. Grimsby, UK, Seafish.

Serra, T. and B. K. Goodwin (2003). "Price transmission and asymmetric adjustment in the Spanish dairy sector." Applied Economics 35(18): 1889-1899.

Simar, L. and P. W. Wilson (2007). "Estimation and inference in two-stage, semiparametric models of production processes." Journal of econometrics 136(1): 3164.

Singbo, A. G. and A. G. J. M. Oude Lansink (2010). "Lowland farming system inefficiency in Benin (West Africa): directional distance function and truncated bootstrap approach." Food Security 2(4): 367-382.

Singbo, A. G., A. G. J. M. Oude Lansink and G. Emvalomatis (2014). "Estimating farmers' productive and marketing inefficiency: an application to vegetable producers in Benin." Journal of Productivity Analysis 42(2): 157-169.

Skevas, T. and A. G. J. M. Oude Lansink (2014). "Reducing pesticide use and pesticide impact by productivity growth: the case of Dutch arable farming." Journal of agricultural economics 65(1): 191-211.

Skevas, T., A. G. J. M. Oude Lansink and S. E. Stefanou (2012). "Measuring technical efficiency in the presence of pesticide spillovers and production uncertainty: The case of Dutch arable farms." European Journal of Operational Research 223(2): 550-559.

Trifković, N. (2014). "Certified standards and vertical coordination in aquaculture: The case of pangasius from Vietnam." Aquaculture 433(0): 235-246.

Troell, M., R. L. Naylor, M. Metian, M. Beveridge, P. H. Tyedmers, C. Folke, K. J. Arrow, S. Barrett, A.-S. Crépin and P. R. Ehrlich (2014). "Does aquaculture add resilience 
to the global food system?" Proceedings of the National Academy of Sciences 111(37): 13257-13263.

Tveteras, S. and F. Asche (2008). "International fish trade and exchange rates: an application to the trade with salmon and fishmeal." Applied Economics 40(13): 1745-1755.

Valderrama, D. and C. R. Engle (2001). "Risk analysis of shrimp farming in Honduras." Aquaculture Economics \& Management 5(1-2): 49-68.

Valeeva, N. I., M. P. M. Meuwissen, A. G. J. M. Oude Lansink and R. B. M. Huirne (2006) "Cost implications of improving food safety in the Dutch dairy chain." European Review of Agricultural Economics 33(4): 511-541.

van Duijn, A., R. Beukers and W. van der Pijl (2012). The Vietnamese seafood sector: a value chain analysis, CBI/LEI, part of Wageningen UR.

van Rijn, J. (2013). "Waste treatment in recirculating aquaculture systems." Aquacultural Engineering 53: 49-56.

Vavra, P. and B. Goodwin (2005). Analysis of price transmission along the food chain. Paris, Organisation of Economic Cooperation and Development (OECD).

Verreth, D. M., G. Emvalomatis, F. Bunte, R. Kemp and A. G. J. M. Oude Lansink (2015). "Price Transmission, International Trade, and Asymmetric Relationships in the Dutch Agri-Food Chain." Agribusiness.

von Cramon-Taubadel, S. (1998). "Estimating asymmetric price transmission with the error correction representation: An application to the German pork market." European Review of Agricultural Economics 25(1): 1-18.

Vose, D. (2008). Risk analysis: a quantitative guide. New York, John Wiley \& Sons.

Wang, H., P. Zhou and D. Q. Zhou (2013). "Scenario-based energy efficiency and productivity in China: A non-radial directional distance function analysis." Energy Economics 40: 795-803.

Ward, R. W. (1982). "Asymmetry in retail, wholesale, and shipping point pricing for fresh vegetables." American journal of agricultural economics 64(2): 205-212.

Webb Jr, K. A., G. M. Hitzfelder, C. K. Faulk and G. J. Holt (2007). "Growth of juvenile cobia, $<\mathrm{i}>$ Rachycentron canadum $</ \mathrm{i}>$, at three different densities in a recirculating aquaculture system." Aquaculture 264(1): 223-227.

Wetengere, K. (2011). "Socio-economic factors critical for intensification of fish farming technology. A case of selected villages in Morogoro and Dar es Salaam regions, Tanzania." Aquaculture international 19(1): 33-49. 
Wilcox, C., N. J. Mallos, G. H. Leonard, A. Rodriguez and B. D. Hardesty (2016). "Using expert elicitation to estimate the impacts of plastic pollution on marine wildlife." Marine Policy 65: 107-114.

Wilkin, J., D. Milczarek, A. Malak-Rawlikowska and J. Fałkowski (2007). "The dairy sector in Poland." series: Regoverning Markets Agrifood Sector Study, International Institute for Environment and Development (IIED), London.

Zhang, S.-Y., G. Li, H.-B. Wu, X.-G. Liu, Y.-H. Yao, L. Tao and H. Liu (2011). "An integrated recirculating aquaculture system (RAS) for land-based fish farming: the effects on water quality and fish production." Aquacultural Engineering 45(3): 93 102.

\section{Website}

Agribank. (2014). "Lãi suất tiết kiệm đối với khách hàng cá nhân." Retrieved February 01, 2014, from http://www.laisuat.vn/ngan-hang/AGRIBANK.aspx.

Directorate of Fisheries. (2012). "Pangasius export revenues increase 40-fold in 10 years." Retrieved February 1, 2014, from http://tongcucthuysan.gov.vn/fisheriestrading/pangasius-export-revenues-increase-40-fold-in-10-years/.

Globefish. (2013, 10 June 2014). "Pangasius-June 2013." Market reports Retrieved September 1, 2014, from http://www.globefish.org/pangasius-june-2013.html.

SeafoodSource. (2016). "Vietnamese pangasius exports to continue to plunge." Retrieved 30 June, 2016, from http://www.seafoodsource.com/all-commentary/vietnamesepangasius-exports-to-continue-to-plunge.

VASEP. (2014). "Poland increased imports chilled and fresh pangasius fillets." Retrieved 18 February 2016, from http://www.seafood.vasep.com.vn/DailyNews/378_9744/Poland-increased-imports-chilled-and-fresh-pangasius-fillets.htm.

VASEP. ( 2013). "Vietnam pangasius exports." Vietnam Seafood Trade Statistics Retrieved February 01, 2014, from http://www.seafood.vasep.com.vn/FisheryStatistics/123_8120/Vietnam-pangasius-exports-Jan-Jul-2013.htm.

Wageningen University. (2013). "Improving waste management for pangasius culture in the Mekong Delta of Vietnam (SUPA project)." Retrieved August 12 2016, from https://www.wageningenur.nl/en/show/SuPa.htm. 


\title{
About the author
}

\section{Curriculum Vitae}

\author{
Publications
}

Training and Supervision Plan 


\section{About the author}

Pham Thi Anh Ngoc was born in Lam Dong, Vietnam, on August 12, 1986. She graduated in Natural Resources and Environmental Economics at Nong Lam University, Ho Chi Minh City, Vietnam from 2004 to 2008. In 2011, she completed with distinction her Master studies in Environmental Protection at Warsaw University of Life Sciences, Poland. Since then she worked as a lecturer at the Department of Natural Resources and Environmental Economics, Faculty of Economics, Nong Lam University, Ho Chi Minh City, Vietnam. In 2012, she started her PhD at the Business Economics Group of Wageningen University. Her $\mathrm{PhD}$ research was to perform an economic analysis of technological innovations to improve the sustainability of pangasius production in Vietnam. The research was financed under the SUPA project (improving waste management for pangasius culture in the Mekong Delta of Vietnam), funded by the bilateral Vietnamese-Netherlands Public Private Partnership between the Vietnamese Ministry of Agriculture and Rural Development (MARD), the Ministry of Economic Affairs from the Netherlands, private companies Queens and Marine Harvest from Europe and Vinh Hoan from Vietnam. NUFFIC also awarded a partial fellowship (Netherlands Organization for International Cooperation in Higher Education) for the last two years. During her $\mathrm{PhD}$ research, she followed her education programme at the Wageningen School of Social Sciences (WASS). She followed various courses in the field of economics and business.

Along her academic career, she has developed a strong background specialized in financial management in agriculture/aquaculture, choice experiments, price analysis and efficiency analysis. 


\section{List of publications}

- Kazimier Banasik, Ngoc Pham. "Modelling of the effects of land use changes on flood hydrograph in a small catchment of the Płaskowicka, southern part of Warsaw, Poland”. Annals of Warsaw University of Life Sciences - SGGW Land Reclamation No 42 (2), 2010: 229-240 (Ann. Warsaw Univ. of Life Sci. SGGW, Land Reclam. 42 (2), 2010)

- $\quad$ Ngoc, P. T. A., M. P. M. Meuwissen, T. C. Le, R. H. Bosma, J. Verreth and A. O. Lansink (2016). "Economic Feasibility of Recirculating Aquaculture Systems in Pangasius Farming”. Aquaculture Economics \& Management 20: 185-200.

- $\quad$ Ngoc, P. T. A., M. P. M. Meuwissen, T. C. Le, R. H. Bosma, J. Verreth and A. O. Lansink (2016). "Adoption of recirculating aquaculture systems in large pangasius farms: A choice experiment." Aquaculture 460: 90-97.

\section{Contributions to conferences and seminars}

- Ngoc, P. T. A., M. P. M. Meuwissen, T. C. Le, R. H. Bosma, J. Verreth and A. O. Lansink (2013). Economic feasibility of recirculating aquaculture systems in pangasius farming (WAS), Ho Chi Minh, Vietnam, 18-13 February 2013.

- $\quad$ Ngoc, P. T. A., M. P. M. Meuwissen, T. C. Le, R. H. Bosma, J. Verreth and A. O. Lansink (2015). Adoption of recirculating aquaculture systems in large pangasius farms: A choice experiment (ICAE), Milan, Italia, 8-14 August 2015.

- Ngoc, P. T. A., Gaitán-Cremaschi D, M. P. M. Meuwissen, T. C. Le, R. H. Bosma, J. Verreth and A. O. Lansink (2016). Technical inefficiency of Vietnamese pangasius farming: A data envelopment analysis (DEA), Wuhan, China, 23-26 May 2016. 
Pham Thi Anh Ngoc

Wageningen School of Social Sciences (WASS)

Completed Training and Supervision Plan

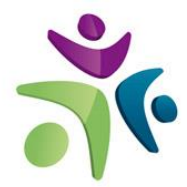

Wageningen School

of Social Sciences

\begin{tabular}{|c|c|c|c|}
\hline Name of the learning activity & Department/Institute & Year & ECTS* \\
\hline \multicolumn{4}{|l|}{ A) Project related competences } \\
\hline Advanced Microeconomics, ECH 32306 & Wageningen University & 2012 & 6 \\
\hline Organization of Agribusiness, BEC 31306 & Wageningen University & 2012 & 6 \\
\hline Decision Science 2, ORL 30306 & Wageningen University & 2013 & 6 \\
\hline Advanced Econometrics, AEP 60306 & Wageningen University & 2013 & 6 \\
\hline Writing PhD research proposal & $\begin{array}{l}\text { Wageningen University, } \\
\text { BEC }\end{array}$ & 2012 & 6 \\
\hline \multicolumn{4}{|l|}{ B) General research related competences } \\
\hline Introduction course & WASS & 2012 & 1 \\
\hline $\mathrm{PhD}$ discussion group & $\begin{array}{l}\text { Wageningen University, } \\
\text { BEC }\end{array}$ & $\begin{array}{l}2012- \\
2016\end{array}$ & 2 \\
\hline $\begin{array}{l}\text { Economic feasibility of recirculating } \\
\text { aquaculture systems in pangasius farming }\end{array}$ & $\begin{array}{l}\text { WAS conference, } \\
\text { Vietnam }\end{array}$ & 2013 & 1 \\
\hline $\begin{array}{l}\text { 'Adoption of recirculating aquaculture } \\
\text { systems in large pangasius farms: A choice } \\
\text { experiment" }\end{array}$ & EAAE conference, Italy & 2015 & 1 \\
\hline $\begin{array}{l}\text { 'Technical inefficiency of Vietnamese } \\
\text { pangasius farming: A data envelopment } \\
\text { analysis' }\end{array}$ & DEA conference, China & 2016 & 1 \\
\hline $\begin{array}{l}\text { Theory and Practice of efficiency \& } \\
\text { productivity measurement: Static and } \\
\text { dynamic analysis }\end{array}$ & WASS & 2015 & 3 \\
\hline \multicolumn{4}{|c|}{ C) Career related competences/personal development } \\
\hline $\begin{array}{l}\text { Information Literacy including EndNote } \\
\text { Introduction }\end{array}$ & $\begin{array}{l}\text { Library Wageningen } \\
\text { University }\end{array}$ & 2012 & 0.6 \\
\hline $\begin{array}{l}\text { Techniques for Writing and Presenting a } \\
\text { scientific Paper }\end{array}$ & WASS & 2013 & 1.2 \\
\hline Total & & & 41.8 \\
\hline
\end{tabular}

*One credit according to ECTS is on average equivalent to 28 hours of study load. 
Acknowledgements 


\section{Acknowledgements}

Today is a very special day. It is to write acknowledgements not only as the finishing touch on my $\mathrm{PhD}$ thesis but also a great pleasure to extend my sincere thanks to the contribution and support of organizations and many people to make this day possible.

I am grateful to the financial support of the SUPA project (improving waste management for pangasius culture in the Mekong Delta of Vietnam), funded by the bilateral VietnameseNetherlands Public Private Partnership between the Vietnamese Ministry of Agriculture and Rural Development (MARD), the Ministry of Economic Affairs from the Netherlands, private companies Queens and Marine Harvest from Europe and Vinh Hoan from Vietnam. Financial support from NUFFIC (Netherlands Organization for International Cooperation in Higher Education) for awarding a partial fellowship which has made it possible to complete my PhD study is gratefully acknowledged.

After an intensive four years of PhD study, I have much grown up both in research capacity and personal traits. This is because I was luckily raised by strong moms and dads whose compliments, encouragement and criticism have made me what I am today.

First and foremost, I would like to express my sincere gratitude to my co-promotor, Assoc Prof. dr. Miranda Meuwissen for the invaluable help to the successful completion of this thesis. Dear Miranda, thank you for all your constant guidance, patience and caring throughout my PhD study. I greatly appreciate that you have inspired me with creativity, challenged me with tough questions and provided me valuable suggestions for significantly improving the thesis. I also want to thank you for your time to take a long way from The Netherlands to visit me and my one-month son in Vietnam in 2013. During your visit in Vietnam, you have worked full-time with me to prepare for my first meeting of the SUPA project. And, I am also thankful for sharing with me your time with Stef, Thomas and Manon while I was in Wageningen.

My deep gratitude goes to my first promoter Prof. dr. Alfons Oude Lansink. Dear Alfons, thank you for your guidance, patience and optimistic thinking of my progress throughout my $\mathrm{PhD}$ study. I really appreciate your time to provide me critical comments and suggestions for the thesis. Sometimes, I was nervous of your challenging questions during the meetings. However, this is the way that I have learnt to be a critical learner and I am grateful to you for that. 
My sincere thanks also go to my second promoter Prof. dr. Johan Verreth. Dear Johan, thank you for your support, helpful comments and positive reactions to my work. You always guided me to think different perspectives on the discussion of each chapter in the thesis. That has always inspired me.

Special thanks to my local supervisor Dr Le Cong Tru. Dear Tru, thank you for your significant and continuous support since I have started working at Nong Lam University. You have not only motivated me to pursue the $\mathrm{PhD}$ program but also been always there to guide me throughout the process and I am grateful to you for that.

I would like to thank Dr Roel Bosma for all your kindness and the contributions to my $\mathrm{PhD}$ study. I sincerely thank to Mr. Nguyen Nhut for all your interesting discussions on the recirculating aquaculture systems that you have designed. I am grateful to Mr. Willem van der Pijl for sharing with me a part of data for the price transmission paper. Thank you to the aquaculture officers in An Giang, Can Tho, Dong Thap, Tra Vinh, Vinh Long and Soc Trang provinces for inviting farmers to the workshops and surveys. I also thank the farmers for sharing their preferences.

To all my colleagues at the Business Economics group, thank you for making the work environment very pleasant. Thank you for giving me helpful feedback and suggestions during the PhD meetings. Also thank you for the nice card and wishes to my little son. To Anne Houwers, Jeannette Lubbers and Ilona van den Berg, thank you for all the administrative support.

To all my friends, especially my best friend, Tsion, thank you for the true friendship and all the good times that will forever stay in my heart. Thank you to Daniel for all the jokes we had and thinking with me to improve the inefficiency paper. Thank you to Jamal for being a good friend and interesting chats we shared. Thank you to Laya, Eliana and Frazen for unforgettable moments we spent. Thank you to Farahnaz, Yani, Jaap, Hugo, Eva, Simon, Nurul, Lien, Viet and Luis for interesting discussions and the laughter.

Thank you to Quyên, Tú, Phú, Trang, Vũ and Bác Bình for caring me during my pregnancy period in Wageningen. Thank you to all Vietnamese friends in Wageningen and my corridor mates for the nice time we spent together.

I am grateful to my parents and my in-laws for giving all the endless support and taking care of my little son whenever I came back to Wageningen to study during these four years. 
Finally, I dedicate this thesis with deep appreciation to my husband, Quang, for all your support and sympathy to help me get through the hardship during the $\mathrm{PhD}$ process.

Pham Thi Anh Ngoc

Sep 05, 2016 


\section{Colophon}

The research described in this dissertation was financially supported by the financial support of the SUPA project (improving waste management for pangasius culture in the Mekong Delta of Vietnam) and a partial fellowship of NUFFIC (Netherlands Organization for International Cooperation in Higher Education).

Cover design by:

Printed by:
Pham Thi Anh Ngoc

Proefschriftmaken.nl ||Digiforce Vianen 